\title{
Fantastically plastic: fish larvae equipped for a new world
}

\author{
Karin Pittman ${ }^{1}$, Manuel Yúfera ${ }^{2}$, Michail Pavlidis ${ }^{3}$, Audrey J. Geffen ${ }^{1}$, Willian Koven ${ }^{4}$, Laura Ribeiro ${ }^{5}$, \\ José L. Zambonino-Infante ${ }^{6}$ and Amos Tandler ${ }^{4}$ \\ 1 Department of Biology, University of Bergen, Bergen, Norway \\ 2 Instituto de Ciencias Marinas de Andalucía (ICMAN-CSIC), Puerto Real, Spain \\ 3 Department of Biology, University of Crete, Heraklion, Greece \\ 4 Israel Oceanographic and Limnological Research, National Center for Mariculture, Eilat, Israel \\ 5 Aquaculture Research Center of Portuguese Institute of Sea and Atmosphere, Olhão, Portugal \\ 6 Ifremer, Unit of Functional Physiology of Marine Organisms, Plouzané, France
}

\section{Correspondence \\ Karin Pittman, Department of Biology, University of Bergen, Thormøhlensgate 53B, 5020 Bergen, Norway. \\ Email: karin.pittman@bio.uib.no}

Received 6 January 2013; accepted 25 March 2013.

Re-use of this article is permitted in accordance with the Terms and Conditions set out at http://wileyonlinelibrary.com/ onlineopen\#OnlineOpen_Terms

\begin{abstract}
Teleost fish are more diverse than any other vertebrate group, and yet only a limited number of species are fished and farmed globally. Efforts to expand the quantity and diversity of fish produced are hampered by the extreme diversity of ontogenetic responses of fish, especially during larval development. This review looks at advances in molecular phylogeny, endocrine and nutrient influences and long-term studies of the phenotypes of commercially important fish to put the sources and consequences of this plasticity into context. This nested context of evolutionary forces of the fish-specific genome duplication, epigenetic influences, ontogenetically conserved processes like metamorphosis and cell determination is further presented in relation to how fish larvae translate the environment into somatic signals, the teleostian diversity of internal processes like sex differentiation and somatogenesis, and the long-term practical consequences of changes in timing or anthropogenic influences. This review aims to present a new baseline of knowledge of marine fish larvae which is useful to scientists, managers and producers.
\end{abstract}

Key words: development, epigenetics, fish-specific genome duplication, juveniles, larvae, metamorphosis, plasticity.

A fish is a fish like a cow is a canary. -Prof. Christoffer Schander (1960-2012)

\section{Introduction}

Fish are the most successful group of vertebrates; they are more numerous than all the terrestrial vertebrates together, and over 25000 living species are grouped into three classes. Their abundance is related to their adaptive diversity, and they occupy a vast range of ecological niches from fresh to saltwater, environmental extremes and some even emerge onto land. A remarkably small number of fish have been studied scientifically, and even fewer are exploited by humans in aquaculture, nonetheless species of ancient (Agnatha), cartilaginous (Chondrichthys) and bony (Osteichthys) fish are represented. Despite the timescale that separates the evolution of ancient and modern fish (c. 500 million of years), they share common features which suit them for life in water and include locomotion and buoyancy, senses, metabolism and excretion and water balance. The most intensely studied fish are the teleosts, which include nearly all living bony fish, for which rearing or analytical protocols are increasingly informed by accumulating information about genes, stages of ontogeny and performance, all factors which are known to impact on form, state, movement or rate of activity (phenotypic plasticity; West-Eberhard 2003).

Identification of the factors that promote phenotypic plasticity is critical to understanding how organisms adapt to their environment (Kingsolver \& Huey 1998). In both fisheries and aquaculture around the world, the environment that fish experience in their early lives has lead to observable changes in their size, growth rate, metabolism and age at reproduction, among other aspects. How these changes are induced and how we can better explore phenotypic plasticity for the benefit of 
managing fish development and biological welfare is the subject of this review.

Fish are special right down to their molecules because of a fish-specific round of whole-genome duplication, giving them more genes than any other vertebrates. Genome evolution is complex and appears to have involved several rounds of whole-genome duplication followed by gene decay (Meyer \& van de Peer 2005; Kondrashov 2012). It seems unlikely that the increase in vertebrate complexity can be explained solely by increased gene number (Venter et al. 2001). In fish, the environmentally exposed gene-rich pluripotent egg initiates a dialogue with external and internal factors which continues throughout ontogeny and even to the next generation. Other mechanisms such as gene regulation (at the level of the promoter and also siRNA, etc), alternative splicing, protein-protein interactions, posttranslational modifications and a range of other mechanisms are proposed to increase novelty and contribute to increased organism complexity. However, in the case of teleosts where a third specific whole-genome duplication (fish-specific genome duplication, FSGD) took place about 350 mya, with up to eight copies of some loci, it seems likely that this has led to further innovations and novel functions. The whole-genome duplication may be the ultimate source of morphological transitions and increased phenotypic diversity, along with epigenetic mechanisms of DNA methylation and histone modification (Peaston \& Whitelaw 2006). The FSGD probably has a major role in the evolution of vertebrate phenotypes and is of major importance to the evolution of teleost pigmentation with more genes encoding pigment synthesis enzymes than in any other vertebrate group (Braasch et al. 2009). In general, duplicated genes may be expressed not only at different regions but also at different times during embryogenesis (Kassahn et al. 2009). This is especially relevant to transcription factors and signalling genes during ontogenesis, giving more specialized regulatory control of development, typically via the acquisition of novel spatial expression domains. For teleosts, this class act means that there is a mechanism with which to respond to a wide variety of environments and ecological demands throughout the life cycle with significant influence on the final phenotype of each individual.

The FSGD has contributed to the preservation of protein complex stoichiometries and overrepresentation of developmental genes in retained duplicates, with a preference for genes of multifunctionality such as lineage specification and differentiation, organelle formation, intracellular transport and homoeostasis (Braasch et al. 2009). This makes extrapolation of highly specific results (i.e. expression and up- and down-regulation of genes at early life stages) from one fish species to the other much more complex. Furthermore, changes in a cell, organ or individual can occur with- out directly affecting the DNA although the behaviour (expression) of the genome may be indirectly influenced (epigenesis).

Another point to consider is the interaction between the developing fish and the environment of either the cell or, later, the individual. Epigenetic effects include more than maternal, paternal or tank effects on developing fish, and the term has been used to describe anything other than the DNA sequence that influences ontogeny. A key distinction is that epigenetic effects produce heritable traits which can be found over either several rounds of cell division or even to the next generation of the organism (Skinner et al. 2010). The phenotype of a cell or individual is influenced by which of the genes are transcribed. Systematic analyses of relevant forms of epigenetic information have drawn focus to the histone code or DNA methylation patterns and included processes such as paramutation, imprinting, gene silencing, position effect as well as maternal effects. Genes are regulated by a series of steps, one of which is remodelling the complex of DNA wrapped around little spheres of histone proteins, which together make up chromatin. Changing the pattern of the wrap changes the expression of genes, either by modifying the shape of the histone proteins (i.e. cell differentiation) or by adding or removing methyl groups to the DNA and influencing the transcriptional activity (i.e. genetic imprinting; Horn \& Petersen 2002). The full details of how structure is inherited from stem cells are not yet clear, but it is clear that as the original egg cell differentiates into cells of different destinies and functions, these cells respond differently to the biological and physical environment and intercellular signalling. In mammals, patterns of DNA methylation are established early in life, with active or passive demethylation producing pluripotent cells where all genes are potentially transcriptionally active (Able et al. 2009; Burdge \& Lillycrop 2010). As in teleost development, mammalian pluripotent embryonic cells differentiate into mature tissues through changes in gene promoters and a series of de novo methylation and demethylation influencing transcription activity. As the individual develops, genes are activated or silenced in the cell lines in an epigenetically heritable fashion, giving cells a 'memory'.

The ability of fish to have 'indeterminate growth' (unlike mammals) means new cells are continuously generated in all organs including neural tissue, so that stem cells or pluripotency is evident throughout the life cycle (Servili et al. 2009). An important indicator that epigenetic effects are at work occurs when individuals of the same genetic background (like a teleost egg batch) express genes in an individually variable manner and grow differently even within the same tank or body of water (Peaston \& Whitelaw 2006; Schneider et al. 2010). As there are no genetic programmes for phenotype, the genes themselves contain only the information necessary for synthesis of proteins important for 
building the organism and the control lies in the information coming from many parts of the organism (epigenetic regulation). Epigenetic mechanisms such as environmental chemicals, diet, temperature and light are well known. Teleost larvae exhibit a general pattern of organogenesis which is similar across groups but differs with respect to timing and functionality between species (Falk-Petersen 2005), and farmed fish usually exhibit variation in growth and morphology within a tank or batch, especially after the onset of the exogenous feeding. Thus, genetic elements are only one aspect of biological regulation: epigenetics play a large role in determining how farmed fish develop and function, and some epigenetic changes can be passed down through the generations (Ho \& Burggren 2010; Pigliucci 2010; Sgaramella 2010; Li \& Leatherland 2012).

A third level of plasticity is derived from something common to all chordates, including fish: metamorphosis. The process of changing from a larval to an adult form affects the morphology, physiology, biochemistry, behaviour and ecology of the animal but not its sexual maturity. Although chordate metamorphoses can be very diverse, unifying factors are that the process is under the influence of thyroid hormones (TH) and thyroactive compounds and that thyroid metabolism is evolutionarily conserved (Paris \& Laudet 2008). Fish can have indirect development (flatfish) or direct development (gadids, sparids) or intermediate development (salmonids) with varying duration of embryo, larval and juvenile stages. There is a long debate over the definitions, but all normally consider the process of metamorphosis to be an end to the larval stage (Balon 1990) that is generally affected by a surge of thyroxine $\left(\mathrm{T}_{4}\right)$ or triiodothyronine $\left(\mathrm{T}_{3}\right)$ from thyroid follicles. The thyroid signalling pathway involves incorporation of extracellular iodine into a thyroglobulin, transformation of thyroglobulin by deiodinase enzymes, transport through the plasma by $\mathrm{TH}$ carrier proteins such as transthyretin, binding to thyroid receptors in the nucleus of the cell and the activation of thyroid response elements towards target genes. How the phenotype changes during the larval-juvenile transition is determined largely by changes in the TH signalling pathway. Incomplete or abnormal metamorphosis can take the obvious form of aberrant pigmentation or lack of eye migration or other skeletal abnormalities, as found in farmed flatfish (Power et al. 2008) or have more subtle effects. The cascading process of metamorphosis is sensitive to photoperiod, water quality, diet, temperature and a host of other signals.

Among the potential stressors, early nutrition of fish larvae has received much attention with the aim to reduce morphological abnormalities that adversely affect the image and profits in the aquaculture industry. Other external stimuli (or factors), like temperature, have been less examined. Similarly, the potential effects of nutrition and tem- perature on physiological processes (other than the morphological differentiation), crucial for the adaptive capacity of the future juvenile, remained poorly studied. Moreover, the possibility to influence or steer-specific metabolic pathways or functions in juvenile fish, for example to facilitate digestion of substitutes for fish meal and oil and to promote sustainability in fish aquaculture, has just begun to be considered in fish larvae. We also give examples of how dietary interventions in early life could promote some positive permanent changes in fish physiology.

This review will concentrate on the ontogeny of mediating epigenetic influences within a variety of fish and what the phenotypic consequences may be. We do not wish to enter into semantic questions, although this could be interesting. We find utility in reviewing in finfish larvae some stressors capable of permanently altering organ development and function, and also stages of development of greatest vulnerability. The appearance and functionality of endocrine organs are critical to teleost larval development, metamorphosis and metabolism and will be emphasized. While the importance of hormones is acknowledged, the ability of any particular substance to initiate transitions between life stages is context dependent because of the necessity to interact with cell communication systems. Species-specific and environmentally induced differences in timing of developmental events make direct comparison of ontogenesis more complicated, especially when related to nondevelopmental events such as hatching. Results of empirical observations incorporate, consciously or unconsciously, the sources of plasticity derived from evolution, epigenetics, life stage and the experimental procedures (Fig. 1). Multidisciplinary methods are necessary when approaching questions which affect many levels of biological organization, from molecule to population, as is the case in current topics in teleost biology.

\section{Mediating environment - structural basis of plasticity}

\section{Pineal}

Sensory perception of, for example, light and temperature dictates the capability of the fish to integrate input from its environment. The pineal organ or gland, a prime mediator of circadian rhythm, has differentiated photoreceptor cells prior to the retina in the salmonid ayu (Plecoglossus aItivelis) and other fish (Omura \& Oguri 1991). The pineal, along with the more rudimentary parapineal, is a medial outgrowth dorsal to the forebrain or telencephalon and just below the roof of the skull, and the stalked mature pineal is composed of photoreceptor cells, neural cells and support or glial cells. The pineal is the only differentiated photoreceptor organ in embryos and early larvae of Atlantic halibut Hippoglossus hippoglossus (Forsell et al. 2002). Flatfish such 


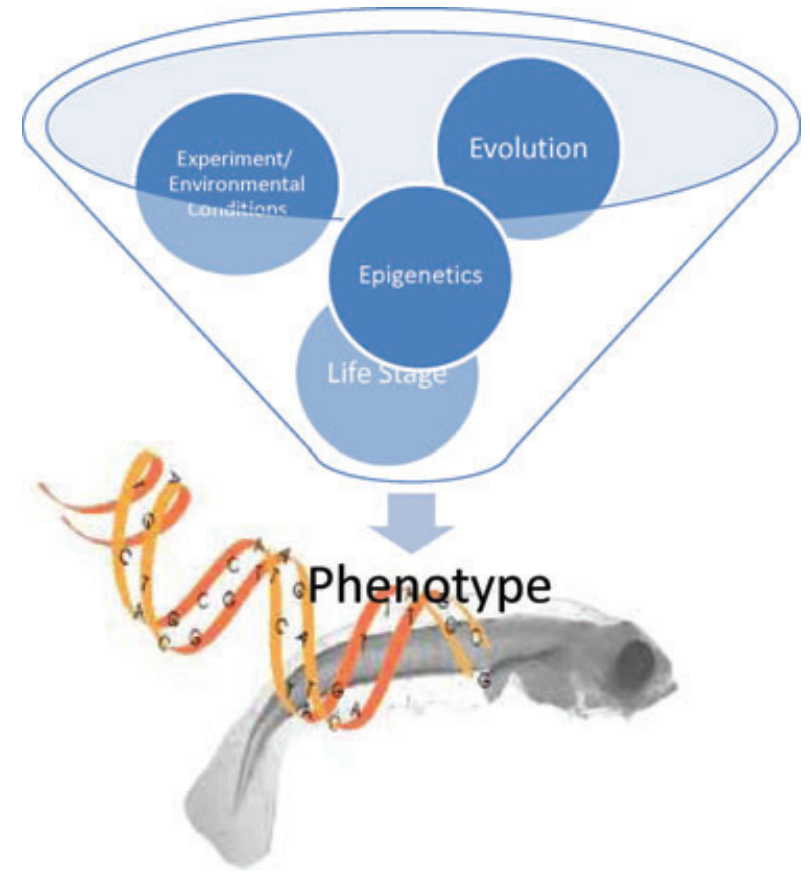

Figure 1 Schematic over the sources of plasticity acting on empirical results in larval teleost research. Evolution represents the effects of the third round of whole-genome duplication (fish-specific genome duplication), epigenetics represents the continual influences of environment and diet on the expression of genes including those acting on the primordial germ cells of the parent fish, life stage includes especially metamorphosis when thyroid-driven up- and down-regulation of genes allow the transition from larval to adult form and finally the experimental conditions under which the larvae have been reared.

as the Japanese flounder (Paralichthys olivaceus) display an anlagen of the pineal and parapineal about 3 days after fertilization which differentiate within several days into two types of cellular nuclei of multiple photoreceptor cells. The retinal development of cone-like outer segments of photoreceptors occurs later, at 6 days after fertilization in Japanese flounder (Omura \& Oguri 1991). In the pineal anlagen of the ayu Plecoglossus altivelis, gap-junction like structures appear 4 days post-fertilization (dpf; indicating neurotransmission), whereas sites of retinal communication between the photoreceptor terminals and the bipolar and horizontal cells are not apparent until about $6 \mathrm{dpf}$ (Omura \& Oguri 1991). In halibut already from $12 \mathrm{dpf}$ and prior to hatch, the embryonal pineal expresses both green and UV opsins, has phototransduction proteins, melatonin-production cells and neuronal connections to the deep brain, is probably sensitive to short and middle wavelength light (Forsell et al. 2002) and may be responsible for regulating larval swimming depth prior to retinal differentiation (Novales Flamarique 2002). In salmon, pineal photoreceptors differentiate 2 days after the eyed egg stage (Østholm et al. 1987). This pattern is similar to that found in the stickleback Gasterosteus aculeatus (Ekström \& Meissl 1997), but there are exceptions such as the mangrove killifish Rivulus marmoratus where retinal photoreceptor differentiation precedes the pineal (Ali et al. 1988 cited in Omura \& Oguri 1993). In rainbow trout Oncorhynchus mykiss, pineal photoreceptor differentiation appears as early as $15 \mathrm{dpf}$ and well-differentiated synaptic contacts are found by about $21 \mathrm{dpf}$, clearly preceding that of retinal differentiation at about $27 \mathrm{dpf}$ (Omura \& Oguri 1993). The pineal, in transducing environmental information, is expected to have an impact on endocrine functions such as the action of the interrenals for cortisol expression and thyroidal uptake of iodine (in catfish; Agha \& Joy 1987, 1989 cited in Ekström \& Meissl 1997). Importantly, not only does the pineal functionally differentiate before the retina, but also the pineal can send out tentative axons which can act as a scaffold for later neural pathways. In this way, the pineal contributes to the early patterning of the teleost brain. Given that it is the means to mediate photoperiod and temperature to the developing fish larva (Blanco-Vives et al. 2010), this indicates that at least these two environmental factors in the hatchery may be more important to longterm physiology and performance than previously suspected.

Pineal phototransduction and regulation of physiological processes may be a conserved element of embryonal vertebrate development. Dark activation of melatonin synthesis and diffusion from the pineal or the retina has been shown in many fish species and, in the pineal, follows the same pattern as in all vertebrates with synthesis coinciding with a nocturnal increase in the activity of arylalkylamine $N$-acetyltransferase (AANAT), the penultimate enzyme in the conversion of serotonin to melatonin. Melatonin diffused from the photoreceptors of the pineal probably reaches other areas of the brain via the cerebrospinal fluid (Ekström \& Meissl 1997).

The pineal responds to small changes in irradiance by synthesizing indolamines (e.g. melatonin) and by changes in the neurotransmission to various segments of the developing brain. Atlantic halibut, cod Gadus morhua and herring Clupea harengus all have pineal photoreceptors which express phototransduction molecules before the retinal photoreceptors do (Forsell et al. 2001). Whether the daily rhythm of pineal melatonin secretion is dependent on photoperiod may be species specific: Oliveira et al. (2009) showed that in the marine flatfish Senegalese sole Solea senegalensis, an exogenous rhythm of light and dark was necessary for in vitro pineal secretion of melatonin, whereas in the freshwater roundfish tench Tinca tinca, photoperiod was not so important, and an endogenous rhythm of production could be maintained in vitro in darkness for about 5 days. In the trout (O. mykiss) pineal gland, the enzyme AANAT2 is not regulated by either clock-containing cells 
or the photic regime, whereas AANAT1 in the retina displays regular oscillations in a light-dark cycle (Falcon et al. 2003). By contrast, in the zebrafish Danio rerio, both the pineal and the retina transcribe otx 5 which regulates genes that have a circadian rhythm of expression such as AANAT2, Rev-ErbA and the interphotoreceptor retinoidbinding protein (Ekström \& Meissl 2003). In teleosts, there are multiple copies of the genes encoding for AANAT and other enzymes as well as photopigment molecules, presumably as a result of the FSGD, which may have aided evolution of two AANAT genes and a variable number of opsin-like molecules and which differ in affinity for indolethylamines or phenylethylamines (Falcon et al. 2003). Although it is clear that melatonin is involved in the rhythmicity of physiological processes, its role in growth of embryos and larvae is less clear.

In general, information about photoperiod may be imparted to the brain from either the pineal or the retina nearly simultaneously and very early in larval development. The pineal is a key organ for responses to environmental photoperiod, in entrainment of developing endogenous rhythms, behaviour - even in the egg stage, hatching and further differentiation of larval tissues - and for steering reproductive maturation (Omura \& Oguri 1993; Forsell et al. 2001). Perhaps notably for hatcheries, the pineal is capable of detecting a wider range of light intensities than is the teleost retina, but the pineal response peak is much delayed relative to the retina, and under prolonged illumination, the pineal response will remain at the same amplitude (Ekström \& Meissl 1997). Nonetheless, a rhythm in temperature can induce a diurnal melatonin rhythm in the absence of a light-dark cycle, although for species capable of maintaining an endogenous circadian rhythm of melatonin secretion, the timing of such intervention may be critical. There may be a direct temperature effect on the kinetics of melatonin synthesis, possibly because temperature may influence the circadian cycle and thus integrate environmental signals for melatonin secretion. There are species-specific differences in the threshold intensity of radiance for survival, while the synergy of prey and light determines growth and development in fish larvae (Boeuf \& LeBail 1999). The way these signals are integrated during the larval stages may have long-term impacts on the scope for growth of the fish.

Pineal photoreceptors secrete melatonin and use glutamate or aspartate as a neurotransmitter. Intrapineal neurons, post-synaptic to the photoreceptors, are known to innervate a large number of brain areas including the thalamic and hypothalamic cell groups (where a number of releasing or stimulating hormones are produced), the preoptic region and the hybenular nucleus (well conserved in all vertebrates, known to release neuromodulators such as dopamine, noradrenaline and serotonin, and involved in pain processing reproduction, learning and stress responses) (Ekström \& Meissl 1997). Neuropeptides found in the adult pineal include growth-hormone-releasing hormone and gonadotrophin-releasing hormone (GnRH), among others, but their presence in the larval-early juvenile stages is not confirmed (Ekström \& Meissl 1997). The role of the pineal as a photosensory and endocrine organ in larvae and juvenile teleosts is far from clarified, although it has been implicated in maturation, behaviour and development. As the pineal is central to mediating temperature and photoperiod, it is the endogenous control switch for seasonal changes in lipid metabolism and growth (Leena et al. 2001).

\section{Thalamus/Hypothalamus}

Separating detectable levels of hormones in the eggs from endogenous production of hormones in the embryo is difficult and often requires corroboration with histochemical evidence. The hypothalamus is part of the diencephalon including the optic chiasma and the pars posterior of the pituitary gland. Hypothalamic nuclei mediate autonomic mechanisms, endocrine activity and somatic functions (body temperature, sleep, appetite, the development of secondary sex characteristics and internal secretion of endocrine hormones via direct regulation of the pituitary). Well-known hypothalamic-releasing or hypothalamicinhibiting hormones include thyroid-stimulating hormone-releasing hormone (TRH), corticotrophin-releasing factor (CRF), growth-hormone-releasing factor, $\mathrm{GnRH}$ and prolactin-inhibiting factor.

Gonadotrophin-releasing hormone neurons arise in embryos, and in adults these neurons may belong to distinct populations of either the terminal nerve, the midbrain or the preoptic area. Gonadotrophin-releasing hormones are involved in eye development, heart function as well as gonad development and reproduction. The ontogeny of GnRH expression starts very early: in the gilthead seabream Sparus aurata, it is found at about 1.5 to $2 \mathrm{dpf}$ in the hind and midbrain (Wong et al. 2004) and in zebrafish at $1 \mathrm{dpf}$ (Palevitch et al. 2007). In the cichlid fish Cichlasoma dimerus, GnRH immunoreactive neurones are found at $4 \mathrm{dpf}$ (Pandolfi et al. 2002), and in the cobia Rachycentron canadum, at the earliest date sampled, 1 day after hatching (dph; Mohamed et al. 2007). However, in Nile tilapia Oreochromis niloticus, GnRH reactive cells are found remarkably later at the onset of gonadal sex differentiation (7-21 dph; Swapna et al. 2008). GnRH acts on the pituitary to regulate synthesis and secretion of gonadotropins which in turn regulate gonadal steroidogenesis, gametogenesis and gonadal growth.

Germ cell differentiation in teleost gonads is correlated with the pituitary innervation by GnRH neurons. In eels, 
there are three separate populations of neuronal cells (olfactory, preoptic and midbrain) which innervate the pituitary to stimulate release of gonadotropin already in embryos at about $5 \mathrm{~cm}$ length. Innervation by the preoptic population of cells is highest at the time when primordial germ cells differentiate into male germ cells (Japanese eels Anguilla japonica at 14-16 cm length; Chiba et al. 1999). In cichlids, it has been suggested that preoptic $\mathrm{GnRH}$ expression coincides with some steps of sex differentiation, because seabream GnRH immunoreactive-fibres entered the adenohypophysis when the presumptive gonadal tissue was differentiating into an ovary (Pandolfi et al. 2002).

There is a gradual change in the amount and function of expressed genes as fish develop. Wong et al. (2004) found that there were four increases in the levels of reproductionrelated genes in the hypothalamus-pituitary-gonad axis at 5, 8, 14 and $28 \mathrm{dpf}$. They propose that the ontogeny and organization of the hypothalamic-pituitary-gonad axis starts as early as $5 \mathrm{dpf}$ and is highly activated within the next 10 days. Within the first 36 days after fertilization, gilthead seabream embryos and larvae express $\mathrm{GnRHr}$, follicle-stimulating hormone $\beta$ (FSH $\beta$ ), FSHr, luteinizing hormone receptor (LHR) and Vasa (a marker gene expressed in the germ cell). Nonclassical expression of sbGnRH in the thalamic area of seabream was found at 39 and $59 \mathrm{dpf}$, and the authors suggest that these cells may have a different origin than the cells of the preoptic anterior hypothalamus which express GnRH (Wong et al. 2004). This may be underlying the development of cobia, where Mohamed et al. (2007) found that three GnRH mRNAs peaked at $26 \mathrm{dph}$, but the gonadal sex of this fish could be determined only at $153 \mathrm{dph}$, when males but not females showed signs of puberty. Cells expressing GnRH-I mRNA have also been found in immature European seabass Dicentrarchus labrax at $30 \mathrm{dph}$ (González-Martínez et al. 2002).
Perciform fish have two forms of GnRH: sGnRH originates from the olfactory placode (the exposed olfactory tissue in the embryonic fish, thus possibly involved in imprinting the smell of the spawning area) therefore involving olfactory nerves, the olfactory bulb and the terminal nerve, while the other form, sbGnRH, originates from the preoptic area and the hypothalamus.

It is apparent that the early perception of environmental signals within the fish embryo has at least the potential to influence the scaffolding upon which the rest of its life cycle (and indeed its progeny) depends: although there are few germ cells, gonads are first seen in gilthead seabream at $14 \mathrm{dpf}$ and remain undifferentiated until about 4 months of age. Wong et al. (2004) suggest that the reproductionrelated genes expressed early are involved in the establishment of the gonads and germ cell proliferation but not sex determination. Notably both Wong et al. (2004) and Mohamed et al. (2007) suggest that there is an early establishment of the hypothalamic-pituitary-gonadal (HPG) axis during the larval phase in at least some commercially farmed fish species.

\section{The pituitary}

The pituitary, major regulator of other endocrine glands such as the thyroid, interrenals and gonads, is an outgrowth of the brain ventral to the hypothalamus. The pituitary comprises an adenohypophysis with hormone-producing cells - somatotrophs in the Proximal Pars Distalis and lactotrophs in the Rostral Pars Distalis - and an interlinked neurohypophysis. It produces a large suite of hormones involved in growth (somatotropin, insulin-like growth factors (IGF)), pigmentation (melanin concentrating hormone; $\mathrm{MCH})$, development $(\mathrm{TRH})$, homoeostasis, reproduction and stress (adrenocorticotropin hormone; ACTH).

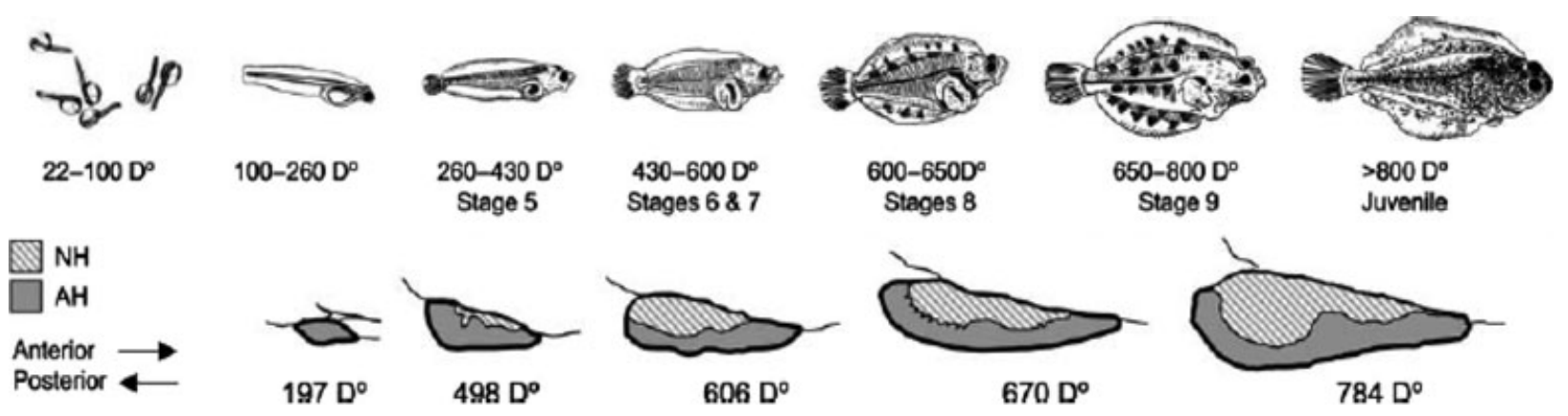

Figure 2 The morphology and pituitary development of Atlantic halibut from a few days after hatching til post-settlement, in daydegrees $\left(D^{\circ}=\right.$ days post-hatch $\times$ average temperature in Celsius). The appearance of the pituitary as a distinct organ coincides with the first traces of cells producing GH, PRL and SL and thyroid follicles. The first detection of TSH-producing cells coincides with first feeding (Stage 5). By metamorphosis (Stage 8), there are numerous thyroid follicles and increased thyroid activity which continues to peak hormone levels leading to the juvenile phenotype. GH, growth hormone; PRL, prolactin; SL, somatolactin; NH, neurohypophysis; AH, adenohypophysis (redrawn from Einarsdóttir et al. 2006, with permission). ( $\mathbb{\nabla}) \mathrm{NH}$; $(\square) \mathrm{AH} ;(\rightarrow)$ anterior; $(\leftarrow)$ posterior. 
Pituitary hormones for stress are encoded by proopiomelanocortin (POMC), a precursor for ACTH, melanophore-stimulating hormone (MSH) and endorphin. The pituitary-specific hormonally regulated expression of POMC is conserved in vertebrates (Bumaschny et al. 2007). Although the pituitary gland itself develops relatively slowly, the physiological responses attributed to it may precede this physical maturation. A morphologically distinct pituitary is found during the yolksac stage of the poorly developed Atlantic halibut larvae (Einarsdóttir et al. 2006; Fig. 2).

In the common carp Cyprinus carpio, the hypothalamus-pituitary-interrenal axis is already functioning at hatching. A stress response can be induced in $50 \mathrm{~h}$ post-fertilization (hpf) eggs which show an increase in whole-body cortisol levels within $5 \mathrm{~min}$ of handling (Stouthart et al. 1998). A distinct pituitary gland can be found already in embryos at $7 \mathrm{dph}$ with ACTH immunoreactive cells in the pars distalis and melanotropes in the pars intermedia (Stouthart et al. 1998). In zebrafish embryos, physical stress raised cortisol at $97 \mathrm{hpf}$ or about $40 \mathrm{~h}$ post-hatch (Alsop \& Vijayan 2008). In mouthbrooding tilapia Orechromis mossambicus larvae, a similar pattern is observed: already at $2 \mathrm{dph}$, a marker for corticotrophin-releasing factor is found in the preoptic nucleus and two hypothalamic nuclei as well as in the neural part of the pituitary, while the endocrine cells of the pars distalis and intermedia contain POMC-derived peptides, and all life stages were able to rapidly increase their response to handling (Pepels \& Balm 2004). It seems that even fish eggs are capable of responding to the stress of their environment, with all that entails.

In the marine hermaphroditic gilthead seabream, the overall sequence of pre-IGFBP-2 (insulin-like growth factor-binding protein) contains elements whose alignment is identical to those of other vertebrate IGFBP-2s. RT-PCR has detected IGFBP-2 mRNA throughout development in unfertilized eggs, embryos and larvae, with the highest levels observed after $3 \mathrm{dph}$. The timing of this peak is intriguing, because at 3 dph there are several concurrent events: a peak in IGF-1 mRNA, the beginning of exogenous feeding and the beginning of growth hormone gene expression and finally the development of visibly distinct liver tissue. This poses a question as to the origin of the IGFBP-2 because the authors found extra-hepatic expression in the larvae. Taken together, the results suggest that this mRNA is the product of both the maternal and embryonic genomes, and that this evolutionarily conserved IGFBP-2 mRNA is expressed during early development and in the gonad during the reproductive cycle, giving it a role for both development and reproduction (Funkenstein et al. 2002). A follow-up study found where the IGF-II protein itself and the mRNA were located in larval and post-larval seabream (Radaelli et al. 2003). There was immunoreactivity in a broad range of larval tissues including skin, muscle, gills, gut, kidney and the olfactory epithelium, whereas postmetamorphic larvae were positive for these tissues as well as showing the strongest reaction in the red axial muscle tissue in addition to the new sites of the pharyngeal and oesophageal epithelia. Not only did these authors localize the expression of IGF-II in a large number of diverse tissues from egg to adult in seabream, they also suggest that IGF-II acts in an autocrine/paracrine manner, in effect helping orchestrate the 'dialogue' of development. This in turn provides a plausible mechanism whereby events impinging on the broodstock maternal IGF axis are able to exert an impact on the next generation affecting their future development.

\section{Thyroid and thyroactive compounds}

Thyroid hormones regulate metabolism (protein, fat, carbohydrates and vitamins) and act on nearly every cell in the body at the level of protein synthesis, and they are important to growth, development and cell differentiation in all vertebrates. Thyroid hormones are produced in thyroid follicles in teleosts, near the ventral aorta (most fish), in the kidneys (carp) or in the gut tissue (platyfish Xiphophorus sp.; Geven et al. 2007; Klaren et al. 2008; Geven et al. 2009; Campinho et al. 2010). The hormone stimulation pathway starts with the integration of environmental signals (pineal-hypothalamus-pituitary-adrenal axis) which act on the pituitary release of thyroid-stimulating hormone (TSH) which acts on the release of hormone from thyroglobulin contained in the follicle. The thyroglobulin, or colloid within the follicle, is produced by the epithelial cells, thyrocytes, in the wall of the follicles and combines sequestered extracellular iodine with the amino acid tyrosine to make the $\mathrm{TH} \mathrm{T}_{4}$ or $\mathrm{T}_{3}$. Maternal deposits of $\mathrm{TH}$ in the yolk of teleosts decrease with egg development and as the embryo's own H-P-T axis becomes functional. In gilthead seabream, this is around the time of first exogenous feeding (Szisch et al. 2005), whereas in Atlantic halibut, it is prior to complete yolk absorption (Einarsdóttir et al. 2006). Thyroid hormones themselves appear early in fish ontogeny: in silver seabream Sparus sarba, both $\mathrm{T}_{3}$ and $\mathrm{T}_{4}$ are found in larvae at $1 \mathrm{dph}$, as are cortisol and heat-shock proteins (Deane \& Woo 2003).

The process of thyroid hormone formation has been well studied for over half a century largely because iodine can be radioactively labelled. Thyroid hormones and the $\mathrm{TH}$ signalling pathway, including thyroid receptors in cell nuclei, are evolutionarily conserved among chordates (Paris \& Laudet 2008). In peripheral tissues which undergo a transformation, current models propose that corticosteroids up-regulate thyroid hormone receptors and TH-converting deiodinases, as well as up-regulating early $\mathrm{TH}$ target genes. 
Metamorphosis in flatfish and other species is initiated by the $\mathrm{THs} \mathrm{T}_{4}$ and $\mathrm{T}_{3}$ (Miwa et al. 1988; Inui et al. 1995; Schreiber \& Specker 1998; Solbakken et al. 1999; Einarsdóttir et al. 2006) and is characterized by a welldefined peak (Blanton \& Specker 2007). Elevated levels of $\mathrm{TH}$ have been reported during metamorphosis in the Japanese flounder P. olivaceus, in the summer flounder Paralichthys dentatus (Tagawa et al. 1990; Schreiber \& Specker 1998) and in the gilthead seabream (Szisch et al. 2005). In support of this, inhibitors of TH synthesis such as thiourea or potassium perchlorate delayed metamorphosis in flatfish (Huang et al. 1998). Comparison of hormone results in individuals or species is made easier through the use of terms like premetamorphosis (in which corticotropes respond to environmental signals), prometamorphosis (during which pituitary thyrotropes respond to hypothalamic signals, modulating TSH secretion and the time of metamorphosis), climax and post-metamorphosis (Denver 2009) or well-defined developmental stages (Parichy et al. 2009) or through the pooling of larvae of the same developmental stage (Sæle \& Pittman 2010) rather than by age.

The adrenals (Early development of the adrenocortical and chromaffin tissues ('adrenals') in fish)

The adrenals in mammals are composed of two different tissues: the outer cortex and the inner medulla. In most vertebrates, both tissues are closely apposed and form a discrete organ. In fish, however, there is no compact adrenal gland but anatomically separated cortical and chromaffin tissue; the adrenal cortical tissue is represented by the interrenal cells associated with major blood vessels in the anterior kidney, while the medullary cells (chromaffin cells) may vary in location. In agnathans, adrenocortical cells are found as separate clusters of cells above the pronephric kidney and along the posterior cardinal veins in the same region (Norris 2007). Chromaffin cells have been identified in the wall of the sinus venosus along the cardinal veins and between the muscle fibres of the heart (Matty 1985). In the cartilaginous fish, adrenocortical tissue is truly interrenal in position, located in the posterior ends or along the medial border of each kidney, while chromaffin tissue occurs as small pair segmented bodies lying along the medial borders of the kidneys. In actinopterygians, the adrenocortical cells could be described anatomically as intrarenal, scattered in small clumps throughout the kidney (chondrosteans and holosteans) or embedded in the head kidney (teleosts) and associated with the post-cardinal veins and their branches (Matty 1985; Norris 2007). The distribution of the chromaffin tissue in actinopterygians varies with species and may form separate clumps or mixed clusters of cells with the adreno- cortical cells. In lungfish, the adrenocortical cells are located adjacent to branches of the posterior cardinal vein, while the chromaffin cells are found mostly in the heart and few of them in association with the cardinal vein.

The organogenesis of the adrenal gland and its homologues in vertebrates is still incompletely understood although its development is believed to share the same origin as the kidney and gonads (Keegan \& Hammer 2002; Morohashi 1997). In higher vertebrates, the adrenal cortex originates from the intermediate mesoderm, whereas the medulla is derived from neural crest cells (Keegan \& Hammer 2002; Unsicker et al. 2005). Tanaka et al. (1995), in a description of the development of some major endocrine organs in marine fish larvae, reported that the first appearance of interrenal cells occurs at 5-10 days after yolk absorption. However, studies in zebrafish showed that the interrenal primordium first appears at 20-22 hpf as bilateral interstitial mesoderm in the region of the 3rd pare of somites (Hsu et al. 2003). At $24 \mathrm{hpf}$, these cells undergo central migration to the axial central line, at $30 \mathrm{hpf}$ they fuse and at $3 \mathrm{dpf}$ they branch out into two separate groups. Chromaffin interrenal primordia converge to the region of the steroidogenic interrenal primordium at $2 \mathrm{dpf}$. From this stage onward, steroidogenic and chromaffin cells remain in close contact and expand together bilaterally to the notochord (To et al. 2007). The primordium at $3 \mathrm{dpf}$ is surrounded by a capsule-like structure, but does not have any epithelial characteristics, or surround a blood vessel, even at $5 \mathrm{dpf}$ (Hsu et al. 2003). Functional differentiation and further growth of the interrenal tissue in zebrafish are driven, after $5 \mathrm{dpf}$, by hypothalamus-pituitary-derived signals (To et al. 2007).

\section{The gonads}

Fish have multiple and different pathways to sex determination and extreme flexibility in sex differentiation. In all vertebrates, the primordial precursor of gonads is derived from two diverse embryological sources. Somatic cells of the presumptive gonads arise from the genital ridges, initially an evagination of the splanchnic mesoderm on the mesial surface of opisthinephroi or mesonephroi. In fish, some somatic cells may also be derived by an invasion of mesenchyme in a similar way that in mammals a thickening of the coelomic epithelium gives rise to the embryonic germinal epithelium and in turn to the primary sex chords (Hildebrand 1995; Devlin \& Nagahama 2002). Later in development the genital ridge of vertebrates develops into an outer peripheral portion, the cortex and a central part the medulla. The cortical part of the indifferent gonad will give rise to the ovary, while the medullar part will form testis. However, in cyclostomes and teleosts, no clear identification of the medullary tissue can be found in the indif- 
ferent gonad (Guraya 1994; Devlin \& Nagahama 2002), and this may be the structural basis of gonadal differentiation plasticity in fish. In mammals, the indifferent gonadal stage is completed early in development, whereas fish exhibit more flexibility because this is delayed either until the juvenile stage or even as in the case of hagfish Eptatretus stouti (Gorbman 1990) until the adult stage.

The gamete-forming cells of the gonads, that is, the primordial germ cells (PGCs), are derived in the vegetal region of the egg (extraembryonic endoderm) and migrate into the splanchnic mesoderm of the gut and then laterally into the germinal ridges. However, in some species, PGCs may migrate to other sites such as the liver (Romanov \& Altufev 1992; Romanov \& Altufyev 1993). Migration of PGCs towards the germinal ridge is guided by stromal-cellderived factor-1a which acts through its G-protein-coupled receptor, CXCR4b (Doitsidou et al. 2002; Blaser et al. 2006). Following arrival of the PGCs into the germinal ridge, cell division occurs to form oogonia and spermatogonia, in parallel to differentiation and migration of the somatic cells. The origin, migration and further development of the PGCs have been described in several commercially important aquaculture fish species like the rainbow trout (Takashima et al. 1980; van den Hurk \& Slof 1981; Lebrun et al. 1982; Devlin \& Nagahama 2002; Takeuchi et al. 2002; Yoshizaki et al. 2010), the common carp (Kawakami et al. 2011), the sturgeon Acipenser gueldentaedti (Akhundov \& Fedorov 1990), as well as the model species zebrafish and medaka Oryzias latipes (Hamaguchi 1982, 1992). In the zebrafish, PGCs are found in a dorsocaudal position of the coelom at $14 \mathrm{dpf}$, and at $28 \mathrm{dpf}$, most individuals (86\%) have gonads containing meiotic germ cells (Maack \& Segner 2003). Sexual differentiation of PGCs into perinucleolar oocytes occurred 1 week later, while at $77 \mathrm{dpf}$ an increased number of gonads (40\%) had been transformed into testis (Maack \& Segner 2003). In salmonids, differentiation of the indifferent gonad into ovaries occurs at 3 weeks post-hatching, whereas differentiation of testicular tissue occurs several weeks or months later (Piferrer \& Donaldson 1989; Nakamura \& Nagahama 1993; Devlin \& Nagahama 2002). The flexibility of sexual maturation in fish is also related to the plasticity of the germ cells themselves following the period of sex differentiation. As showed recently by Yoshizaki et al. (2010), rainbow trout spermatogonia and oogonia transplanted into the peritoneal cavity of newly hatched embryos of both sexes started to proliferate and differentiate into oocytes in female and into spermatocytes in male recipients, respectively. From this pioneer study, it was concluded that the germ cells possess a high level of plasticity, and that their differentiation is controlled epigenetically by the somatic microenvironment, rather than being cellularly autonomous.
Besides the germ cells, the somatic cells of the gonad differentiate into the granulosa and Sertoli cells for ovary and testis, respectively. In addition, the mesenchymal cells of the genital ridge differentiate in the testis into Leydig cells and in the ovary into thecal cells which are devoted to the synthesis of gonadal steroids (Raman 2002). Finally, the embryonic excretory ducts become associated with reproductive tracts in a species- and sex-specific manner. The gonad of cyclostomes is unpaired and suspended from the dorsal wall of the body cavity. In hagfish, the gonads are initially paired, but during early life, the left part atrophies and only the right part becomes functional. In lampreys, the single gonad lays in the middle of the body. It is hypothetized that early in development, the paired embryonic gonadal ridges fuse to form the median gonad. During the process of sex differentiation in hagfish, either the anterior or the posterior part of the indifferent gonad develops and the individual becomes female or male, respectively (Patzner 1998). In some cases, none or both parts develop forming sterile or hermaphrodite individuals. Both myxini and chephalaspidomorphi lack ovarian and testicular ducts, and gametes are shed into the coelom and deposited through the cloaca (hagfish) or the anus (lampreys) through specific openings serving as genital pores. Most elasmobranchs have paired ovaries, but in some species, only one may develop. The Müllerian duct forms the oviduct and differentiates into four specific regions (funnel, shell gland, isthmus and uterus) to meet the specific requirements of the ovoviviparous or viviparous reproductive strategies and internal fertilization. In male elasmobranchs, the Müllerian duct regresses and short tubules within the anterior part of the archinephric duct form the epididymis and the vas deferens (Kardong 2002). In female teleosts, the Müllerian ducts form the oviducts that serve the paired ovaries and the archinephric ducts the kidneys. There is a vast morphological variety in the female reproductive track and ovaries of teleosts. As cited in the study by Matty (1985), the ovary may be 'a hollow sac or a solid body, bilobed or single, with or without an oviduct'. In most teleost species, the oviducts regress entirely and egg transport is facilitated by new ovarian ducts deriving from peritoneal folds that embrace each ovary (Kardong 2002).

It is as difficult to generalize about fish gonado- and gametogenesis as it is to generalize about fish: the developmental patterns vary greatly and much is yet unknown. However, one thing is clear: the product of the gonads, namely the derived germ cells which become egg and sperm, come from the PGCs and these are subject to epigenetic influences. Thus, the development of the next generation is partly a result of the imprinting of gene expression patterns on the PGC of the parent during its own embryonic stage. This indicates that domestication of fish is a powerful process which can overrun Darwinistic 
selection of favourable genes (Li \& Leatherland 2012). This does not exclude natural selection but places it at a different level: the mosaic germline may be subject to selection at the cellular level based on (unspecified) mutational differences in the developmental biology of PGC and offers an explanation for rapid change in allelic frequencies from one generation to the next (Extavour 2008). Germ cells themselves in fish arise from the germ plasm. In fish and many elasmobranchs, the germ cells are first found in the extraembryonic endoderm near the border of the embryo; they then move through the embryonic gut and dorsal mesentery to the gonadal ridge (Bachvarova et al. 2009). Theories about how and when such events take place, even on an evolutionary scale, are inconsistent and reflect the genetic diversity arising from the FSGD: how germ plasm evolved in teleost fish is more confusing than in frogs because the mechanisms are not conserved across all species' (Johnston et al. 2011).

In developing fish embryos, these germ cells are usually quiet or inactive until gametogenesis begins in either the late larval or juvenile stage of life (although the patterns are variable in the few species studied; Extavour 2008). Two basic types of molecular mechanisms help specify what becomes a gamete: preformation and epigenesis, each working at either end of a continuum for germ cell development. Both mechanisms are observed in Chondrichthyes and Actinopterygii (Extavour 2008). The major difference between epigenesis and preformation is that in epigenesis, germ cell-specific genes are downregulated and/or their products are eliminated from the oocyte, after gametogenesis. Their products are not present in the cytoplasm of the fertilized egg and cannot therefore be autonomously inherited by future PGCs; instead, the genes must be zygotically activated in progeny PGCs through epigenetic signalling. By contrast, in preformation, germ cell-specific genes persist and can be found in the zygote's cytoplasm and can be included in the future PGC before zygotic transcription (Extavour 2008). Extavour (2008) makes a very significant point about the importance of epigenesis and the persistence of gene products in fish: that to go from epigenesis (influenced by the outside) to preformation (carrying that information as an integral part of self) 'only three things are necessary: (i) persistence of germ cell-specific gene products through the end of gametogenesis; (ii) cytoplasmic localization of these germ cell-specific gene products within the oocyte and (iii) inheritance of these products, which would now constitute germ plasm components, by future PGCs'. This means it is possible to 'jumpstart' selection for suitable traits for rearing fish by focussing on the signals perceived and incorporated by the early embryo's Primordial Germ Cells. It also means that normal breeding selection outcomes can be confounded by those same signals acting in the parent fish's embryonic life.

\section{The acoustic-lateralis system}

Structure of the otolith system and its components

Otoliths are aragonite structures that are integral to the acoustic-lateralis system. They function in concert with the macula which contains both the sensory apparatus (kinocillium) and the secretory cells responsible for biomineralization. The mineralized components of the otolith precipitate on a matrix of protein under both physiological control and environmental influence. The otoliths are enclosed by the otic (or otolith) membrane, with its outer gelatinous layer on the proximal surface facing the macula. The gelatinous layer communicates the relative otolith movement along the cilia to the macula's sensory cells. Pores in the gelatinous layer may represent sites involved in delivery of materials for otolith growth - either protein or mineral components.

Three pairs of otoliths are contained within separated sections of the labyrinth: the saggita otoliths within the saccule, the lappilus otoliths within the lagena and the asteriscus otoliths within the utricle. Each otolith is surrounded by an endolymph fluid enclosed in a separate otic membrane composed of glycoproteins (identified in adult fish as a $95-\mathrm{kDa}$ glycoprotein). Ionocytes are active in the supply of otolith precursors; these are not homogenously distributed throughout the epithelium of the otic membrane, but are most concentrated opposite the proximal surface of the otolith (facing the macula) and opposite the distal otolith surface (Mayer-Gostan et al. 1997).

\section{Otolith formation}

Otolith formation begins during the same time frame as optic system development, and fully formed otoliths are present in communication with the macula already before hatching. At least two of the three otolith pairs are present at hatching in most teleost species. During embryonic development, the rudimentary macula must develop first because this is the source of the glycoconjugates that form the gelatinous layer of the otic membrane, which initiates and controls the biomineralization, with respect to rate of growth and shape, of the otolith. The initiation of otolith development has been demonstrated to occur by the delivery of drops of protein matrix moving from the shaft of the kinocilium towards the tip where they coalesce and initiate the mineral precipitation (Dale 1984; Tytler et al. 2002). The protein Otop I has been identified as critical to early otolith formation (Hughes et al. 2004), but it does not seem to play an important role in controlling later biomineralization, that is, otolith growth. The Starmaker gene (Sollner et al. 2003) has been linked to control of otolith shape, by regulating the otolith protein matrix. The matrix proteins are a complex mixture and include high-molecular-weight water-insoluble protein, with a structural role 
(Degens et al. 1969), and calcium-binding glycoproteins (Wright 1991; Sasagawa \& Mugiya 1996; Morales-Nin 2000; Tomas et al. 2004) which likely control otolith precipitation. Several proteins have been identified; otolith matrix protein 1 (OMP-1) is responsible for production of the collagen otolin 1 and thus controls otolith growth (Murayama et al. 2005). Otolin 1, in turn, and a highmolecular-weight protein called otolith matrix macromolecule-64 (OMM-64) control the mineral polymorph and otolith shape (Murayama et al. 2005; Tohse et al. 2008).

\section{Otolith growth - biomineralization and control}

Otolith growth proceeds without direct contact to the secretory epithelium, and the mineral and organic constituents are brought together from the endolymph to form layered growth increments. Control of otolith growth has three aspects: rate, periodicity and shape. The rate of growth is controlled ultimately by protein synthesis and the availability of energy resources at the whole-organism level (Wieser 1994), with the added affect of temperature which drives the kinetic chemical processes in biomineralization. Otolith growth is a cyclical process, with matrix production and mineral precipitation primarily occurring during the day, resulting in a wide incremental zone, and reduced accumulation of both protein and mineral at night, resulting in a narrow, dark, discontinuous zone. The constituents of the otolith are dissolved in the surrounding endolymph fluid, with $\mathrm{Ca}$ ions and accompanying trace elements supplied from the blood plasma so that they vary in relation to individual physiology and seasonality. Supply of ions into the endolymph is mostly by active transport, and there are gradients in the $\mathrm{Ca}, \mathrm{Na}$ and $\mathrm{K}$ concentrations in different zones surrounding the otoliths (Payan et al. 1997, 2002). As $\mathrm{CaCO}_{3}$ is formed, the endolymph should become more acidic, but protons are actively pumped out by the otolith epithelium (Mayer-Gostan et al. 1997). Biomineralization is regulated by carbonic anhydrase causing endolymph $\mathrm{pH}$ change, which is under neuronal and hormonal control (Anken 2006). This is critical to the entrainment of periodicity, and manipulation experiments have shown that otolith growth is extremely sensitive to thyroid hormone (Shiao \& Hwang 2004; Shiao et al. 2008).

There is little evidence for periodicity to otolith growth in the early embryonic stages, but the characteristic visible growth increments can often be seen before hatching, especially in species which hatch at more advanced stages of development (e.g. salmonids, Geffen 1983). Entrainment to a circadian rhythm after hatching usually produces a pattern of otolith growth with one increment (consisting of an incremental and a discontinuous zone) formed each day (Morales-Nin 2000). There are some exceptions to this pattern, and slower increment formation is usually linked to low somatic growth rates (Fox et al. 2003).
Otolith shape changes gradually throughout ontogeny, from the nearly spherical form common in most larvae to highly specialized shapes that are unique to species and often with variations within species (Torres et al. 2000; Lombarte \& Cruz 2007). To achieve this change, new nucleation sites form, usually at or around the time of metamorphosis (Geffen et al. 2002). The resulting shapes are flattened and usually elongated in the anterior-posterior axis, with lobes or points often growing around the periphery. Although the main programming of these changes must be under genetic control, there has been less research in this area compared with studies of otolith formation during early development. Environmental factors, especially temperature, also play a significant role through their influence on biomineralization rate (Torres et al. 2000).

\section{Osmoregulation system}

Teleostean fish can live in a wide range of salinities from fresh water to hypersaline water or restricted to narrow ranges of salinity (freshwater or marine stenohaline) or tolerate broad ranges (euryhaline). Fish have different strategies to maintain the homoeostasis: osmoconformity, hypoosmoregulation and hyperosmoregulation. The organs and tissues generally responsible for maintaining the ionic and osmotic homoeostasis are gills, gastrointestinal tract and urinary system. All these morphological and functional aspects related with osmoregulation have been recently exhaustively reviewed (see for instance: Evans et al. 2005; Hiroi \& McCormick 2012; Edwars \& Marshall 2013; Marshall 2013), and therefore, this topic is not addressed in the present review. Although most teleosts are able to osmoregulate at hatch, the ability of larvae of euryhaline species to withstand changes in salinity depends on one or both of two factors: first, the ability of the physiological apparatus to function in an abnormal range of internal osmotic and ionic concentrations and second, the ability of the larva to regulate the body fluids in order to restore the levels of osmolarity to near normal. In very early developmental stages, the osmoregulation relies on the skin integument that is covered by ionocytes, in which the ion pumping activity takes place. With the progressive development of gills, digestive tract, kidney and urinary system, there is a shift of the osmoregulatory function to these sites (Varsamos et al. 2005; Bodinier et al. 2010). Drinking sea water and actively excreting the excess of salts throughout the urinary system is the way marine teleosts avoid dehydration. The ontogeny of the organs involved in the osmoregulation, and therefore, the acquisition of the full ability to hypo- and hyper-regulate is age dependent, and consequently the salinity tolerance tends to increase with the larval development and become complete at the achievement of juvenile stage. 


\section{Functional plasticity - interactions between the internal and external environment which define the phenotype}

\section{Sex differentiation}

Diversity and plasticity characterize sex differentiation processes and the sex determination mechanisms in fish species. Sex differentiation can follow a variety of models/ strategies, from the formation of gonads that contain functional ovarian and testicular tissue at the same time, as is the case of synchronous hermaphrodites, to individuals which develop only as males or females throughout their life span, as is the case of differentiated or primary gonochoristic species (reviews by Yamamoto 1969; Buxton \& Garratt 1990; Shapiro 1990; Devlin \& Nagahama 2002). Different strategies of gonadal development also include undifferentiated gonochorism, rudimentary hermaphroditism or secondary gonochorism, sequential hermaphroditism (protogynous or protandrous hermaphroditic species) and abnormal hermaphrodites or intersex individuals. The causes of this enormous plasticity in this fundamental feature of life are related to genetic, epigenetic and environmental factors and their interactions with the fish throughout its lifetime.

In mammals, the sex of an individual is determined on the basis of sex chromosomes: the females being homogenetic (XX), while males are heterogametic (XY). However, in comparison with other vertebrate classes, the cytological observation of structurally distinct sex chromosomes in fish is sporadic, and heterogametic sex chromosomes have been reported in only 104 to 176 species $(6-10 \%)$ of 1700 species cytogenetically characterized so far (Arkhipchuk 1995; Kumar \& Tembhre 1995). In about 63 species, the XX/XY or XX/XO mechanism is present (Kumar \& Tembhre 1995); for example, male heterogamety (XY or XO) has been reported in several species like the Atlantic stingray Dasyatis sabina, the Mediterranean moray eel Muraena helena, the salmoniform Galaxias platei and the stomiform Stenoptyx diaphana. Male homogamety (ZZ) has been reported in about 27 species like the European eel Anguilla anguilla and Japanese eel and several Poecilidae (Gampusia spp.; reviewed in Devlin \& Nagahama 2002). The multiple sex chromosome mode of sex determination has been reported in about 12 species like the salmonine

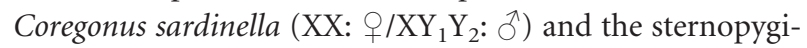

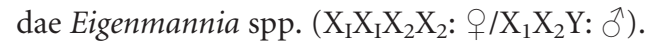

Polygenic sex determination is a more primitive mechanism and most common in fish. In polygenic mechanisms, the cumulative genetic action of several sex genes located on different chromosomes drives the differentiation of germ cells to oogonia or spermatogonia leading to the formation of ovaries and testis, respectively. Polygenic sex determination may be also present in fish species in which sex chromosomes are present. Recent studies have shown that while the upstream genes on the sex determination pathway vary among different vertebrates, the downstream components tend to be conserved (Charlesworth \& Mank 2010). Several genes, like Sry (sex determining region Y), Sox9 (Sry box-9), Dmrt1 (doublesex and mab-3 related transcription factor 1), Daxl (dosage-sensitive sex reversal, adrenal hypoplasia critical region, on chromosome $\mathrm{X}$, gene 1), Lhx9 (LIM homeobox gene 9), Foxl2 (forkhead box protein L2), Cyp19a (aromatase) and Wnt4 (wingless-type MMTV integration site 4), are known to play a role in the sex determination mechanism of different animal species (Raman 2002; Ijiri et al. 2008). In the medaka, Dmy (DM domain gene on the $\mathrm{Y}$ chromosome) has shown to be the master gene for male sex determination (Matsuda 2005). In Nile tilapia, male-specific expression of Dmrt1 has been reported during the critical period for sex determination (Kobayashi et al. 2008). However, recently Eshel et al. (2012) showed that sex determination in tilapia is controlled by interactions between major and minor genetic factors on the sex chromosomes and autosomes, as well as environmental factors. More important, in fish the phenotypic sex is not always concordant with sex determined by genetics. Environmental factors like exogenous steroids, water temperature and $\mathrm{pH}$ or behavioural factors may affect sex determination in various fish species.

Remaining one sex throughout the lifetime is not always the strategy exhibited by fish species. Even in mammals, the post-gonad determination phase of sex differentiation is almost exclusively hormone dependent and is an active sexually unimorphic process for the male (Hughes 2011). In fish, endocrine and molecular control of sex differentiation involves a complex interaction of specific genes involved in the biosynthesis of enzymes responsible for the production of steroids, various hormones (gonadotropins, androgens, oestrogens, progestagens, etc) and receptors at the level of gonads and brain. In addition, the administration of exogenous steroids in a critical period for sex determination may change the phenotypic sex even in species with a sex chromosomes mechanism (Yamamoto 1969; Hunter \& Donaldson 1983). Even the much-used zebrafish model contains a relevant peccadillo: $D$. rerio gonads are all initially ovaries, and in those individuals which will become males, the ovaries degenerate through apoptosis several weeks after hatching, although the ovarian cavity persists (Uchida et al. 2002). Similarly, the white seabream Diplodus sargus has a special type of protandric juvenile hermaphrodite which then gives rise to males and females. The red sea bream Pagrus major has a bisexual gonad with an ovarian lumen in the juvenile phase from which ovaries or testes develop for the females or males. The red porgy Pagrus pagrus has intersexuals with either ovaries or undifferentiated gonads, and while primary males with testes may arise from those 
with undifferentiated gonads, there are secondary males which arise from those fish bearing ovaries. Even the popular groupers Epinephlinae do not have young males because this subfamily has protogynous hermaphrodites although the mechanism to drive the sex change is so far unknown but linked to the social environment (Pandian 2012).

In endotherms like mammals, the process of sex differentiation occurs under controlled temperature conditions. However, fish being exotherms are exposed during the critical period of sex differentiation to a variable physical environment. The ambient temperature has a relevant role in phenotypic sex determination being, either per se or in relation to genetic sex determination mechanisms, responsible for the sex ratio of a given population in many fish species (Conover \& Kynard 1981; Ospina-Alvarez \& Piferrer 2008). The thermal effect on sex differentiation has been described in several cultured species like the European sea bass (Blázquez et al. 1998; Pavlidis et al. 2000), sockeye salmon, Oncorhynchus nerka (Azuma et al. 2004), Atlantic halibut (van Nes \& Andersen 2006) and Nile tilapia (Bezault et al. 2007; Rougeot et al. 2008). In the past, it was believed that there were several patterns of sex ratio response to temperature, but now it seems like the relatively few species of fish with temperature-dependent sex determination have generally one pattern in which low temperatures produce female-biased sex ratios and high temperatures produce male-biased sex ratios (Ospina-Alvarez \& Piferrer 2008).

The effect of temperature, and other environmental disruptors, during a critical period of sex differentiation is mediated by the androgen-to-oestrogen ratio in the undifferentiated gonad, which depends on the activity of the enzyme aromatase (Cyp19a). Aromatase, the product of the cyp19a gene, irreversibly converts androgens into oestrogens. The European sea bass is a gonochoristic fish in which sex can be controlled by both genetic and temperature effects (Pavlidis et al. 2000; Piferrer et al. 2005). In this species, exposure to high temperatures $\left(>17^{\circ} \mathrm{C}\right)$ even before the formation of the gonadal ridges results in male-biased sex ratios (Roblin \& Bruslé 1983; Pavlidis et al. 2000; Koumoundouros et al. 2002; Navarro-Martín et al. 2009). Recently, it was shown that epigenetic factors control this sex ratio shift in response to ambient water temperature (Navarro-Martín et al. 2011). In particular, it was shown that methylation of the sea bass cyp19a promoter is the cause of the lower expression of cyp19a in temperaturemasculinized fish.

Recent work by Pandian (2012) on the genetic sex differentiation in fish summarizes the consequences of the diversity of strategies found in teleosts: we need to look for more than one sex determining gene on more than one chromosome to understand how the sexes and the generations of fish (yearclasses) are produced and, armed with the knowl- edge of how sex determination and differentiation occurs in various fish species, we can use this to identify the optimal broodstock size and select appropriate candidates for new commercial endeavours.

There is another potential use for this knowledge when considering a common method to assess fish maturity status, the gonadosomatic index, which measures the relative weight of the gonad. If the fish populations are sequentially hermaphroditic, simultaneous hermaphrodites, protandrous or protogynous instead of being just males or just females, then the easy application of the short equation might be significantly more challenging to interpret correctly.

\section{Implication of $\mathrm{TH}$ in metamorphic processes}

\section{Thyroid hormone and metamorphic transformations}

Since Lam (1980) first reported the positive effect of $\mathrm{T}_{4}$ treatment on larval development and survival in tilapia, numerous trials using exogenous $\mathrm{TH}$ have been conducted with the aim of developing practical protocols to manipulate metamorphosis. de Jesus et al. (1998) found that immersing premetamorphosing grouper (Epinephelus coiodes) in various concentrations of $\mathrm{T}_{4}$ and $\mathrm{T}_{3}$ resulted in the synchronization and shortening of the duration of metamorphosis in a dose dependent manner, independent of larval size. Their TH doses were comparable to those inducing metamorphosis in flounder larvae (Inui \& Miwa 1985; Miwa \& Inui 1987) and the appearance of black stripes and settlement in the red sea bream (Hirata et al. 1989). Immersion of Japanese flounder larvae in a $\mathrm{T}_{4}$ solution promoted the differentiation of the gastric gland as well as pepsinogen synthesis (Miwa et al. 1992). The accelerated onset of pigmentation and differences in swimming behaviour among TH treated larvae suggest an influence of this hormone on the peripheral development of the neuromuscular system (Brown \& Kim 1995). Yamano et al. (1991) showed that $\mathrm{T}_{4}$ treatment accelerated the shift from larval to juvenile-type muscle proteins in the Japanese flounder, coincident with the onset of benthic behaviour. The emerging picture from these studies is that hormone immersion and/or introduction during earlier developmental stages can have a profound impact on metamorphosis and in certain cases enhance juvenile quality in commercially valuable fish. On the other hand, this approach may prove costly in large-scale operations and raise justifiable questions about fish welfare from an increasingly environmentally aware public. A better approach is to understand the dependence of ontogeny on the fish's own endocrine production and provide it with the appropriate building blocks for a natural transition to a quality juvenile.

Thyroid hormones act with glucocorticoids (GC), prolactin and growth hormone to transform larvae to juveniles 
(metamorphosis). Corticosteroid signals are mediated by glucocorticosteroid receptors, of which teleosts have two types presumably as a result of the FSGD (although zebrafish only have one type, Alsop \& Vijayan 2008), and the mineralocorticoid receptor. Tanaka et al. (1995) described an elevated cortisol peak that preceded that of TH in early fish metamorphosis. Szisch et al. (2005) found that cortisol synthesis increased markedly prior to both $\mathrm{T}_{4}$ and $\mathrm{T}_{3}$ production during early metamorphosis in gilthead seabream. Cortisol and TH appear to act synergistically on various developmental processes such as fin re-absorption in Japanese flounder and improved survival and growth (de Jesus et al. 1990, 1991; Lam 1994; Brown \& Kim 1995).

Broadly speaking, this could mean that dietary factors modulating the cortisol response may also be critical precursor nutrients in metamorphosis. In support of this, Koven et al. (2003) found that dietary levels of the essential fatty acid arachidonic acid (ArA; 20:4n-6) correlated with cortisol synthesis during chronic stress. A chronic stress response, in terms of cortisol synthesis, might also be occurring during the profound physiological and morphological changes characterizing the species-specific period of metamorphosis which, in turn, might be influenced by available tissue ArA. On the other hand, a surfeit of dietary ArA might cause excessive cortisol levels and a detrimental effect during this critical developmental stage apart from reducing the fish's immunocompetance (Barton \& Iwama 1991; Vijayan et al. 1997; Wendelaar Bonga 1997). Synergistic gene activation by thyroid hormone and corticosteroids has been implicated in a variety of animal tissues, regulating the HPT and HPA axes and sensitizing target tissue to low concentrations of thyroid hormone. Elucidation of the detailed regulatory role of the pituitary and TH in teleosts will come from studies on the tissue distribution of receptors and other molecules mediating hormone action (Einarsdóttir et al. 2006).

Different tissues within the intestine undergo different changes at different developmental stages. The specific tissue response to TH may be regulated in three ways: through cellular TH levels regulated by external and internal controls; through free TH levels as regulated by cytosolic TH binding proteins and intracellular TH metabolism; and finally through tissue-specific variations in thyroid hormone receptors (TR). Expression of TR seems to be involved in promoting cell proliferation and apoptosis, depending on the cell type (Shi \& Ishizuya-Oka 2001). In anurans, it seems that TR levels may control the temporal regulation of metamorphosis. Several studies using zebrafish as model have studied the effect of TH on the transition from larvae to juvenile and on intestinal development maturation development (Brown 1997; Liu \& Chan 2002), mainly for biomedical purposes; however, little informa- tion exists for fish species with commercial importance (see review by Rønnestad et al. 2013).

\section{Thyroid hormone response genes in the intestine}

Several decades of research on the influence of TH on the development and maturation of intestinal epithelium in anurans has led to well-defined boundaries between the different stages of metamorphosis based on $\mathrm{T}_{3}$ levels, where each stage is characterized regarding structure, cellular structure, degree of functionality, among others aspects (Heusser et al. 1992; Shi \& Browns 1993; Shi \& IshizuyaOka 2001; Shi et al. 2001; Schreiber et al. 2009). This enabled researchers to correlate gene expression studies with cellular and biochemical transformations at distinct stages during amphibian metamorphosis, and consequently to identify molecular pathways characterizing intestinal development and maturation in amphibians, as well the identification of genes under thyroid regulation (Heimeier et al. 2010).

Based on PCA and genetic ontology analysis, these authors were able to group genes in six clusters occurring before, during and after metamorphosis, where the largest cluster is composed of genes associated with cell proliferation signal transduction, transcription factor activities and cell-to-cell signalling (e.g. basic leucine zipper motif-containing a transcription factor and an extracellular matrixdegrading metaloproteinase stromelysin 3 ). This suggests a deeper role for these genes in the remodelling processes occurring at metamorphic climax. In addition, the expression of genes from this cluster followed the endogenous levels of $\mathrm{T}_{3}$, suggesting that these genes are $\mathrm{TH}$ dependent. Heimeier et al. (2010) highlighted that only half of the genes regulated in the intestine during natural development were common with those regulated upon treatment with $\mathrm{T}_{3}$, indicating that significant differences might exist between $\mathrm{T}_{3}$-induced and natural metamorphosis. This is possibly because metamorphosis was anticipated and the cell response at that time is different or following different pathways. Other hypotheses can be addressed, but this observation reflects individual flexibility in using different pathways, to attain the same objective, in this case the metamorphic climax. This is an important aspect to considerer when manipulating environmental conditions or nutritional conditioning during fish development.

Due to the degree of conservation between zebrafish and mammals regarding organ physiology and gene regulatory networks throughout vertebrate development including metamorphosis (Stuckenholz et al. 2009), it has been expected that similar changes in gene expression might also occur during fish intestinal development and maturation. Despite the studies on gene expression of the digestive tract in zebrafish, no correlations have been established so far for fish (Stuckenholz et al. 2009). This 
might be related with the absence of a drastic remodelling in fish intestine during metamorphosis although $\mathrm{TH}$ is considered critical for the transformation from larval to juvenile in zebrafish (Brown 1997). The climax of anuran metamorphosis is characterized by a peak in TH. In flatfish, a similar peak occurs around climax metamorphosis, although in round fish thyroid hormone peaks are not so obvious (Power et al. 2008). Perhaps a positive correlation can be expected between thyroid hormone levels and the degree of transformation that may be expressed as anurans $>$ flatfish $>$ roundfish.

\section{Environmental iodine as a TH precursor}

To synthesize sufficient levels of TH leading to successful metamorphosis, iodine must be available in the correct molecular form and concentration. Fish can absorb iodine in various inorganic forms from seawater (iodide; $\mathrm{I}^{-}$, iodate; $\mathrm{IO}_{3}$; reviewed by Wong 1991), via the gills, with the uptake rate inversely proportional to water calcium content (Gregory \& Eals 1975). In seawater, a constant level of total inorganic iodine (400-500 nM) has been reported from 0 to $1000 \mathrm{~m}$ depth, independent of geographical location although the ratio of the two forms, iodide and iodate, varies with depth and latitude (Wong 1991; Schwehr \& Santschi 2003). Although very young larvae do not have fully developed gills, Moren et al. (2008) reported that Atlantic halibut larvae concentrated iodide 100-fold higher in the tissues than inorganic levels found in the seawater. Importantly, iodide-deficient water can originate from seawater inland wells (Witt et al. 2009) or from the use of recirculation systems coupled with ozonation which have high oxidation-reduction potential (Sherrill et al. 2004). Ozone oxidizes iodide $\left(\mathrm{I}^{-}\right)$to iodate $\left(\mathrm{IO}_{3}\right.$; Bichsel \& von Gunten 1999; Sherrill et al. 2004) significantly reducing the bioavailability of iodine that can lead to the development of thyroid lesions. This suggests that recirculation systems must be adapted for life stages where there is a critical dependence on iodide.

Iodine is absorbed and concentrated as iodide in the follicles of the thyroid gland and is mobilized together with tyrosine for $\mathrm{T}_{4}$ synthesis (Solbakken et al. 2002). In this process of iodination, the enzyme thyroperoxidase (TPO) oxidizes iodide in the presence of $\mathrm{H}_{2} \mathrm{O}_{2}$ which results in high oxidative stress that is counteracted by antioxidant systems such as the seleno-enzyme GPx (Glutathione peroxidase). $\mathrm{T}_{4}$ is converted to $\mathrm{T}_{3}$ which is the more biologically active form (Eales \& Brown 1993; Power et al. 2001) by selenium-dependent enzymes (outer ring 5'-monodeiodination; ORD) called deiodinases (Eales \& Brown 1993) in the peripheral tissues (Klaren et al. 2005). Studies with pacific threadfin (Polydactylus sexfilis) showed that $\mathrm{T}_{4}$ levels increased markedly and displayed a metamorphic peak when fish were exposed to iodide containing seawater from the ocean compared with a gradual increase in cohorts reared in iodide-deficient seawater from a well indicating incomplete synchronization of development or metamorphosis (Witt et al. 2009). On the other hand, $\mathrm{T}_{3}$ was independent of environmental iodine as its tissue levels are closely regulated (Eales \& Brown 1993) and increase only by ORD activity (Burel et al. 2000; van der Geyten et al. 2001).

\section{Dietary iodine and the superiority of natural larval zooplankton prey}

It is unclear whether marine fish larvae can satisfy their iodine requirement from only the inorganic forms in the surrounding seawater medium, particularly during metamorphosis, or if they also require an exogenous source in their natural zooplankton diet (Solbakken et al. 2002; Moren et al. 2006). Studies on Atlantic halibut, turbot and Japanese flounder have reported greater metamorphic success, in terms of pigmentation, eye migration and general development, when premetamorphosing larvae were fed natural marine zooplankton comprised mostly of copepods compared with enriched Artemia (Seikai 1985; McEvoy et al. 1998; Pittman et al. 1998; Shields et al. 1999). Not surprisingly, natural marine zooplankton are universally regarded as a superior food compared to Artemia nauplii, as they are a richer source of essential fatty acids, phospholipids, carotenoids, free amino acids and inorganic compounds such as iodine. On the other hand, Artemia and copepods have similar levels of tyrosine (an amino acid precursor of $\mathrm{TH}$ ) and selenium (necessary for the synthesis of antioxidants and the conversion of $\mathrm{T}_{4}$ to $\mathrm{T}_{3}$ ), while Artemia have somewhat higher concentrations of the $\mathrm{TH}$ amino acid precursor, phenylalanine (Solbakken et al. 2002). Copepods contain up to 700 times (60-350 $\mu \mathrm{g}$ iodine $\left.\mathrm{g}^{-1} \mathrm{DW}\right)$ more iodine than Artemia nauplii (0.5$\left.4.6 \mu \mathrm{g} \mathrm{g}^{-1} \mathrm{DW}\right)$, and rotifers $\left(0.52-7.9 \mu \mathrm{g} \mathrm{g}^{-1} \mathrm{DW}\right.$; Hamre et al. 2008a,b). Artemia and copepods have similar selenium levels (Solbakken et al. 2002; Moren et al. 2006). Unfortunately, an industrial protocol for the mass rearing of copepods in sufficiently high quantities to meet the demands of commercial mariculture has not been developed.

There appears to be a species-specific critical window for feeding copepods to fish larvae to positively influence metamorphic success. In Atlantic halibut, Artemia and copepods served equally well as growth promoters for the first 46 days of feeding (Harboe et al. 1998; McEvoy et al. 1998; Shields et al. 1999). However, after 46 days, larvae that continued feeding on Artemia began to show differences in eye migration and pigmentation (Næss et al. 1995) while those that had fed on copepods transformed normally. Næss and Lie (1998) claimed that the copepod window for halibut was 2-3 weeks following first feeding, 
while normally pigmented halibut can be obtained when fed on copepods for only 7 days before larvae reach the myotome height of $2.5 \mathrm{~mm}$ which is associated with eye migration at the initial stage of metamorphosis. The critical period for Japanese flounder was around $15 \mathrm{dph}$ or about $7.5 \mathrm{~mm}$ in total length (Seikai et al. 1987), while the pigmentation window for larvae of the yellowtail flounder was up to $9 \mathrm{~mm}$ in total length (Copeman et al. 2002). In plaice, on the other hand, what was deemed the relevant factor was the duration of feeding natural zooplankton rather than the exact timing (Dickey-Collas 1993). Taken altogether, these findings suggest a nutritional factor found in copepods and not in Artemia that aids normal metamorphosis.

Does dietary iodine, as a TH precursor, drive metamorphosis? An iodine deficiency can lead to goitre or hypothyroidism (Sonstegard \& Leatherland 1978; Moccia et al. 1981; Leatherland 1994) and is characterized by low $\mathrm{T}_{4}$ levels, thyroid tissue hyperactivity (goitre) and high ORD activity to maintain $\mathrm{T}_{3}$ production from the available $\mathrm{T}_{4}$ (Burel et al. 2000; van der Geyten et al. 2001). Iodine enrichment of live feed prevented Senegalese sole larvae from developing thyroid hyperplasia and increased their iodine content four times at premetamorphic and metamorphic stages which significantly decreased after metamorphosis (Ribeiro et al. 2011). This pattern was similar in halibut fed wild copepods (Solbakken et al. 2002). Moreover, it has been claimed that iodine enrichment of live feed is required from the onset of feeding because it improved growth, survival and thyroid status in Senegalese sole larvae (Ribeiro et al. 2011) which undergo metamorphosis between 12 and 20 dph (Ortiz-Delgado et al. 2006). Klaren et al. (2008) reported that at premetamorphosis, $\mathrm{T}_{4}$ levels increased at around $10 \mathrm{dph}$, peaked at starting eye migration $(16 \mathrm{dph})$ and reduced at $17 \mathrm{dph}$. These time intervals can oscillate with different feeding regimes, diet type and larval size (Fernández-Díaz et al. 2001). Iodine or selenium supplementation alone does not necessarily guarantee improved metamorphosis (Moren et al. 2006; Ribeiro et al. 2011). The question remains whether there are other factors, apart from the level of selenium, certain amino acids as well as $\mathrm{T}_{4}$ and $\mathrm{T}_{3}$, which are also pivotal in advancing metamorphic development.

During metamorphosis in teleosts, class II nuclear receptors (Nhr), thyroid hormone receptors (Thr) and class I Nhrs, glucocorticoid receptors (Gr) play vital signalling roles in determining the juvenile and adult phenotype. However, the multiplicity and diversity of the teleost receptors remains poorly understood. Recent evidence suggests that the paralog-specific isoforms are important during the metamorphic process. Studies in teleosts are revealing how earlier events during the larval phase can significantly affect the outcome over the lifetime of the fish. Thus, understanding the evolution of fish can influence the profit margin today.

An elegant example of the interaction between metamorphosis, evolution and epigenesis in the form of exogenous hormones on the red drum Sciaenops ocellatus has recently been published by Applebaum et al. (2012). The red drum is an acanthomorph species, a relatively recently evolved clade of about 14000 species of fish originally grouped on the basis of morphology but for which this grouping has also been substantiated molecularly. Acanthomorphs, both recent and extinct, are characterized by a morphological innovation: hollow and unsegmented spines at the anterior edge of the dorsal and anal fins. Red drum undergo metamorphosis using the classic thyroid and corticosteroid hormone axes to transition from larvae with a primordial finfold along the body to juveniles with distinct medial and paired fins and adult organ systems. These authors experimentally examined the evolutionarily conserved superfamily of nuclear receptors (nr) for $\mathrm{TH}$ and corticosteroids. The expression of these nuclear receptors is central to the function of each hormone and to the interactive function of both hormones in the developing fish. Using three variants of nuclear receptor (two nrla transcripts thraa and a long isoform of thrb-L, and a single long isoform of an $\mathrm{nr} 3 \mathrm{cl}$ called $\mathrm{gra}-L$ ), the authors characterized receptor functions and, in the developing red drum larvae from 0 to $33 \mathrm{dph}$, quantified the in vivo expression patterns of these receptors both under control conditions and when given exogenous $\mathrm{T}_{3}$ or cortisol. They found that peak expression levels of sogra- $L$ and sothraa coincided with the highest levels of $\mathrm{T}_{4}$ and cortisol in prometamorphic larvae. When younger larvae were given exogenous $\mathrm{T}_{3}$, a short-term increase in the mRNA for thyroid nuclear receptors was found, but there was no concomitant increase in the corticosteroid receptor mRNA. Their integration of phylogenetic inference with genomic synteny and functional applications suggests that the majority of teleosts have three types of nrla and two types of $n r 3 c 1$ genes with doubleconserved synteny, consistent with a whole-genome duplication event for teleosts. Interestingly, their analyses suggest that some paralogs of these genes, so central to metabolism and cell performance, have full separation and possibly new functions in 14 families of acanthomorph fish, but they do not find this in older groups such as protocanthopterygii, ostiophysi and elopomorphs. The evolutionary diversity of these genes in teleosts is made further complex by the existence of splice variants, exons and inserts which affect their binding properties and thus their functions in various species at various life stages.

Thus, the conclusion so far is that fish larvae express the nuclear receptors for $\mathrm{TH}$ and corticosteroids around the time of metamorphosis in a manner that is species- and 
paralog-specific. While upregulation of thrb around metamorphosis is found for more ancestral types of fish (whitespotted conger eel Conger myriaster and zebrafish), it is thraa genes which are upregulated in many of the newer Acanthomorphs (Japanese flounder, turbot Psetta maxima, Pacific bluefin tuna Thunnus orientalis and gilthead seabream), sometimes co-upregulated with thrb (Atlantic halibut, Senegalese sole and gilthead seabream; Applebaum et al. 2012).

Taken altogether, the TH precursor iodine, in the environment and/or the diet, clearly affects thyroid production of $\mathrm{T}_{4}$ and the incidence of goitre while falling short as a driving force in metamorphic change in flatfish. On the other hand, ArA may modulate the high levels of cortisol which reputedly works synergistically with $\mathrm{TH}$ initiating the rapid physiological and morphological change characterizing pre- and climax metamorphosis. In addition, ArA in the form of eicosanoids or effectors of gene expression can dramatically change pigmentation, which is a major feature of metamorphosis in many species. The early life of fish has many variations on the functional mechanisms of the conserved process of thyroid-driven metamorphosis, so that understanding the evolutionary relationships will inform even short-term fish farming goals of quality juvenile production.

\section{The cortisol stress response}

\section{Profile of whole-body cortisol concentrations during early ontogeny}

Changes in cortisol content in fertilized eggs, embryos and larvae at various developmental stages have been examined in several fish species. The plasticity in early life stages and variability in the rate of embryonic development among the different fish species is also reflected in the pattern of cortisol changes. However, a direct comparison is complicated by the fact that in most published studies, the pattern of cortisol changes is related to the time after fertilization (or hatching) and not to specific morphological characteristics that characterize early development.

Cortisol is present in fertilized eggs and embryos of all fish species studied to date. In marine teleosts, with short embryonic development, cortisol concentrations in fertilized eggs range from 0.21 to $2.5 \mathrm{ng} \mathrm{g}^{-1}$, while in salmonids from 6 to $26 \mathrm{ng} \mathrm{g}^{-1}$. The cortisol content in fertilized eggs is probably of maternal origin and necessary for the metabolic needs and for the functional development of various organs during early development (de Jesus et al. 1991). However, the dynamics of maternal cortisol are different at different stages of embryonic development. Most species show a general pattern of changes in cortisol content during embryogenesis, with relatively high levels after fertilization followed by a decline around the time of hatching.
This pattern has been observed in the Mozambique tilapia O. mossambicus (Hwang et al. 1992), rainbow trout (Barry et al. 1995), coho salmon, Oncorhynhus kisutch (Stratholt et al. 1997), Asian sea bass Lates calcarifer (SampathKumar et al. 1995), yellow perch Perca flavescens (Jentoft et al. 2002), white sturgeon Acipenser transmontanus (Simontacchi et al. 2009), zebrafish (Alsop \& Vijayan 2009), Japanese flounder (de Jesus et al. 1991), gilthead seabream (Szisch et al. 2005), red drum (Applebaum et al. 2010) and European seabass (Pavlidis et al. 2011). In contrast, in common carp, increased cortisol content is found well before hatching (at 36 hpf; Stouthart et al. 1998), indicating early endogenous production. Similarly in the chum salmon Oncorhynhus keta, cortisol levels show a slight increase 1 week before hatching to peak after the completion of the yolk sac absorption or at about the time of emergence (de Jesus \& Hirano 1992), while in chinook salmon, Oncorhynchus tshawytscha, cortisol content peaks at hatch (Feist \& Schreck 2001).

While marine fish show a similar pattern of changes in cortisol concentrations during early development, there are evident differences in the magnitude of the pattern. In marine teleosts, cortisol content starts to increase around the transition from endogenous to exogenous nutritional sources, to reach a peak around notochord flexion (i.e. start of metamorphosis). The onset of cortisol biosynthesis close to first feeding may be important for the proper utilization of exogenous dietary proteins and carbohydrates for energetic and growth purposes (Szisch et al. 2005; Applebaum et al. 2010). Peak basal cortisol concentrations in European sea bass at flexion and at the more advanced developmental stages are in the range $32-48 \mathrm{ng} \mathrm{g}^{-1}$ (Pavlidis et al. 2011). This value is the highest reported among marine species and similar to that reported for chum salmon (30 $\mathrm{ng} \mathrm{g}^{-1}$, after the completion of yolk sac absorption, when the fry emerged from the gravel bed) (de Jesus \& Hirano 1992), a species with a very different ontogenetic pattern. Peak cortisol levels of $11 \mathrm{ng} \mathrm{g}^{-1}$ were reported during metamorphic climax in the Japanese flounder (de Jesus et al. 1991), of $14.8 \mathrm{ng} \mathrm{g}^{-1}$, in gilthead seabream at melanophore formation (Szisch et al. 2005), of around $18 \mathrm{ng} \mathrm{g}^{-1}$ at $14 \mathrm{dph}$ in the cod (King \& Berlinsky 2006), of $6.1 \mathrm{ng} \mathrm{g}^{-1}$ at approximately $7 \mathrm{dph}$ in the Asian seabass (Sampath-Kumar et al. 1995) and of $1.72 \mathrm{ng} \mathrm{g}^{-1}$ at $9 \mathrm{dph}$ in the red drum (Applebaum et al. 2010). In freshwater species, values of $7.0 \mathrm{ng} \mathrm{g}^{-1}$ in the yellow perch (Jentoft et al. 2002), and of $5.5 \mathrm{ng} \mathrm{g}^{-1}$, towards the end of yolk sac absorption, in tilapia (Hwang et al. 1992) have been reported.

\section{Onset of the cortisol stress response}

The appearance of interrenal cells, the expression pattern of genes encoding steroidogenic enzymes and the timing of endogenous production of hypothalamic or pituitary hor- 
mones in combination with rising cortisol concentrations are often used to study stress responsiveness of the HPI axis and the development of corticosteroid stress response during early life stages. The timing for a functioning HPI axis and the onset and magnitude of the stress response during early ontogeny is variable among the different fish species depending on their life cycle. In addition, within the same species, genetic and/or environmental factors may also contribute to the observed variation.

A larval stress response has been shown in many studies. ACTH acts on the normal development of interrenal cells. In general, maternal deposits of cortisol are depleted by about the time of hatching when endogenous production increases. Cortisol is suggested to control chloride cell function immediately after hatching of carp and may have major consequences for further development. This is corroborated by evidence in tilapia, where freshwater adaption increased the cortisol response of larvae by over five times relative to saltwater adapted larvae/juveniles but did not affect the CRF and ACTH levels (Pepels \& Balm 2004). These authors further suggest that the early cortisol response in tilapia is regulated independently from CRF and ACTH.

In cod, stressed and unstressed newly hatched larvae have the same amount of whole-body immunoreactive corticosteroids. This changes within about 8 days as significant increases in whole-body corticosteroid levels are found in response to crowding and netting (King \& Berlinsky 2006), while decreased salinity does not reduce the response in juvenile cod. This is similar to Asian seabass which at $4 \mathrm{dph}$ has a functioning pituitary-interrenal axis capable of synthesizing cortisol from exogenous precursors (such as $3 \mathrm{H}$ 17alpha-hydroxyprogesterone 17P4) and two groups of cells in the pituitary staining for ACTH (Sampath-Kumar et al. 1995).

Several studies confirm that the necessary components for a functioning HPI axis are in place before or at the time of hatching (Fig. 3). Early embryonic expression of mRNA encoding CRF, urotensin I (UI), CRF-binding protein (CRF-BP), CRF receptors (CRF-R1 and CRF-R2), POMC and melanocortin 2 receptor (MC2R) has been observed in zebrafish, suggesting a function in the early organization of the developing embryo (Alderman \& Bernier 2009; Alsop \& Vijayan 2009). Expression of fflb (fushi tarazu factor 1 , FTZ-F1 b), one of the earliest developmental markers of interrenal tissue and a homolog of the mammalian steroidogenic factor 1 (SF 1), has been reported in zebrafish embryos at $22 \mathrm{hpf}$ (To et al. 2007). In addition, transcripts of genes StAR (steroidogenic acute regulatory protein), P11B and CYP21 (P450c21, steroid 21-hydroxylase) encoding enzymes catalysing the first and final steps in the production of cortisol have been detected prior to hatching and in all post-hatch larvae examined in the red drum and

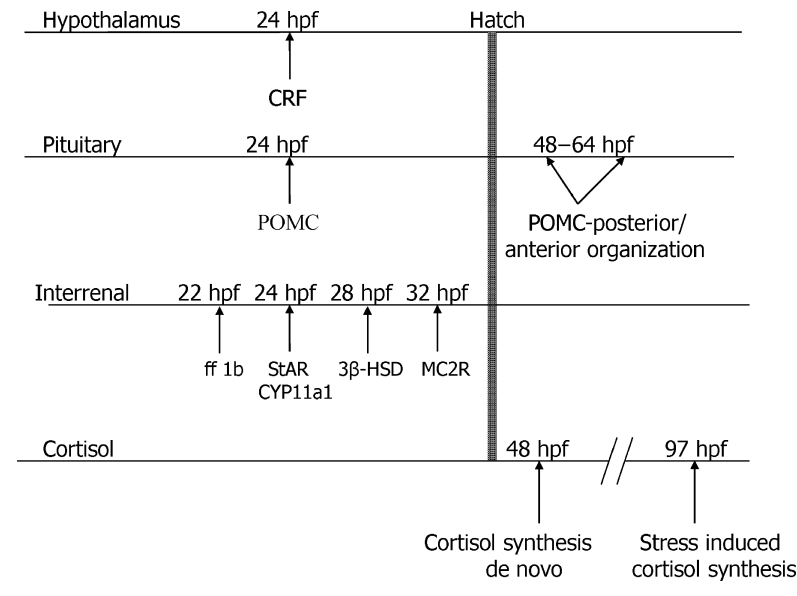

Figure 3 Development and functioning of the HPI axis in zebrafish (redrawn from Alsop \& Vijayan 2009, with permission).

zebrafish (Alsop \& Vijayan 2009; Applebaum et al. 2010). In general, de novo cortisol synthesis begins shortly after hatching, with the exception of carp for which endogenous production of cortisol (as well as of ACTH and $\alpha-\mathrm{MSH}$ ) has been demonstrated at the embryonic stage (Stouthart et al. 1998). Studies in other species also confirm that an increase in cortisol in response to various types of stressors is observed after hatching or around first feeding (Barry et al. 1995; Feist \& Schreck 2001; Auperin \& Geslin 2008; Pavlidis et al. 2011). Again the only exception is the common carp, where basal cortisol synthesis and increases in cortisol with stressor exposure are both observed prior to hatch (Stouthart et al. 1998).

Two main explanations are provided for the absence of a stress response, despite the capacity for cortisol synthesis around hatching in some fish. Alsop and Vijayan (2009) suggested that this may be due to a yet undeveloped element of the HPI axis. Alternatively, Applebaum et al. (2010) proposed that a well-developed and integrated HPI axis may be present but suppressed around the transition to exogenous feeding, to protect early larvae with limited energetic reserves from elevated metabolic demands caused by increased cortisol levels. Despite differences in the onset of the stress response, all available data concur that as development proceeds, the dynamics of the cortisol stress response mature from a low magnitude, slow recovery response, to a response similar to that observed in juvenile and adult fish.

\section{Digestive tract development and remodelling}

Flatfish undergo a dramatic metamorphosis which is often studied through comparison with that of anurans. In anurans, the morphogenetic transformation of the intestine subjacent to the transition of larva to adult type of epithelium includes shortening of the intestine, an increase in the 
number of mucosal folds, neuronal aggregation, and epithelium and mesenchymal proliferation (review Shi \& Ishizuya-Oka 2001; Schreiber et al. 2009). These mechanisms involve a degenerative process of the larval epithelium as programmed cell death (apoptosis), whereas stem cells of adult epithelium develop de novo and proliferate (Shi \& Ishizuya-Oka 2001; Schreiber et al. 2009; Heimeier et al. 2010). Although marine fish larvae do not exhibit such a dramatic intestinal remodelling during development, structural and functional epithelium changes are observed during intestinal maturation until an adult mode of digestion is achieved (Zambonino-Infante et al. 2008). This pattern can be more clear for species like sea bass and Senegalese sole, where the achievement of an adult mode of digestion is characterized by the decrease in cytosolic activity (leucine-alanine peptidase) and a concomitant increase in the activity of brush border enzymes (aminopeptidase and alkaline phosphatase; Cahu \& Zambonino-Infante 1995; Ribeiro et al. 1999), in comparison with species like cod, Atlantic halibut or white seabream, where cytosolic level is maintained around the same level within the first 3-4 weeks, maybe reflecting a delay in the intestinal maturation process (Kvåle et al. 2007; Guerreiro et al. 2010).

Based on studies of zebrafish, intestinal morphogenesis is initiated during gastrulation, $21 \mathrm{hpf}$ (Wallace \& Pack 2003). Afterwards structural, cellular reorganization, differentiation of the intestinal epithelium and other mechanisms proceed before mouth and anus opening, and a fully functional gut was reported at $5 \mathrm{dpf}$ (Holmberg et al. 2004; $\mathrm{Ng}$ et al. 2005; Wallace et al. 2005). In fish with small eggs such as the zebrafish, the biological mechanisms underlying intestinal development and differentiation are exposed to environmental conditions at least from gastrulation. Due to the similar pattern of digestive tract development (review Zambonino-Infante et al. 2008), it is expected that fish eggs from marine species with commercial importance also start the morphogenesis of intestine at gastrulation. The morphogenesis implies a precise spatial and temporal expression of some specific genes, so critical events occurring during the embryonic period have consequences on fish digestive capacity at later stages of development.

After mouth opening, fish larvae are exposed to different food quantity and quality and exhibit a remarkable phenotypic plasticity in response to external factors like diet type and food availability, which is expressed by the adaptation of digestive enzyme activities levels and/or gene expression to the type or amount of diet (see review by ZamboninoInfante et al. 2008). The plasticity of the intestine is related to the proliferation and continuous self-renewing capacities of the developing tissue (Buddington et al. 1997). These process are genetically programmed, involving tissue differentiation, remodelling and degenerative processes, just as observed for other vertebrates (Henning 1979; Shi \& Ish-
izuya-Oka 2001; Zabielski et al. 2008; Schreiber et al. 2009; Heimeier et al. 2010). Therefore, inadequate nutrition and other environmental conditions during development might have long-term consequences on fish digestive capacity. Several studies reported growth delay and mitigated digestive capacity of fish larvae when microdiets were introduced early during development (Zambonino-Infante et al. 2008; Guerreiro et al. 2010). However, in the majority of these studies, digestive capacity was assessed by quantifying digestive enzymes activities and/or expression, but no information was available on the effect of the intestinal ultrastructure. Still insufficient information exists on the molecular pathways regulating and controlling these processes on fish (see review by Rønnestad et al. 2013). However, as some aspects of intestinal development seem to be conserved during evolution (zebrafish, mouse, frogs), analysing the aspects of the intestinal remodelling in anurans and mammals might provide insights on fish development.

\section{Pigmentation}

The enormous variety of pigmentation patterns in fish is the most complex among vertebrates and the genes reflect this complexity. Teleosts have about 30\% more genes for pigmentation than do tetrapods, and teleost pigment bearing cells include all types of chromatophores: melanophores (with melanin, black or brown), xanthophores (with carotenoids or pteridine, yellow), erythrophores (with carotenoids, red), iridophores (with reflective guanine crystals, metallic colours), leucophores (with chrystalline purines, white) and cyanophores (blue; Goda \& Fujii 1995). For melanophores, there are genes for melanophore development, melanosome components, melanosome biogenesis, melanosome transport, regulation of melanogenesis and systemic effects. For xanthophores, there are genes for xanthophore development and for synthesis of pteridine, while iridophores genes are a single category. About $30 \%$ of the duplicated pigmentation genes have been retained after the FSGD for both melanophores and iridophores, whereas the retention of duplicate genes is over $80 \%$ in xanthophores (yellow; Braasch et al. 2009). This gives at least a reductionistic background for the variety of pigmentation patterns seen, even within a tank of fish.

In a recent study by Nakamura et al. (2010) on the Japanese flounder, there were striking differences in the placement and appearance of pigment cells before and after metamorphosis. Large larval-type melanophores with long dendrites appear early in the larval stage and are bilateral even in flatfish species. Around metamorphosis, the larvaltype melanophores are relocated to the subepidermal layers, leaving the adult melanophores near the surface normally only on the ocular side of flatfish. Xanthophores (possibly a larval type) decreased in density towards meta- 
morphosis, after which numbers increased again only on the ocular side. The bilateral leucophore density of larval flounder gradually decreased after metamorphosis until none were visible at the juvenile stage, while on the ocular side iridophores first appeared slightly prior to the disappearance of leucophores. The density of all chromatophores increased markedly after metamorphosis on the ocular side. As the flounders grew, xanthophores were found deeper in the skin $17 \mu \mathrm{m}$, whereas melanophore depth was constant at about $4 \mu \mathrm{m}$. As for the leucophores and iridophores, the authors suggest that difference in the time of appearance could be due to differences in skin development around metamorphosis, when cycloid spineless scales appear on both sides followed by the appearance of ctenoid scales on the ocular side only.

Skin colouration in teleosts is under multi-parametric control, and a number of external (physical, nutritional) or internal factors (genetic, cellular, neuro-hormonal) have been known to influence the chromatic state of fish (reviewed by Fujii 1993). Control of skin pigmentation seems to be a result of endocrine control by the pituitary and paracrine control by the skin itself (Takahashi et al. 2009). Pigmentation of fish skin is largely due to melanophores, the only pigment cell type present in all groups of vertebrates, which originate in the neuroectoderm of the embryo and which contain large numbers of melanin granules. These granules can be rapidly spread out to the arms of the cells or concentrated at the cell centre. Dispersion of these granules gives the appearance of dark skin (mediated by $\alpha$-MSH), whereas central concentration gives pale skin (MCH; Kawauchi 2006). Melatonin can also make pigment cells contract, sometimes giving a night-time coloration or blanching in fish by affecting either melanophores or erythrophores (Ekström \& Meissl 1997).

A variety of hormones has been reported to be involved in the regulation of motility of the light-absorbing type of pigment cells. The two main hormones involved in pigment distribution and concentration in chromatophores are $\mathrm{MCH}$ and alpha-melanophore-stimulating hormone $(\alpha \mathrm{MSH}) . \mathrm{MCH}$ and $\alpha \mathrm{MSH}$ act as functional antagonists to mediate pigmentation in fish (Kawauchi 2006). The timing of $\mathrm{MCH}$ system differentiation depends on lifestyle and habitat, occurring early in surface-living larvae needing light skin colour but later in bottom dwellers (Risold et al. 2009). MCH is synthesized in the hypothalamus in neurons whose fibres extend to the neurohypophysis (pituitary) and is a preprohormone regulator of the release of pituitary hormones as well as regulating food intake in goldfish Carassius auratus and energy homoeostasis (Kawauchi 2006; Matsuda et al. 2006; Fig. 4) The MCH system can be found in the gilthead seabream at $36 \mathrm{hpf}$ in the margin of the developing hypothalamus (Mancera \& Fernandez-Llebrez 1995). Cichlids exhibit MCH cells at 2 dph coinciding with

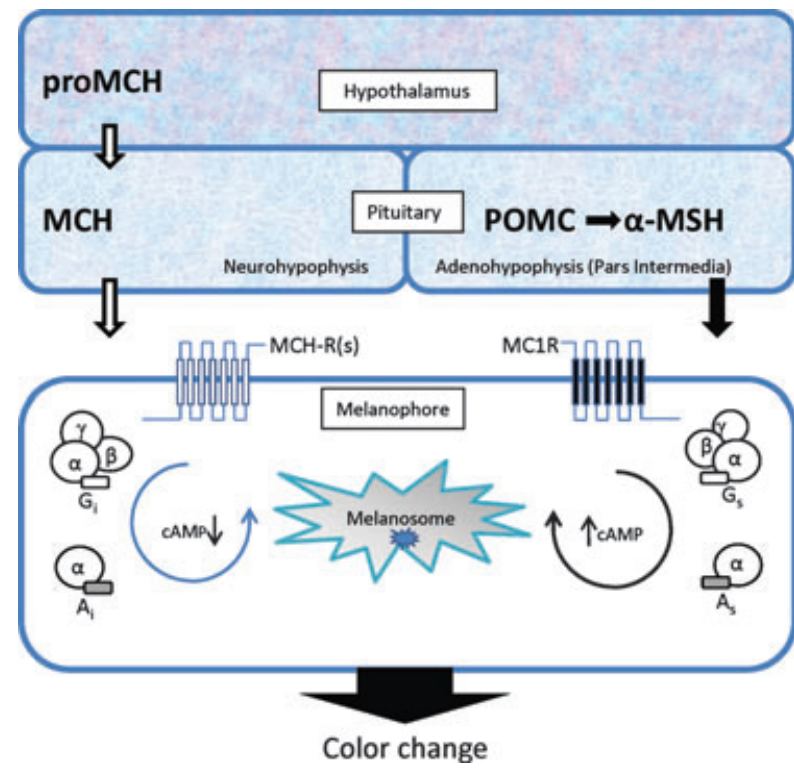

Figure 4 Proposed action of melanin concentrating hormone $(\mathrm{MCH})$ and $\alpha$-melanophore-stimulating hormone $(\alpha \mathrm{MSH})$ signalling to induce colour changes in fish. The antagonistic action of the hormones moves the melanosomes, where MCH stimulates aggregation and aMSH stimulates dispersion via receptors on the cell membrane, activation of the Gi or Gs protein and their action on cAMP levels (redrawn from Kawauchi 2006, with permission).

first feeding and the period when fibres extend from the hypothalamus to the developing pituitary. This is followed by a second group of $\mathrm{MCH}$-ir neurons in the medial hypothalamus at $6 \mathrm{dph}$, suggesting that the system controlling skin colour is already differentiated about 3 weeks before the three main parts of the adenohypophysis are innervated (Pandolfi et al. 2002).

Melanophore-stimulating hormone is derived from a precursor molecule POMC synthesized in the pituitary pars intermedia. Cells expressing ACTH and $\mathrm{MSH}$ are found around hatching in carp (Stouthart et al. 1998) and ayu (Saga et al. 1999). The alpha-MSH-expressing cells are found immediately after hatching in the caudal part of the pituitary in cichlid, and later they are found in the same regions of the hypothalamus as the MCHir neurons (Pandolfi et al. 2002). In fish, MCH can depress alpha-MSH, stimulate somatolactin release and depress ACTH release (Kawauchi 2006).

In general, light, diet and behaviour can control fish pigmentation, and there are various related hypotheses for mechanisms underlying malpigmentation. Dietary ARA fed during larval rearing has been shown to have a profound effect on juvenile pigmentation in flat fish (Estévez et al. 1997; Willey et al. 2003; Villalta et al. 2008). Elevated ARA fed during a crucial premetamorphic (Seikai et al. 1987; Copeman et al. 2002) or early metamorphic 'pigmentation 
window' (Næss \& Lie 1998) produces malpigmentation. Conversely, dietary ARA fed during metamorphosis (35 dph) and after the 'window' improved pigmentation compared with fish feeding on high DHA rotifers and Artemia (Estévez et al. 2001). Lund et al. (2008) found sole larvae consuming high ARA diets from 3 to $21 \mathrm{dph}$ were almost all malpigmented, whereas fish fed the same diets from $11 \mathrm{dph}$ exhibited moderate but significantly lower levels of hypomelanosis. Similarly, low dietary EPA/ArA ratios fed during the 'pigmentation window' hindered juvenile dorsal pigmentation in turbot, halibut and Japanese flounder (McEvoy et al. 1998; Estévez et al. 1999, 2001). In yellowtail flounder Limanda ferruginea and Senegalese sole larvae, increasing dietary ARA levels significantly increased the incidence of malpigmented fish (Copeman et al. 2002; Villalta et al. 2005). This negative effect may be related to an eicosanoid imbalance due to the competition of ARA and EPA for the lipoxygenase and cycloxidgenase enzyme (Izquierdo et al. 2000; Furuita et al. 2003; Izquierdo et al. 2005). Interestingly, although an Artemia ARA increase similarly reduced growth in white bass (Morone chrysops) larvae, this effect was reversed if DHA level was increased (Harel et al. 2001). In addition, DHA has been associated with typical pigmentation in Atlantic halibut (Hamre \& Harboe 2008). Clearly, when determining the efficacy of ARA, the presence of other EFA must be taken into account such as that of EPA (McEvoy et al. 1998; Bessonart et al. 1999; Estévez et al. 1999; Sargent et al. 1999; Copeman et al. 2002; Atalah et al. 2011) and DHA (Hamre \& Harboe 2008). Overall, an optimum DHA/EPA/ARA ratio seems to be necessary in early developing flatfish larvae to achieve normal metamorphosis and dorsal skin pigmentation (Sargent et al. 1999). Thus, both absolute and relative dietary essential fatty acid levels fed during specific periods of development appear to determine the success in pigmentation processes in flatfish.

The physiology underlying the developmental-stagedependent effect of long-chain polyunsaturated fatty acids (LCPUFA) on pigmentation could be closely related to prostaglandin production. ARA-derived prostanoids play an important role in melanocyte development and melanin production in mammals (Scott et al. 2005) and may modify the production of tyrosinase, a key enzyme involved in the L-tyrosine to melanin pathway (Bransden et al. 2005). Moreover, free ARA and/or leukotrienes and thromboxanes can modulate changes to pigmentation in mammalian cells (Tomita et al. 1992; Maeda \& Naganuma 1997; Norris et al. 1998). Estévez et al. (1999) suggested that an imbalance in neural membrane composition and ARA-derived eicosanoids in the brain or pituitary during critical developmental periods prior to metamorphosis might affect neuroendocrine control of processes involved in flatfish pigmentation. However, these authors found no relation- ship between dietary ARA and levels of ACTH or MSH in the pituitary (Estévez et al. 2001). Hamre et al. (2007) hypothesized that high ARA incorporation in specific tissues during premetamorphosis may have lowered membrane concentrations of other LCPUFAs which ligand with peroxisome proliferator-activated receptor (PPAR) and then dimerize with retinoic acid $\times$ receptor $(\mathrm{R} \times \mathrm{R})$. These dimers bind to DNA at sequence-specific sites called peroxisomal proliferator response elements (PPRE) and modulate expression of genes involved in pigment cell development and differentiation during critical periods of larval development. Lower levels of these dimers would reduce the expression of key genes and consequently interfere with normal pigmentation.

An alternate explanation is given by Nakamura et al. (2010) who give more emphasis to the skin itself. Pseudalbinic juvenile Japanese flounder have white areas on the ocular side with iridophores and cycloid scales instead of the normal ctenoid scales. Ambicoloured fish have areas on the abocular side with adult-type pigment cells and ctenoid scales, instead of few larval pigment cells and cycloid scales. Together these findings suggest mistakes in the formation of bilaterally asymmetric juvenile skin from symmetric larval skin, and the authors invite investigation into determination of all components of an area simultaneously (scale, epidermis, dermis, pigment cells) rather than a narrow focus on individual factors.

\section{Consequences of external factors}

The developmental programme follows a chronological sequence of rapid change in the expression of the genome in which the characteristics of the typical phenotype (or wild type) are buffered against genetic and epigenetic changes. However, for many organisms, development represents a critical period during early life when the environment may irreversibly influence the phenotype, allowing rapid adaptations. These different phenotypes predict the future environment, and this confers a fitness advantage when the 'prediction' is correct. By contrast, any mismatch between the anticipated and the actual mature environment exposes the organism to risk adverse consequences.

The influence of the environment may occur in two different ways: (i) induction, deletion or impaired development of a somatic structure resulting from a stimulus or injury and (ii) physiological 'setting' by an early stimulus or injury. These physiological responses reflect a biological mechanism which is turned irreversibly 'on' or 'off only once during an individual's lifetime in response to conditions prevailing at some critical stages. Regulatory processes in eukaryotes include chromatin remodelling (DNA methylation and histone modification), transcription factors, hormones, mRNA processing and DNA-rearrangement via 
duplications, transversions and transposable elements. The terms epigenetics ('above genes') and programming are often used to describe these biological processes (Lucas et al. 1996). Some authors consider that phenotype induction could be a better term for describing these processes because programming has connotations of genetic programme for development and is deterministic (Burdge \& Lillycrop 2010). However, it is clear that external factors leave their mark on the developing fish larvae.

\section{Environmental information content of the otoliths}

Otolith increments encode information about an individual and its interaction with the environment. The regular, incremental biomineralization process gives otoliths a unique time-keeping property so that the increments formed throughout life, and indeed the shapes and structures formed at previous stages, can be accessed and analysed to reveal the individual growth history and responses to environmental factors. Thus, otoliths form a record of individual plasticity, and otolith analyses provide valuable information about ontogenic changes and individual variation, recording environmental responses.

Information from otolith analyses has made a significant contribution to our understanding of early life-history processes in wild populations and holds promise for equally valuable insights in the context of aquaculture populations (Folkvord et al. 2010). The otolith increments formed during the larval and early juvenile stages are particularly amenable to analysis, providing information about the growth and duration of different life-history stages. There are structural landmarks in the otolith that can be related to developmental events such as hatching or metamorphosis, or to behavioural changes such as settling (Geffen et al. 2002). Increment counts between hatching and metamorphosis or settlement provide data on hatching dates, and the duration of the larval period (Fox et al. 2007; Comerford et al. 2013) and the increment widths can be used to determine relative growth rates which can be compared between areas or years (Catalán et al. 2010).

The formation, growth and timing of otolith structural landmarks are well documented in gadoid and flatfish species. Growth increments are usually formed daily, beginning at hatching or sometimes, as in common sole, Solea solea, at mouth opening (Lagardere \& Troadec 1997). The first increment at hatching is usually distinct, and metamorphosis is also marked by wide and distinct increments and the initiation of accessory growth centres (Wright 1993; Modin et al. 1996; Fox et al. 2007). These accessory growth centres are the nucleation sites which lead to alteration of otolith shape and so mark a significant period of developmental events associated with metamorphosis and changes in habitat and behav- iour. Experimental studies with temperate and tropical species confirm that these landmarks are part of a fixed developmental sequence, and not a consequence of larval size or age (Modin et al. 1996). However, in some cases, manipulation of metamorphosis by delaying the timing of behaviour settlement cues still resulted in landmarks typically associated with settling (McCormick 1999). In many flatfish, tidal cycles induce a regular pattern of 'checks' to the increments formed after settlement, and as these are often associated with feeding patterns, it is expected that they could be used to interpret behavioural changes in an aquaculture environment as well (Geffen \& Nash 1995).

Deviations in otolith growth are also clear signals of disruption of an individual's condition and can be used as an indication of present and past welfare. Otoliths in most fish species are completely composed of calcium carbonate $\left(\mathrm{CaCO}_{3}\right)$ in its aragonite polymorph. However, some fish do use other $\mathrm{CaCO}_{3}$ morphs: calcite or vaterite. Vaterite otoliths have also been observed occasionally in individuals instead of aragonite, and this substitution of morph may be linked to fish condition and especially welfare in the aquaculture environment (David et al. 1994; Tomas \& Geffen 2003; Sweeting et al. 2004; Oxman et al. 2007). Vaterite otoliths are more prevalent in aquaculture fish, occurring with a frequency of $50-80 \%$ of hatchery fish in some cases, compared with 3-20\% in samples of wild fish (David et al. 1994; Bowen et al. 1999; Tomas \& Geffen 2003; Ma et al. 2008). The shift from aragonite to vaterite formation is linked to changes in the protein matrix. Differences in the amino acid composition have been measured in total protein extracts (Gauldie 1993), but not in the water-soluble proteins of the matrix (Tomas et al. 2004). The starmaker and otopetrin1 genes have been shown to control several aspects of otolith formation and growth and knockout zebrafish without functional copies developed with missing or mis-shapen otoliths composed of calcite instead of aragonite (Hughes et al. 2004). Tohse et al. (2008) determined that the matrix protein OMM-64 is also capable of controlling the shift in crystal polymorph.

The shift from aragonite to vaterite deposition in the otoliths is a good example of the plasticity of otolith growth, which simultaneously forges a permanent record of the events and conditions that trigger the change. In most cases, the presence of vaterite does not affect the behaviour, feeding or growth of the individual, although hearing loss has been measured (Oxman et al. 2007). However, the plasticity of the otolith preserves its function and allows for normal fish growth. Vaterite otoliths are generally larger, with more fluted margins, and this compensates for differences in mass density that could otherwise disturb the functioning of the acousti-lateralis system (Tomas et al. 2004; Oxman et al. 2007). A normal aragonite centre is vis- 
ible within most vaterite otoliths, suggesting that the switch is the result of disease, crowding, handling or thermal stress which occurs late in larval development or once into the juvenile stage (Tomas \& Geffen 2003; Sweeting et al. 2004; Ma et al. 2008). Payan et al. (2004) showed experimentally that stress induced by chlorine gas leads to increased $p \mathrm{CO}_{2}$ in the otolith endolymph and changes in mineralization, similar to what could result from crowding during handling. By counting the increments in the aragonitic section, it is possible to determine the age and size that the individual was when the polymorph shift occurred, and by extension, to determine the timing of previous stress events.

\section{Adapting to salinity}

Larval fish are more sensitive to environmental fluctuations than are adults, but they are sometimes able to transform this sensitivity into a functional adaptation. Marine teleosts avoid dehydration by drinking sea water and then actively excreting the excess of salts. The excretion or acquisition of salts across membranes against a concentration gradient requires energy. Where the ambient salinity is the same as that of the body fluids of the fish, the energy required is minimal, increasing both in more diluted and in more concentrated media. Tandler et al. (1995) found that gilthead seabream larvae were able to maintain the body osmolality from very early stages of development in the range $25-40 \mathrm{~g} \mathrm{~L}^{-1}$ salinity. They also found that the survival and growth were higher under the lower salinity. The authors concluded that this increase in weight gain was attributable to the $15 \%$ of energy saved on the metabolic cost of osmoregulation. On the other hand, very early after release from mouth-brooding at $0.03 \mathrm{~g}$ weight, some tilapia species can successfully adapt to full seawater when the acclimation period is from 48 to $120 \mathrm{~h}$ (Jonassen et al. 1997). The survival in the tested Oreochromis spiluris spiluris larvae was high (over 94\% in all 12 regimes) as this adaptable species developed stable plasma sodium levels within $12 \mathrm{~h}$ of seawater acclimation and significantly more chloride cells per unit gill filament. The number of chloride cells stabilized within $24 \mathrm{~h}$ of acclimation, having increased in both size and density. However, of the four size groups, only the newly released larvae exhibited high growth 2 weeks after acclimation, whereas the energetic costs of seawater adaptation were reflected in the initially low growth rates in other groups compared with later, higher growth rates. This suggests that fish can adapt successfully at a very early stage and show even better salinity tolerance than larger fish.

Such knowledge has already been applied to the real world of fish culture, where there is generally less conflict for use of marine areas than for freshwater areas. Ridha (2013) achieved hybrid vigour (the increase in fitness in the offspring of two different species) when he crossed the salinity-tolerant $O$. spiluris and the O. niloticus strain which has been selected for improved performance in fishfarms around the world, the GIFT tilapia (Genetically Improved Farmed Tilapia). This is much like the beneficial results achieved by Lahav and Ra'anan (1997) who developed a tilapia hybrid (O. mossambicus $\times$ red tilapia $O$. niloticus) which performed well in salinities as high as $41 \mathrm{~g} \mathrm{~L}^{-1}$. While adaptation to seawater is possible, frequent problems include skin lesions and eye cataracts, problems which Ridha sought to address. Even though the fish size at acclimation was relatively large (mean weight $3.5 \mathrm{~g}$ at stocking) in the pure and hybrid strains, survival was over $90 \%$ in the hybrids, whereas it was around $80 \%$ in the pure strains. More importantly, the hybrids had almost no skin lesions or fin rot although cataracts were found in $<5 \%$ of the fish at harvest 180 days later. The author attributes the result to the higher number and size of the chloride cells, and possibly the level of prolactin, a hormone which regulates sodium retention. That there was an energetic cost to this adaptation was also clear, because the pure and hybrid strains raised in fresh water had better growth and survival than their counterparts in seawater.

We are left to speculate whether even earlier adaptation could have improved the outcome. Osmosensitivity and salinity detection are extremely important to the physiology of fish (Boeuf \& Payan 2001). At the adult stage, there are prolactin cells reacting directly to ambient salinity, chemoreceptors in the pseudobranch and direct connections between these cells and the central nervous system, triggering drinking behaviour and linked with both the rennin-angiotensin system and growth hormone production. By contrast, in young fish larvae, many of these systems and associations are yet to be established. Thus, generally median or brackish salinities are linked with better weight increase and swimbladder inflation (gilthead seabream), better egg fertilization and yolk absorption (Rhombosolea tapirina) as well as a host of other functions such as larval development and metabolic rate in other flatfish and roundfish (Boeuf \& Payan 2001). In terms of the energetic cost of this, adaptation must be achieved through the commonly identified organs involved in osmoregulation, the digestive tract, gills, kidney, urinary bladder and sometimes the liver. In many newly hatched fish larvae, these organs are poorly developed at best, such that matching the environmental requirements of the early stages can indeed lead to better food conversion and growth later, as seen for example in cod (Boeuf \& Payan 2001; Imsland et al. 2011). In this and other species, it has been speculated that changes in early exposure are involved in controlling food intake later. This has important implications for management of both cultured and captured teleost species. 


\section{Effects of temperature}

Common effects of temperature in metabolic rates

Temperature is one of most relevant abiotic factor influencing development and growth in fish (Blaxter \& Hempel 1963; Chamber \& Leggett 1987). In exotherms, the temperature determines the metabolic rates. Consequently, the raising of temperature tends to accelerate the development and growth during the early fish stages. Nevertheless, a change in the temperature during the development does not mean just a change in the size attained at a given age. Temperature variations also affect several physiological and developmental processes that may significantly be reflected in the external aspect, shape and behaviour of juveniles and adults. In fact, temperature is the environmental factor that induces most phenotypic plasticity in fish.

Obviously such an effect occurs only within the range of tolerance of each species, and the response in general follows a parabolic pattern with increasing the temperature (Jobling 1996). As with other environmental factors, each species has characteristic windows for optimal, suboptimal and sublethal temperature of growth and development. At extreme values, outside the tolerance range, the fish larvae cannot survive. At suboptimal and sublethal temperatures, fish larvae exhibit progressively lower development rates, inadequate or incomplete organogenesis, morphological changes and malformations that eventually may result in subtle or severe disadvantage that may be lethal at a later stage. The temperature affects developmental rates of organs, tissues and cells differentially, leading to critical differences in physiology, behaviour and morphology (size, shape and anatomy). The changes in morphology and behaviour within a natural ambient temperature range can be considered as the regular response to softening the effects of changing environmental temperature on physiological processes. The temperature effects on the developing larval phenotype may be transitory during a relatively short period or permanent, persisting into the juvenile and adult stages. On the other hand, developmental-stage-specific temperature optima have been observed in many species (Herzig \& Winkler 1986) and the consequences of temperature variation change through the development.

\section{Effects on spawning and embryonic development}

The embryonic development from fertilization to the end of yolk absorption has particular characteristics because the yolk reserves are being transformed in larval tissues and organs at determined rates greatly influenced by water temperature. The first step occurs before spawning. Average egg volume varies with the maternal feeding and environmental conditions, such as water temperature, during the vitellogenesis (Chamber \& Leggett 1996). A seasonal variability in egg characteristics has been described in many species (Pauly \& Pullin 1998). As a general rule, larger eggs with more yolk reserves need more time to hatching and produce larger larvae at the onset of feeding (Pascual \& Yúfera 1993; Trippel 1998).

There is a significant inverse relation between incubation temperature and time to hatching and first feeding and the yolk utilization rates in fish (May 1974; Polo et al. 1991; Hardy \& Livak 2004; Yúfera et al. 2011). However, there is not a direct relation between yolk absorption efficiency and temperature (Laurence 1973; Arul 1991; Polo et al. 1991). Yolk efficiency has been calculated as the length or mass attained by the embryo after the complete yolk reabsorption in relation to yolk volume. There is an optimum temperature that maximizes the conversion efficiency, but in general, energy losses during transfer from yolk to tissue are higher at higher temperatures, and therefore, the larvae are smaller. In general, the optimal temperature for yolk utilization is lower than for growth (Hard \& Purser 1995).

The key issue of these processes is size attained by the larvae at the time of first feeding. Total length and mouth gape can be critical features at first feeding because they modulate the pattern of feeding incidence during the first days after the opening of the mouth (Parra \& Yúfera 2000; Yúfera \& Darias 2007). This situation confers an ecological advantage for both predation and escaping capacity to those larvae having greater length, mass and mouth gape. Under culture conditions, in the absence of predators and with permanent food availability, this potential advantage is not so obvious. Although larger larvae after the yolk absorption show greater ability to start feeding and apparently grow better during the first weeks, it is not clear whether or not they become larger juveniles after metamorphosis.

\section{Effects on muscle and skeletal development}

Water temperature during the larval growth and development affects shape and meristic characters of juveniles (Hempel \& Blaxter 1961; Georgakopoulou et al. 2007). Differences in juvenile shape can be due to different allometric growth at different temperatures. Shape, and hence locomotion ability, is mainly dependent on skeletal and muscular structures.

Muscle growth in larval fish occurs by both hyperplasia (production of new muscle fibres) and hypertrophy (increase in muscle fibre size). The proliferation and differentiation of these cells lead to the formation of new fibres, a process regulated by several myogenic regulatory factors that can be also influenced by environmental (temperature) and nutritional parameters (Johnston 2006; Valente et al. 2013). In general, there is an acceleration of the myogenesis during early larval stages under increasing water temperatures. Such effects have been observed in many teleosts (Alami-Durante et al. 2006). In some fish species, an elevation in temperature incubation can lead to faster muscle 
development relative to bone, with potential consequences in the appearance of deformities. Albokhadaim et al. (2007) have shown that salmon larvae reared at $5^{\circ} \mathrm{C}$ grow faster until 6 weeks after first feeding when the eggs have been incubated at $10^{\circ} \mathrm{C}$ rather than $5^{\circ} \mathrm{C}$, but the lower temperature induced a more sustained period of muscle growth that goes beyond week 6 up to week 21. By week 21, the salmon resulting from eggs incubated at $5^{\circ} \mathrm{C}$ were significantly longer, heavier and had more muscle fibres than salmon incubated at $10^{\circ} \mathrm{C}$. Interestingly, the fish raised at $5^{\circ} \mathrm{C}$ exhibited an increased feeding behaviour throughout development, and it was suggested this activity may explain their better growth and muscle development. This suggestion was supported by Kronnié (2000), who reported that the longitudinal growth of the muscle fibres is decreased and the growth rate among fibres is diminished in all fibres when zebrafish larvae were immobilized. These effects of immobilization reveal that the locomotion itself has an effect on the morphogenesis of the somites and the myotomes. It is interesting to note that between 21 and 32 days of zebrafish development, continuous and interval training enhances both the axial muscle tissue and tail fin capillary supply, with an increased mitochondrial density (Pelster et al. 2003). Such increases in capillarization and mitochondrial density enhance the aerobic capacity of the muscle and may improve the swimming efficiency and resistance to hypoxic conditions. Likewise, Alami-Durante et al. (2006) working in European seabass found that the larvae reared during early days at lowest temperatures within the tolerance range exhibit higher growth capacity when transferred to ambient water temperature than those first reared at higher temperature. This performance enhancement was due to a greater and longer capacity to recruit new white muscle fibres.

The temperature may affect both hyperplasia and hypertrophy processes although the relative contribution to muscle growth varies with temperature, through developmental stages and among species (Nathanailides et al. 1996; Johnston et al. 1998). The variety of experimental protocols and conditions preclude a clear general picture of the complex role of temperature in the muscle development in teleosts (Johnston 2006). There is probably an important specific impact of temperature on muscle development as there is on the ontogeny of other organs. Several studies have demonstrated that the water temperature during embryonic and early larval stages affects the subsequent myogenesis and somatic growth of postlarvae and juveniles (Vieira \& Johnston 1992; Johnston et al. 1998; Ayala et al. 2000; López-Albors et al. 2003; Alami-Durante et al. 2006, 2007; Johnston 2006; Koumoundouros et al. 2009). Therefore, in these studies, early warm temperature regimes induce higher number of white muscle fibres and greater length. Somatic growth and white muscle hyperplasia are correlated in postlarvae and juveniles. By affecting the mus- cle phenotype, the early temperature conditions also affect swimming performance via developmental stage at the same body size (Johnston et al. 2001). This convergence of influences also affects final performance after completion of metamorphosis and fin development in the juvenile (Koumoundouros et al. 2009). The performance in postlarval fish will be a result of functional differences in the muscle anatomy (red muscle area and myofibre number).

The irreversibility or permanence of the early temperature effects on myogenesis, fish length and locomotory capacity is difficult to assess. The feeding conditions and seasonal environmental changes during juvenile growth help blur the thermal-induced differences observed during post-larval and early juvenile stages. In herring, the temperature before the onset of endogenous feeding affects the relative timing of development of components of the locomotory system more than a month later (Johnston et al. 2001). When the morphological characters are essentially complete, the differences due to the early temperature regimes tend to disappear. As observed in European seabass (Alami-Durante et al. 2006, 2007) and Atlantic salmon (Albokhadaim et al. 2007), the larvae are therefore able to physiologically compensate for some growth retardation experienced during early life.

Temperature also affects skeletal ontogeny (Boglione et al. 2013). Completion of structures, chondrogenesis and ossification processes are delayed at lower temperatures within the viable range (Balon 1983; Campinho et al. 2004; Sfakianakis et al. 2004). Incomplete structures and skeletal deformities affecting cranium, notochord and fins at suboptimal or sublethal temperatures at hatching, yolk resorption or first feeding have been described in many species of different families (gilthead seabream, Polo et al. 1991; wolf fish Anarhichas lupus, Pavlov \& Mokness 1997; Mozambique tilapia, Campinho et al. 2004; common Pandora Pagellus erythrinus Sfakianakis et al. 2004; green sturgeon Acipenser medirostris, van Eenennaam et al. 2005; Japanese eel, Kurokawa et al. 2008). Principal effects of extreme rearing temperature in the skeletal formation are spinal curvatures (lordosis, kyphosis and scoliosis), cranium and jaw deformities, deoperculation, vertebrae fusion and primordial finfold and fin deformities. Many of these deformities are lethal because they prevent adequate feeding. Conversely many deformities confer abnormal appearance, but the larvae can continue the development to juvenile stage. Other types of malformation are initially so subtle that they cannot be externally observed.

\section{Effect of dietary factors}

Diet and endogenous hormone influences are clearly important factors during the early larval stage during which 
high cellular diversification occurs. Dietary protein-, lipidand carbohydrate-specific compounds may exert significant changes in growth and morphology. As explained in previous sections, not only does the morphology of the digestive system change in response to the diet, but also dietary precursor nutrients (iodine and arachidonic acid) play critical roles in metamorphic synchrony, development, growth, survival and morphological changes in flatfish as well as other species (Hamre et al. 2007; Ribeiro et al. 2011). Cortisol is implicated in nutrient- and bone metabolism, energy allocation, immune response, learning and memory, and hydromineral regulation in the marine environment. Typical disturbances during sensitive early ontogeny, such as handling and crowding, act via dietary uptake, environment and these neuroendocrine axes to modify the adaptative development of an aquaculture fish species. Such modifications directly or indirectly related to dietary factors may be evidenced on different tissues and organs and functions as skeleton, musculature, respiratory capacity and reproduction.

\section{Consequences on skeletal structures and anatomy}

The skeletal structure consists of bones and cartilage and supports the structural integrity of the body, allowing locomotion and development. It also determines the morphology of the body. The skeletal development in bony fish (Teleostei) follows a conserved pattern in vertebrate evolution (Lall \& Lewis-McCrea 2007). This process is intrinsically linked to morphogenesis, which implies a precise spatial and temporal expression of some specific genes, like Hox genes (a subset of homeobox genes) that are major actors in body patterning (limbs, vertebrae, craniofacial structures) (Krumlauf 1994). The genes involved in morphogenesis (which includes bone and cartilage differentiation) could be particularly sensitive to dietary modulations of some transcription factors during these temporal windows of development. Therefore, the same diet could have a different impact on morphogenesis if given to larvae at different ontogenetic periods.

Inadequate dietary vitamin A levels during early life can induce important modifications in skeletal structures. For example, Japanese flounder larvae fed with Artemia containing high concentrations of vitamin $\mathrm{A}$ at different developmental stages exhibited vertebral deformities when exposed to these high vitamin A doses during 25-27 dph, a period that corresponds to the notochord segmentation (Dedi et al. 1997). After this period, larval exposure to high dietary vitamin A levels did not induce any malformations. Similarly, Villeneuve et al. (2006) have shown that inadequate vitamin A or high HUFA levels in diets strongly affected sea bass larval morphogenesis when given earlier than $18 \mathrm{dph}$. High levels of dietary vitamin A delayed development and induced an up-regulation of retinoic acid receptor retinoid $\times$ receptor $(\mathrm{R} \times \mathrm{R}-\alpha)$ and bone morphogenetic protein (BMP-4), gene regulation that is likely responsible for the reduction in the vertebrae number and the high level of deformities in the cephalic region. More recently, Mazurais et al. (2009) have revealed that the optimal level of retinol for harmonious ontogenesis fluctuates during European sea bass larvae development: the skeletal structures that develop earlier (like the skull structures) were less affected by low dietary vitamin A than those that develop later. However, very low dietary retinol levels altered morphogenesis through the modulation of Hox gene expression, at least for the pelvic fin.

Dietary regime can influence morphology, as has been shown in the cichlids Cichlasoma spp. and Geaphagus spp. for which the jaw and skull morphology responds to food type (Meyer 1987; Wimberger 1991). Similarly, when three-spined sticklebacks G. aculeatus were fed with large preys, they developed deeper heads and larger mouth gape (Day \& McPhail 1996). In Artic charr Salvelinus alpinus, the choice of prey at first feeding can influence the anatomy of the head and mouthparts. In European sea bass larvae, vitamin levels in the early feeds affect the development of the spinal column and how the bones are formed (Mazurais et al. 2008): the higher the percentage of vitamin mix in the diet, the lower the percentage of vertebral column deformities, improving the formation of mineralized bone. At the highest experimental doses, the vitamin mix induced a 'sequence of coordinated growth factor expression, in which the expression of bone morphometric protein (BMP-4) preceded the expression of IGF-1, which stimulated the maturation of osteoblasts (revealed by high osteocalcin expression levels)' (Mazurais et al. 2008). When seabass larvae were fed low levels of vitamin mix, the resulting high levels of PPAR $\gamma$ (a dominant transcription factor of adipocyte precursors) converted some osteoblasts into adipocytes during the first 2 weeks of life. This loss of osteoblasts was postulated to have caused skeletal deformities and is a good example of how the pluripotency of early cells can be manipulated with long-term consequences (Mazurais et al. 2008).

These studies clearly showed how the timing of intake of certain nutrients and the feeding behaviour influence the skeletal structures development (with a risk of appearance of deformities) and durably determine the anatomy of the future juvenile fish. They are further a good example of how it is necessary to evaluate more than just growth or survival when designing larval diets.

Nutritional status has profound effects on the growth and development of somatic tissues, and particularly the skeletal muscle. Rodgers et al. (2003) showed that myostatin mRNA levels in tilapia larvae were sometimes elevated after a 3-day fast and significantly reduced with a longer fasting (6 days). Myostatin is known to regulate muscle 
growth and development, by inhibiting specifically myoblast proliferation via cell-cycle arrest (Thomas et al. 2000). The effect of nutrition has been mostly studied comparing extreme conditions, that is, fasting/feeding, which does not facilitate understanding of how to 'programme' (and improve) further skeletal muscle development. Recent results obtained in European sea bass (Alami-Durante et al. 2010) revealed that dietary vitamin D3 levels regulate the expression of different molecular actors involved in myogenesis (MRFs) and muscle structure (MHC). It remains to determine to what extent these molecular changes could affect the recruitment and the growth of the skeletal muscle fibres. Other dietary nutrients, like ascorbic acid, are worth studying; indeed, as this nutrient is a precursor of collagen, it could have a crucial role for muscle development in fish, particularly in the white myotomal muscle which exhibits a certain plasticity during larval period (Alami-Durante et al. 2006).

\section{Consequences on metabolic pathways}

High levels of dietary carbohydrates cannot be used efficiently by carnivorous teleosts, and this constitutes a real bottleneck for lowering the protein levels in feeds, proteins being naturally first used for energy purposes in carnivorous fish. More than 20-30\% of digestible carbohydrates in diets induces prolonged post-prandial glycaemia and adversely affects growth in rainbow trout (Moon 2001). The general mechanisms for the digestion of carbohydrates, absorption and metabolism of glucose in carnivorous fish are not different from those in herbivorous or omnivorous fish, but the enzymes involved in carbohydrate metabolism seem to be less expressed and roughly regulated in the carnivorous species (Hemre et al. 2002). However, a certain adaptive ability of the digestive enzymes to respond to the level of the dietary starch exists in salmonids (Krogdahl et al. 2004), and it has to be pointed out that high levels of amylase and maltase are expressed during larval stages of omnivorous fish and are modulated by dietary glucides (Péres et al. 1998; Ma et al. 2005). This adaptation does not allow juvenile carnivorous fish to deal with high carbohydrates loads, because high dietary glucose does not induce a retro-inhibition of gluconeogenic enzyme expression, which is usually observed in omnivorous fish and nondiabetic animals (Panserat et al. 2002). An acute but short (few days) nutritional stimulus, that is, hyperglucidic diet, applied in early post-hatch life of trout induced a persistent positive effect on carbohydrate utilization at the digestive level, which was revealed at the juvenile stages by a higher persistent expression of amylase and maltase in early-stimulated fish compared with controls. The possible involvement of caudal-related homeo box $2(\mathrm{Cdx} 2)$ and hepatocyte nuclear factor $1 \propto(\mathrm{HNF} 1 \alpha)$ in nutritional pro- gramming of fish larval intestinal genes has been suggested but has never been demonstrated and would constitute an interesting field for future research (Geurden et al. 2007). The fact that it was not possible to find any persistent effect on glucose transport or metabolism does not refute the existence of an early nutritional programming in fish. These data emphasize the need for further investigations to better define (i) the developmental windows where the nutritional stimulus could have the maximal effect on larvae, (ii) the duration of the glucidic stimulations and (iii) the possible mechanisms of this process.

There is notable variation between farmed fish species in their ability to synthesize HUFA. These fatty acids (with more than 18 carbons) play essential roles in metabolism of all animals: they determine the biophysical properties of the cell membranes, and they are also precursors of several biologically active eicosanoids including prostaglandins, thromboxanes and leukotrienes (Gill \& Valivety 1997). Freshwater species and salmonids are able to synthesize EPA and DHA by fatty acid elongation and desaturation from short n-3 fatty acids, but this pathway is not functional in marine fish (Geay et al. 2010). It is necessary to supply such n-3 HUFA in the feeds in order to allow fish survival and also to maintain a certain level of n-3 HUFA in fish flesh (for both marine and freshwater species). Worldwide supplies of fish oils and meals from capture fisheries have reached their sustainable limits, forcing industries to look for alternative lipid sources for use in marine fish diets. Consequently, there is a considerable interest in producing fish species or fish strains able to synthesize n-3 HUFA, in order to lower the dependency of fish aquaculture on fisheries and maintain the human health value of aquaculture species.

Although many fatty acid desaturase genes may be found in some marine fish species, the fatty acid desaturation pathway exhibits an apparent deficiency. This deficiency could be the result of relaxation of constraints on a prototypic pathway in an environment providing a diet naturally rich in HUFA (Hastings et al. 2001). Vagner et al. (2009) showed a persistent elevated expression of delta- 6 desaturase (D6D) gene in European sea bass that have been fed during the larval period with a diet incorporating a low level of n-3 HUFA, compared with a control group without any early nutritional conditioning. These authors suggested the involvement of PPAR in the D6D mRNA level stimulation and concluded that it is possible to influence juvenile fish metabolism by a nutritional conditioning during the larval stage. However, such nutritional conditioning had no significant effect on juvenile growth and lipid composition. As already evoked for glucose metabolism, the early-programming process is very promising in terms of practical applications, but needs further studies in fish larvae. 
Consequences on cardiovascular performance

Cardiac activity can either be determined by a genetic programme alone or be responsive to environmental and epigenetic factors early on. Indeed, many studies have shown that the ultimate phenotype also depends on environmental influences like temperature or oxygen saturation (Pelster et al. 2003). In developing zebrafish larvae, Schwerte et al. (2005) have reported that clutch effects caused by maternal and/or genetic influences can affect some early developmental parameters like blood cell concentration and cardiac performance (heart rate, stroke volume and cardiac output). In particular, they have revealed an effect of maternal nutrition on heart performance and blood cell concentration in the offspring of parent animals fed with either compound diet or live preys. Such changes in cardiac physiology may contribute to improve the aerobic capacity of the fish and may then improve the resistance to hypoxic conditions as suggested by Pelster et al. (2003).

\section{Consequences in reproduction}

Effects of recent or current nutrition and of environmental factors on the reproductive performance of many species have long been recognized, and this knowledge has likely been applied to maximize the production of domestic species. However, it is only recently that we have a clearer picture of the importance of factors acting at early developmental stages, especially nutrition, in the programming of the reproductive function (Rhind et al. 2001). Reproduction of animals can be affected by several factors acting at different stages of development, which are mediated by changes in the HPG axis (Davies \& Norman 2002). Gonadotropins constitute an important group of pituitary regulatory hormones which comprise luteinizing hormone (LH) and follicle-stimulating hormone (FSH). The secretion of gonadotropin hormones is controlled by the $\mathrm{GnRH}$ pulse generator that is an integrator of hormonal, metabolic and neural signals. Experimental data in mammals (and observations in humans) revealed that early life exposures influence the development and functioning of the HPG from a programming perspective. The effects of nutrition on the reproductive health of fish have not been well studied (Migaud et al. 2013), especially in comparison with the effects of other environmental factors. However, at earlier stages of foetal development, the normal ontogeny of gonadal development and function can be disrupted by under-nutrition on the process of tissue differentiation or the influence of endocrine disrupting compounds. Clearly, any effect of under-nutrition on the process of tissue differentiation, gonad formation and the establishment of associated enzyme systems is likely to have a fundamental effect on the subsequent function of these organs (Rhind et al. 2001). This kind of work has to be undertaken in fish species to investigate the effects of different dietary compo- nents as proteins and other specific nutrients (like HUFA and vitamins), to identify the critical developmental periods and the relationships between developmental abnormalities and adult reproductive performance.

\section{Integrating the effect of external factors}

It is clear that no single factor is at work and different levels of biological organization function in concert for the survival of the organism. The combination of signals from the tank colour and the photic environment act via the neuroendocrine systems involved in feeding behaviour and growth (POMC, MCH, GnRH) as exemplified by barfin flounder Verasper moseri which grow better in white tanks than in black, and better under green light than under red (Takahashi et al. 2009). Rearing halibut larvae under continuous light accelerated the appearance of haemoglobin in the circulation of metamorphosing halibut larvae and gave a higher frequency of normal pigmentation and higher survival than did a 12L:12D regime (Solbakken \& Pittman 2004). The interaction between ontogeny, photoperiod and endocrinology should be further investigated (Falk-Petersen 2005). Even here there may be evidence of latitudinal adaptation and evolution, such that species or populations from high latitudes have different response mechanisms than do those from low latitudes. The phenotypic differences due to changing environmental factors during the early stages of development are particularly evident in larvae that have undergone suboptimal dietary conditions during early weaning experiments (Murray et al. 2010; Fig. 5).

A very concrete example of how growth can be increased is given for cod, G. morhua, which increased their harvest weight through short-term manipulations, at the larval stage, of natural feeds, temperature and salinity (Imsland et al. 2011). This study was the first to be able to retrospectively analyse the growth response of cod during and after fixed environmental and dietary manipulations on random family effects. Briefly, the cod larvae fed zooplankton during c. 30 days after hatching were $12 \%$ heavier than those of the groups fed rotifers, a not-unexpected result. Early rearing temperature manipulations gave up to $24 \%$ heavier fish. Importantly, the growth differences persisted over the next 26 months and the long-term growth trajectories were significantly affected by the early limited treatment. Digging deeper into the data, the authors found that size variation at the end of the laboratory trial was largely explained by the different first feeds $(16.7 \%)$, the temperature $(39.7 \%)$ and the salinity $(30.8 \%)$, but not by family. This was in contrast to the long-term trial when growth variation was explained by family (30.1\%) and early life conditions explained $16 \%$ of the variations in growth. Imsland et al.'s (2011) study indicates that the magnitude of the parental effect on growth in cod is dependent on rearing 


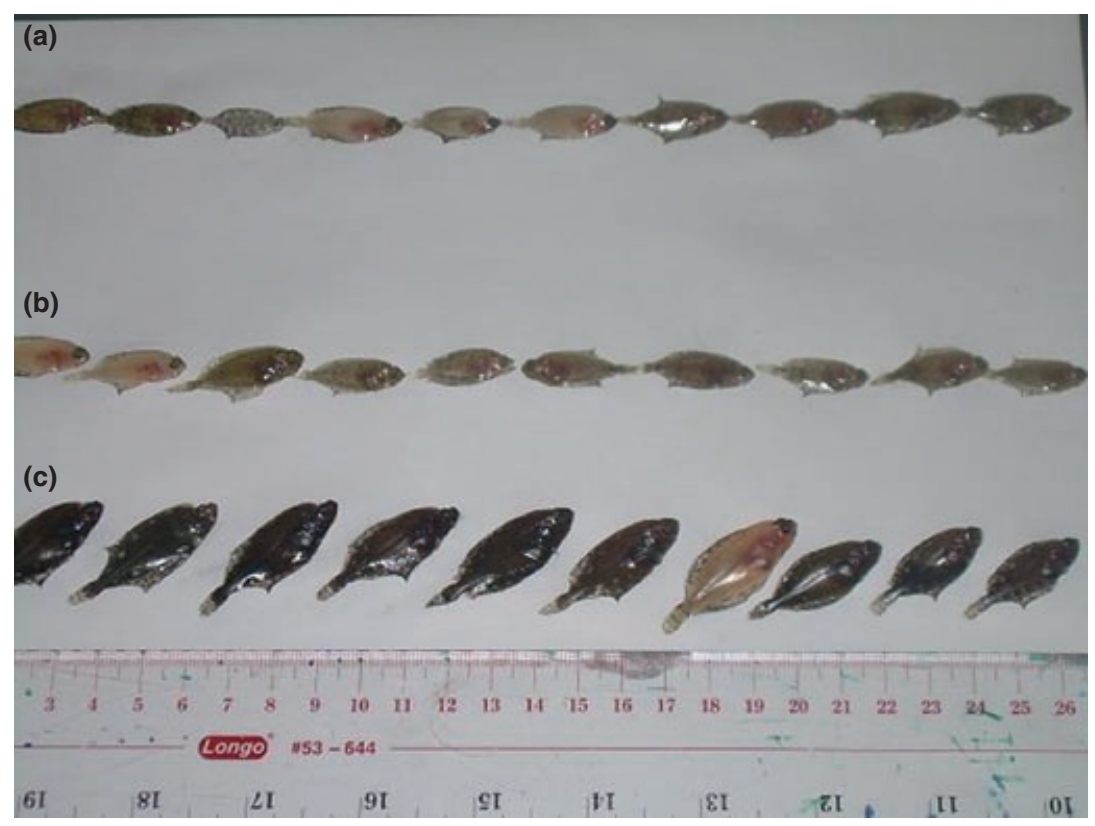

Figure 5 Phenotypic differences in size and pigmentation in 53 dph postlarvae of Atlantic halibut between early-weaned and control fish at the end of the trial. (a) Trial group weaned at 32 days post-first feeding; (b) trial group weaned at 43 days post-first feeding; (c) control fish fed on live prey (from Murray et al. 2010, with permission).

environment and life stage. Imsland et al. (2011) clearly state that environmentally related differences in growth in the 0 -year group are mirrored in size differences at harvest several years later, and that diet and environmental manipulation during the first-feeding period account for nearly $90 \%$ of the growth differences in the early juvenile period.

When the ease with which natural, simple, cheap and brief changes in the early life of a marine fish can improve harvest weight years later are contrasted with the intense effort needed to bring a fast-growing transgenic salmon to market (AquAdvantage $^{\mathrm{TM}}$, AquaBounty Technologies, Waltham, MA, USA), the choice of research avenues seems starkly obvious. There has been extremely little research on salmon larval development despite the significant industrial development. Enhancing the long-term scope for growth using the natural plasticity of fish larvae requires a better understanding than we currently have, yet there is a wide range of applications for fisheries and for culture.

Summarizing, altered size and shape are the main visible impacts of the rearing temperature on fish larvae and early juveniles, although it is difficult to separate the influence of other environmental factors and the parallel consequences of the feeding activity. Modification of the relative timing of development of organs and tissues due to temperature is usually reflected as changes in mass and total length. Size is considered a better index or predictor of development status than age as observed in many species (Amara \& Lagar- dere 1995; Fuiman et al. 1998; Fernández-Díaz et al. 2001; Campinho et al. 2004; Hatchinson \& Hawkins 2004; Sæle \& Pittman 2010). However, thermal-induced changes may also alter the development status reached at a given size (Johnston et al. 2001; Choa et al. 2010). All these factors point to a continuing and indeed increasing need for careful multidisciplinarity when examining factors influencing the larval stages of marine fish. They are the basis for future fish stocks, whether captured or cultured.

\section{Conclusions}

The number of fish species examined is extremely limited relative to the number which exist. Most of those examined are phylogenetically distant from each other, with wide inherent variations in developmental strategy. The fish larval stage is a crucial one, integrating the genotype consequences of the FSGD with influences from the environment on up- and down-regulation of genes in pluripotent or undifferentiated cells and using a variety of paralog genes to go through metamorphosis to become a functional juvenile. The bases of the next generation, the primordial germ cells, are also affected by the experiences of the parent fish in its larval stage. The understanding of the multiple sources of plasticity is a necessary focus of research. Such knowledge will be the basis of the next generation of scientific advances in aquaculture and is equally important to 
incorporate into aquaculture, fisheries and ecosystem management strategies. Morphological and physiological plasticity could be beneficial or detrimental depending on the final anthropogenic interest (better growth, good aspect, sustainability, etc). Only a deep knowledge of the mechanisms driving these processes will allow the evolution of appropriate management strategies to attain specific objectives.

Epigenetics is a burgeoning area in developmental physiology, and embryonic and larval fish are well suited for the study of programming effects, particularly as they influence physiological functions. Most of the programming studies conducted with larvae fish concern the development of the axial musculature, cardiovascular performance, metabolism of carbohydrates and lipids, and hypoxic tolerance (not reviewed here).

There is a great opportunity for many diverse larval models exhibiting very different adaptation processes to environmental and nutritional changes. Zebrafish has become a standard for studying and modelling vertebrate development, but its characteristics and adaptational responses cannot be extrapolated to all vertebrates or even to all fish. The fact that important information on genome and gene expression is now available for several fish species offers great opportunities not only for the understanding of evolution and development but also for its practical applications to the fields of ecosystem regulation, fisheries management and aquaculture production of robust healthy fish. Major research questions remain to be resolved: the genotypic determinants of environmental sensitivity during the developmental period, the identification of the key regulatory genes and the epigenetic processes involved in phenotypic plasticity.

One relevant subject is how to access to this information without altering the functioning of these mechanisms. Generally, the laboratory experiments with developing fish larvae modify and simplify the environmental and feeding conditions of wild habitats. Natural trends and rhythms of environmental factors are usually eliminated or reduced to a minimum so as to optimize those parameters supposedly giving the best growth. The importance of such environmental fluctuations and cycles for a correct signalling and the adequate coordination of early developmental processes has been recently evidenced (Vallone et al. 2007; Villamizar et al. 2009; Blanco-Vives et al. 2010).

The offered food is also far from being as varied and complete: the short live food chain used in the industry and in most of the research work may lack of some essential nutrients (Hamre et al. 2008b; Conceição et al. 2010), while experimental microdiets for first-feeding larvae are still unable to support efficiently the development at these very early stages in most species (Yúfera et al. 2005; Seiliez et al. 2006; Kolkovski 2008). All these modifications bias and skew growth results and accompanying measures. But in addition, the theoretical developmental programme can become imbalanced due to the alteration of the timing and sequence of signalling for specific developmental events. During this fast-growing larval stage, it is difficult to isolate one single physiological parameter from the whole. Different values of a particular abiotic or nutritional factor usually affect both the developmental rate and the somatic growth in similar degree, although in some cases, development and growth progress independently. Consequently, the status attained at a given age could be quite different depending on a number of factors. This is particularly evident when comparing changes in levels of biochemical activities and gene expression. Important sequential changes in gene expression occur during early development in fish reared under standard rearing conditions (Darias et al. 2008; Douglas et al. 2008; Manchado et al. 2008). When testing different feeds, the differential expression can be dramatic. Murray et al. (2010) working with halibut postlarvae and Yúfera et al. (2008) working with Senegal sole larvae found that most of the genes involved in replication, translation and cell proliferation were downregulated in fish fed an experimental microdiet relative to controls fed on live prey. Unfortunately, it is not always possible to have a complete sample's sequence during a developmental study without compromising other biological variables of the experiment. Therefore, it is difficult to separate developmental changes from treatment effect. In other words, the measured value of a particular biological variable could be higher or lower due to the effect of the treatment or simply because the size of the larvae differs among treatments.

On the other hand, faster growth does not necessarily mean an equilibrated development, and it can mask important defects that will be evident in later life. Mesocosm experiments could provide a reasonable approach to this research preventing potential negative effects of crowding and keeping an almost-natural environmental regime, but this system is not useful for testing several treatments simultaneously. Moreover, a good knowledge of the developmental consequences of the intensive fish larval rearing is also important for designing industrial protocols assuring the production of well-developed and healthy juveniles. Parallel advances with different approaches may help to solve the development puzzle and how the regulatory genes are working at these early stages.

Besides the interesting perspective in animal production offered by epigenetic studies, the results provide valuable insight into the ecological importance of this natural biological process. Epigenetics provides a mechanism for individual adaptations during development in response to cues about future environment. These adaptations alter the developmental programme in a manner that generates novel phenotypes. The fish-specific whole-genome dupli- 
cation, which took place hundreds of millions of years ago, has led to a greater variety in teleosts than in any other vertebrate group, and this is clearly reflected in the variety of molecular pathways used in central physiological pathways, even those which are involved in generally conserved processes like metamorphosis. This allows the production of different phenotypes from a single genome more rapidly than could be achieved by mutation or selection. For fish, one could argue that evolution and mutation never produce phenotypes, only genotypes, and that phenotypes are always produced rapidly, 'on demand' so to speak.

In the context of global climate change, the physiological plasticity of fish larvae will be a key mechanism for species survival and adaptation to environmental conditions and anthropogenic influences. Several decades of research in aquaculture have let us understand the fish as animals better than we ever have from millennia of fishing. Fish larvae have a plethora of undifferentiated cell types and undifferentiated organ functions. It is abundantly clear that environmental influences will affect much more than patterns of larval drift in the oceans and recruitment to the fishable stock (Pankhurst \& Munday 2011). The plasticity of larval developmental responses may also extend into subsequent generations through impacts on the primordial germ cells already carried by the larvae. One can argue that the impact of environmental cues has already been extensively investigated for species of economic and/or ecological importance, but few studies have been performed on marine fish larvae and fewer still at the genomic level (Mazurais et al. 2011; Yúfera et al. 2012; García Fernández et al. 2013). This is a significant hole in our understanding because even a small rise in temperature can modify physiological functions and behaviours in fish (Roessig et al. 2004), both in the current and in the future generations. This review's outline of the burgeoning importance of fish larvae as the basis of multiple industries and conservation efforts does not yet take into account the prevalence of acidification, persistent organic pollutants and other external factors.

Fish larvae are the basis for juvenile production, growout fish and fishable stocks. Knowledge of the subtlety of adaptations to local conditions experienced by the larval stage should inform management processes, especially with regard to growth, reproduction and the physiology of feed conversion efficiencies. Larval ontogenesis is affected by both environment and anthropogenic changes, and the adaptation can occur at many levels of biological organization and from many variables acting alone or in synergy. Inherent in fish larval plasticity is the difficulty of interpreting genomic results. While the FSGD allows a wealth of responses, candidate genes require functional annotation in each fish species, because neofunctionalization can have occurred in nonmodel species. Furthermore, the small size of marine fish larvae encourages pooling and homogenization of whole larvae, whereas interpretation of results benefits from dissection of specific tissues, organs or cell types in stage-specific individuals. Recent advances in microdissection allow such discrimination, and we are beginning to understand the 'internal dialogue' of fish ontogeny.

It is our hope that this review of some of the known influences and pathways used by fish larvae to adapt to their surroundings will encourage a more sensitive appreciation of this vital yet vulnerable life stage, in both aquaculture and fisheries. It is a growing truism that fish have the molecular vocabulary to survive in a new world perhaps better than we will.

\section{Acknowledgements}

This study benefited from participation in LARVANET COST action FA0801 (EU RTD framework Programme). M.Y. received financial support from the Spanish National Scientific Research Plan MINECO + FEDER/ERDF (projects AGL2011-23722 and Consolider Ingenio 2010 Program-Project Aquagenomics CSD2007-0002), and L.R. acknowledges Ciencia 2008 Programme (FCT, Portugal). We thank Mr. Truls Wergeland for his inestimable help in the preparation of the figures.

\section{References}

Able K, Sakowicz GP, Lamonaca JC (2009) Scale formation in selected fundulid and cyprinodontid fishes. Ichthyology Research 56: 1-9.

Akhundov MM, Fedorov KE (1990) Early gameto- and gonadogenesis in sturgeons: 1 . Criteria of comparative assessment of gonad development in young individuals with reference to Acipenser gueldenstaedti. Journal of Ichthyology 30: 963-973.

Alami-Durante H, Rouel M, Kentouri M (2006) New insights into temperature-induced white muscle growth plasticity during Dicentrarchus labrax early life: a developmental and allometric study. Marine Biology 149: 1551-1565.

Alami-Durante H, Olive N, Rouel M (2007) Early thermal history significantly affects the seasonal hyperplastic process occurring in the myotomal white muscle of Dicentrarchus labrax juveniles. Cell and Tissue Research 327: 553-570.

Alami-Durante H, Cluzeaud M, Mazurais D, ZamboninoInfante JL (2010) Dietary vitamin D3 level affects the expression of myogenic regulatory factors and myosin heavy chain in European sea bass larvae. Poster, 9th International Congress on the Biology of Fish, Barcelona, 5-9 July 2010.

Albokhadaim I, Hammond CL, Ashton C, Simbi BH, Bayol S, Farrington S et al. (2007) Larval programming of post-hatch 
muscle growth and activity in Atlantic salmon (Salmo salar). Journal of Experimental Biology 210: 1735-1741.

Alderman SL, Bernier NJ (2009) Ontogeny of the corticotropinreleasing factor system in zebrafish. General and Comparative Endocrinology 164 (1): 61-69.

Alsop D, Vijayan MM (2008) Development of the corticosteroid stress axis and receptor expression in zebrafish. American Journal of Physiology. Regulatory, Integrative and Comparative Physiology 294: R711-R719.

Alsop D, Vijayan MM (2009) Molecular programming of the corticosteroid stress axis during zebrafish development. Comparative and Biochemical Physiology 153A: 49-54.

Amara R, Lagardere F (1995) Size and age at the onset of metamorphosis in sole (Solea solea L.) of the Gulf of Gascogne. ICES Journal of Marine Science 52: 247-256.

Anken RH (2006) On the role of the central nervous system in regulating the mineralisation of inner-ear otoliths of fish. Protoplasma 229: 205-208.

Applebaum SL, Wilson CA, Holt GJ, Nunez BS (2010) The onset of cortisol synthesis and the stress response is independent of changes in CYP11B or CYP21 mRNA levels in larval red drum (Sciaenops ocellatus). General and Comparative Endocrinology 165 (2): 269-276.

Applebaum SL, Finn RN, Faulk CK, Holt GJ, Nunez BS (2012) Developmental expression, differential hormonal regulation and evolution of thyroid and glucocorticoid receptor variants in a marine acanthomorph teleost (Sciaenops ocellatus). General and Comparative Endocrinology 176: 39-51.

Arkhipchuk VV (1995) Role of chromosomal and genome mutations in the evolution of bony fishes. Hydrobiological Journal 31: 55-65.

Arul V (1991) Effect of temperature on yolk utilization of Channa striatus. Journal of Thermal Biology 16: 1-5.

Atalah E, Hernandez-Cruz CM, Benitez-Sánchez T, Ganga R, Roo J, Izquierdo M (2011) Importance of dietary arachidonic acid and eicosapentaenoic acid for culture performance of gilthead seabream (Sparus aurata) larvae. Aquaculture Research 42 (9): 1279-1288.

Auperin B, Geslin M (2008) Plasma cortisol response to stress in juvenile rainbow trout is influenced by their life history during early development and by egg cortisol content. General and Comparative Endocrinology 158: 234-239.

Ayala MD, López-Albors O, Gil F, Latorre R, Vázquez JM, García-Alcazar A et al. (2000) Temperature effects on muscle growth of the axial musculature of sea bass (Dicentrarchus labrax L.). Anatomical and Histological Embryology 29: 235-241.

Azuma T, Takeda K, Doi T, Muto K, Akutsu M, Sawada M et al. (2004) The influence of temperature on sex determination in sockeye salmon Oncorhynchus nerka. Aquaculture 234: 461473.

Bachvarova RF, Crother BI, Johnson DA (2009) Evolution of germ cell development in tetrapods: comparison of urodeles and amniotes. Evolution and Development 11 (5): 603-609.
Balon EK (1983) Epigenetic mecanisms: reflections on evolutionary processes. Canadian Journal of Fisheries and Aquatic Sciences 40: 2054-2058.

Balon EB (1990) Epigenesis of an epigeneticist: the development of some alternative concepts on the early ontogeny and evolution of fishes. Guelph Ichthyology Reviews 1: 1-48.

Barry TP, Malison JA, Held JA, Parrish JJ (1995) Ontogeny of the cortisol stress response in larval rainbow trout. General and Comparative Endocrinology 97: 57-65.

Barton BA, Iwama GK (1991) Physiological changes in fish from stress in aquaculture with emphasis on the stress response and effects of corticosteroids. Annual Reviews of Fish Diseases 1: 336.

Bessonart M, Izquierdo MS, Salhi M, Hernández-Cruz CM, Gonzalez MM, Fernández-Palacios H (1999) Effect of dietary arachidonic acid levels on growthand survival of gilthead sea bream (Sparus aurata L.) larvae. Aquaculture 179: 265-275.

Bezault E, Clota F, Derivaz M, Chevassus B, Baroiller JF (2007) Sex determination and temperature induced sex differentiation in three natural populations of Nile tilapia (Oreochromis niloticus) adapted to extreme temperature conditions. Aquaculture 272 (Suppl 1): S3-S16.

Bichsel Y, von Gunten U (1999) Determination of Iodide and Iodate by Ion Chromatography with Post column reaction and UV/Visible detection. Analytical Chemistry 71: 34-38.

Blanco-Vives B, Villamizar N, Ramos J, Bayarri MJ, Cherenguini O, Sánchez-Vázquez FJ (2010) Effect of daily thermo- and photo-cycles of different light spectrum on the development of Senegal sole (Solea senegalensis) larvae. Aquaculture 306: 137-145.

Blanton ML, Specker JL (2007) The hypothalamic-pituitarythyroid (HPT) axis in fish and its role in fish development and reproduction. Critical Reviews in Toxicology 37: 97-115.

Blaser H, Reichman-Fried M, Castanon I, Dumstrei K, Marlow FL, Kawakami K et al. (2006) Migration of zebrafish primordial germ cells: a role for myosin contraction and cytoplasmic flow. Developmental Cell 11: 613-627.

Blaxter JHS, Hempel G (1963) The influence of egg size on herring larvae (Clupea harengus, L.). Journal du Conseil Permanent International Pour l'Exploration de la Mer 28: 211-240.

Blázquez M, Zanuy S, Carillo M, Piferrer F (1998) Effects of rearing temperature on sex differentiation in the European sea bass (Dicentrarchus labrax L.). Journal of Experimental Zoology 281: 207-216.

Bodinier C, Sucré E, Lecurieux-Belfond L, Blondeau-Bidet E, Charmantier G (2010) Ontogeny of osmoregulation and salinity tolerance in the gilthead sea bream Sparus aurata. Comparative Biochemistry and Physiology, Part A 157: 220228.

Boeuf G, LeBail PY (1999) Does light have an influence on fish growth? Aquaculture 177: 129-152.

Boeuf G, Payan P (2001) How should salinity influence fish growth? Comparative Biochemistry and Physiology, Part C 130: 411-423. 
Boglione C, Gisbert E, Gavaia P, Witten PE, Moren M, Fontagné $S$ et al. (2013) A review on skeletal anomalies in reared European fish larvae and juveniles. Part 2: main typologies, occurrences and causative factors. Reviews in Aquaculture (in press).

Bowen CA, Bronte CR, Argyle RL, Adams JV, Johnson JE (1999) Vateritic sagitta in wild and stocked Lake trout: applicability to stock origin. Transactions of the American Fisheries Society 128: 929-938.

Braasch I, Brunet F, Wolff JN, Schartl M (2009) Pigmentation pathway evolution after whole-genome duplication in fish. Genome Biology and Evolution 1: 479-493.

Bransden MP, Butterfield GM, Walden J, McEvoy LA, Bell JG (2005) Tank colour and dietary arachidonic acid affects pigmentation, eicosanoid production and tissue fatty acid profile of larval Atlantic cod (Gadus morhua). Aquaculture 250: 328 340.

Brown DD (1997) The role of thyroid hormone in zebrafish and axolotl development. Proceedings of the National Academy of Sciences of the United States of America 94: 13011-13016.

Brown CL, Kim BG (1995) Combined application of cortisol and triiodothyronine in the culture of larval marine finfish. Aquaculture 135: 79-86.

Buddington RK, Krogdahl A, Bakke-McKellep AM (1997) The intestines of carnivorous fish: structure and functions and the relations with diet. Acta Physiologica Scandinavica 161: 67-80.

Bumaschny VF, de Souza FSJ, Lopez Leal RA, Santangelo AM, Baetscher M, Levi DH et al. (2007) Transcriptional regulation of pituitary POMC is conserved at the vertebrate extremes despite great promoter sequence divergence. Molecular Endocrinology 21 (11): 2738-2749.

Burdge GC, Lillycrop KA (2010) Nutrition, epigenetics, and developmental plasticity: implications for understanding human disease. Annual Review of Nutrition 30: 315-339.

Burel C, Boujard T, Escaffre M, Kaushik SJ, Boeuf G, Mol $\mathrm{K}$ et al. (2000) Dietary low-glucosinolate rapeseed meal affects thyroid status and nutrient utilization in rainbow trout (Oncorhynchus mykiss). British Journal of Nutrition 83: 653-664.

Buxton CD, Garratt PA (1990) Alternative reproductive styles in seabreams (Pisces: Sparidae). Environmental Biology of Fishes 28: 113-124.

Cahu C, Zambonino-Infante JL (1995) Maturation of the pancreatic and intestinal digestive functions in sea bass (Dicentrarchus labrax): effect of weaning with different protein sources. Fish Physiology and Biochemistry 14: 431-437.

Campinho MA, Moutou KA, Power DM (2004) Temperature sensitivity of skeletal ontogeny in Oreochromis mossambicus. Journal of Fish Biology 65: 1003-1025.

Campinho MA, Galay-Burgos M, Sweeney GE, Power DM (2010) Coordination of deiodinase and thyroid hormone receptor expression during the larval to juvenile transition in sea bream (Sparus aurata, Linnaeus). General and Comparative Endocrinology 165: 181-194.
Catalán IA, Folkvord A, Palomera I, Quílez-Badía G, Kallianoti F, Tselepides A et al. (2010) Growth and feeding patterns of European anchovy (Engraulis encrasicolus) early life stages in the Aegean Sea (NE Mediterranean). Estuarine, Coastal and Shelf Science 86: 299-312.

Chambers RC, Leggett WC (1987) Size and age at metamorphosis in marine fishes: an analysis of lab-reared winter flounder Pseudopleuronectes americanus with a review of variations in other species. Canadian Journal of Fisheries and Aquatic Sciences 44: 1936-1947.

Chambers RC, Leggett WC (1996) Maternal influences in variation in egg sizes in temperate marine fish. American Zoologist 36: 180-196.

Charlesworth D, Mank JE (2010) The birds and the bees and the flowers and the trees: lessons from genetic mapping of sex determination in plants and animals. Genetics 186: 9-31.

Chiba H, Nakamura M, Iwata M, Sakuma Y, Yamauchi K, Parhar IS (1999) Development and differentiation of gonadotropin hormone-releasing hormone neuronal systems and testes in the Japanese eel (Anguilla japonica). General and Comparative Endocrinology 114: 449-459.

Choa BI, Carter CG, Battaglene SC (2010) Effects of temperature regime on growth and development of post-larval stripped trumpeter (Latris lineata). Aquaculture 305: 95-101.

Comerford S, Brophy D, Fox CJ, Taylor N, van der Veer H, Nash RDM et al. (2013) Growth rates and pelagic phase durations of larval plaice (Pleuronectes platessa) in three regions of the North East Atlantic. Marine Ecology Progress Series 476: 215226.

Conceição LEC, Yúfera M, Makridis P, Morais S, Dinis MT (2010) Live feeds for early stages of fish rearing. Aquaculture Research 41: 613-640.

Conover DO, Kynard BE (1981) Environmental sex determination - interaction of temperature and genotype in a fish. Science 213: 577-579.

Copeman LA, Parrish CC, Brown JA, Harel M (2002) Effects of docosahexaenoic, eicosapentaenoic and arachidonic acids on the early growth, survival, lipid composition and pigmentation of yellowtail flounder (Limanda ferruginea): a live food enrichment experiment. Aquaculture 210: 285-304.

Dale T (1984) Embryogenesis and growth of otoliths in the cod (Gadus morhua L.). Flodevigen Rapportser 1: 231-250.

Darias MJ, Zambonino-Infante JL, Hugot K, Cahu CL, Mazurais D (2008) Gene expression patterns during the larval development of European sea bass (Dicentrarchus labrax) by microarray analysis. Marine Biotechnology 10: 416-428.

David AW, Grimes CB, Isley JJ (1994) Vaterite sagittal otoliths in hatchery-reared juvenile red drums. Progressive Fish-Culturist 56: 301-303.

Davies MJ, Norman RJ (2002) Programming and reproductive functioning. Trends in Endocrinology and Metabolism 13: 386392.

Day T, McPhail JD (1996) The effect of behavioural and morphological plasticity on foraging efficiency in the threespine stickleback (Gasterosteus sp.). Oecologia 108: 380-388. 
Deane EE, Woo NYS (2003) Ontogeny of thyroid hormones, cortisol, hsp70 and hsp90 during silver sea bream larval development. Life Sciences 72: 805-818.

Dedi J, Takeuchi T, Seikai T, Watanabe T, Hosoya K (1997) Hypervitaminosis A during vertebral morphogenesis in larval Japanese flounder. Fisheries Science 63: 466-473.

Degens ET, Deuser WG, Haedrich RL (1969) Molecular structure and composition of fish otoliths. Marine Biology 2: 105113.

Denver RJ (2009) Stress hormones mediate environment-genotype interactions during amphibian development. General and Comparative Endocrinology 164: 20-31.

Devlin RH, Nagahama Y (2002) Sex determination and sex differentiation in fish: an overview of genetic, physiological, and environmental influences. Aquaculture 208: 191-364.

Dickey-Collas M (1993) The occurrence of juvenile pigmentation abnormalities in plaice (Pleuronectes platessa) larvae fed on enriched and unenriched Artemia salina nauplii. Journal of Fish Biology 42 (5): 787-795.

Doitsidou M, Reichman-Fried M, Stebler J, Koprunner M, Dorries J, Meyer D et al. (2002) Guidance of primordial germ cell migration by the chemokine SDF-1. Cell 111: 647-659.

Douglas SE, Knickle LC, Williams J, Flight RM, Reith ME (2008) A first generation Atlantic halibut microarray: application to developmental studies. Journal of Fish Biology 72: 2393-2408.

Eales JG, Brown SB (1993) Measurement and regulation of thyroidal status in teleost fish. Reviews in Fish Biology and Fisheries 3: 299-347.

Edward SL, Marshall W (2013) Principles and patterns of osmoregulation and euryhalinity in fishes. In: McCormick SD, Farrell AP, Brauner CJ (eds) Fish Physiology, Vol. 32, Euryhaline Fishes, pp. 1-44. Elsevier, New York.

van Eenennaam JP, Linares-Casenave J, Deng X, Doroshov SI (2005) Effect of incubation temperature on green sturgeon embryos, Acipenser medirostris. Environmental Biology of Fishes 72: 145-154.

Einarsdóttir IE, Silva N, Power DM, Smáradóttir H, Björnsson BT (2006) Thyroid and pituitary gland development from hatching through metamorphosis of a teleost flatfish, the Atlantic halibut. Anatomy and Embryology 211: 47-60.

Ekström P, Meissl H (1997) The pineal organ of teleost fishes. Reviews in Fish Biology and Fisheries 7: 199-284.

Ekström P, Meissl H (2003) Evolution of photosensory pineal organs in new light: the fate of neuroendocrine photoreceptors. Philosophical Transactions of the Royal Society of London, Series B 358: 1679-1700.

Eshel O, Shirak A, Weller JI, Hulata G, Ron M (2012) Linkage and physical mapping of sex region on LG23 of Nile tilapia (Oreochromis niloticus). G3 (Bethesda) 2 (1): 35-42.

Estévez A, Ishikawa M, Kanazawa A (1997) Effects of arachidonic acid on pigmentation and fatty acid composition of Japanese flounder, Paralichthys olivaceus (Temminck and Schlegel). Aquaculture Research 28: 279-289.
Estévez A, McEvoy LA, Bell JG, Sargent JR (1999) Growth, survival, lipid composition and pigmentation of turbot (Scophthalmus maximus) larvae fed live-prey enriched in Arachidonic and Eicosapentaenoic acids. Aquaculture 180: 321-343.

Estévez A, Kaneko T, Seikai T, Dores RM, Tagawa M, Tanaka M (2001) Ontogeny of ACTH and MSH cells in Japanese flounder (Paralichthys olivaceus) in relation to albinism. Aquaculture 202: 131-143.

Evans DH, Piermarini PM, Choe KP (2005) The multifunctional fish gill: dominant site of gas exchange, osmoregulation, acidbaseregulation, and excretion of nitrogenous waste. Physiological Reviews 85: 97-177.

Extavour CGM (2008) Evolution of the bilaterian germ line: lineage origin and modulation of specification mechanisms. Integrative and Comparative Biology 47 (5): 770-785.

Falcon J, Gothilf Y, Coon SL, Boeuf G, Kleinz DC (2003) Genetic, temporal and developmental differences between melatonin rhythm generating systems in the teleost fish pineal organ and retina. Journal of Neuroendocrinology 15: 378-382.

Falk-Petersen IB (2005) Comparative organ differentiation during early life stages of marine fish. Fish and Shellfish Immunology 19: 397-412.

Feist G, Schreck CB (2001) Ontogeny of the stress response in chinook salmon, Oncorhynchus tshawytscha. Fish Physiology and Biochemistry 25: 31-40.

Fernández-Díaz C, Yúfera M, Cañavate JP, Moyano FJ, Alarcón FJ, Díaz M (2001) Growth and physiological changes during metamorphosis of Senegal sole reared in the laboratory. Journal of Fish Biology 58: 1086-1097.

Folkvord A, Koedijk R, Lokøy V, Imsland AK (2010) Timing and selectivity of mortality in reared Atlantic cod revealed by otolith analysis. Environmental Biology of Fishes 89: 513-519.

Forsell J, Ekström P, Novales Flamarique I, Holmqvist O (2001) Expression of pineal ultraviolet- and green-like opsins in the pineal organ and retina of teleosts. Journal of Experimental Biology 204: 2517-2525.

Forsell J, Holmqvist B, Ekström P (2002) Molecular identification and developmental expression of UV and green opsin mRNAs in the pineal organ of the Atlantic halibut. Developmental Brain Research 136: 51-62.

Fox CJ, Folkvord A, Geffen AJ (2003) Otolith micro-increment formation in herring Clupea harengus larvae in relation to growth rates. Marine Ecology Progress Series 264: 83-94.

Fox CJ, Geffen A, Taylor N, Davison P, Rossetti H, Nash RDM (2007) Birth-date selection in early life stages of plaice Pleuronectes platessa in the eastern Irish Sea (British Isles). Marine Ecology Progress Series 345: 255-269.

Fuiman LA, Poling KR, Higgs DM (1998) Quantifying developmental progress for comparative studies of larval fish. Copeia 1998: 602-611.

Fujii R (1993) Coloration and chromatophore. In: Evans DH (ed.) The Physiology of Fishes, pp. 535-562. CRS Press, Boca Raton. 
Funkenstein B, Tsai W, Maures T, Duan C (2002) Ontogeny, tissue distribution, and hormonal regulation of insulin-like growth factor binding protein-2 (IGFBP-2) in a marine fish, Sparus aurata. General and Comparative Endocrinology 128: 112-122.

Furuita H, Yamamoto T, Shima T, Suzuki N, Takeuchi T (2003) Effect of arachidonic acid levels in broodstock diet on larval and egg quality of Japanese flounder Paralichthys olivaceus. Aquaculture 220: 725-735.

García Fernández C, Roufidou C, Antonopoulou E, Sarrapoulou E (2013) Expression of developmental-stage-specific genes in the gilthead seabream Sparus aurata L. Marine Biotechnology (in press) doi:10.1007/s10126-012-9486-8.

Gauldie RW (1993) Polymorphic crystalline structure of fish otoliths. Journal of Morphology 218: 1-28.

Geay F, Santigosa E, Culi I, Corporeau C, Boudry P, Dreano Y et al. (2010) Regulation of FADS2 expression and activity in European sea bass (Dicentrarchus labrax, L.) fed a vegetable diet. Comparative Biochemistry and Physiology 156B: 237243.

Geffen AJ (1983) The deposition of otolith rings in Atlantic salmon, Salmo salar L., embryos. Journal of Fish Biology 23: 467474.

Geffen AJ, Nash RDM (1995) Periodicity of otolith check formation on juvenile plaice Pleuronectes platessa L. In: Secor DH, Dean JM, Campana SE (eds) Recent Developments in Fish Otolith Research, pp. 65-76. University of South Carolina Press, Columbia.

Geffen AJ, Pontual HD, Wright PJ, Mosegaard H (2002) Chapter III - Sclerochronological studies. B. Life history events. In: Panfili J, Pontual HD, Troadec H, Wright PJ (eds) Manual of Fish Sclerochronology, pp. 99-104. Ifremer-IRD, Brest.

Georgakopoulou E, Angelopoulou A, Kaspiris P, Divanach P, Koumoundouros G (2007) Temperature effects on cranial deformities in European sea bass, Dicentrarchus labrax (L.). Journal of Applied Ichthyology 23: 99-103.

Geurden I, Aramendi M, Zambonino-Infante J, Panserat S (2007) Early feeding of carnivorous rainbow trout (Oncorhynchus mykiss) with a hyperglucidic diet during a short period: effect on dietary glucose utilization in juveniles. American Journal of Physiology. Regulatory, Integrative and Comparative Physiology 292: R2275-R2283.

Geven EJW, Nguyen NK, van der Boogart M, Spanings FAT, Klaren PHM (2007) Comparative thyroidology: thyroid gland location and iodothyronine dynamics in Mozambique tilapia (Oreochromis mossambicus Peters) and common carp (Cyprinus carpio L.). Journal of Experimental Biology 210: 40054015.

Geven EJW, Flik G, Klaren PHM (2009) Central and peripheral integration of interrenal and thyroid axes signals in common carp (Cyprinus carpio L.). Journal of Endocrinology 200: 117123.

van der Geyten S, Toguyeni A, Baroiller JF, Fauconneau B, Fostier A, Sanders JP et al. (2001) Hypothyroidism induces type I iodothyronine deiodinase expression in tilapia liver. General and Comparative Endocrinology 124: 333-342.

Gill I, Valivety R (1997) Polyunsaturated fatty acids, part 1: occurrence, biological activities and applications. Trends in Biotechnology 15: 401-409.

Goda M, Fujii R (1995) Blue chromatophores in two species of callionymid fish. Zoological Science 12 (6): 811-813.

González-Martínez D, Zmora N, Mañanos E, Saligaut D, Zanuy S, Zohar Y et al. (2002) Immunohistochemical localization of three different prepro-GnRHs in the brain and pituitary of the European sea bass (Dicentrarchus labrax) using antibodies to the corresponding GnRH-associated peptides. Journal of Comparative Neurology 446: 95-113.

Gorbman A (1990) Sex differentiation in the hagfish Eptatretus stouti. General and Comparative Endocrinology 77: 309323.

Gregory LA, Eals JG (1975) Factors contributing to high levels of plasma iodide in brook trout, Salvelinus fontinalis. Canadian Journal of Zoology 53: 267-277.

Guerreiro I, de Vareilles M, Pousão-Ferreira P, Rodrigues V, Dinis MT, Ribeiro L (2010) Effect of age-at-weaning on digestive capacity of white seabream (Diplodus sargus). Aquaculture 300: 194-205.

Guraya SS (1994) Gonadal development and production of gametes in fish. Proceedings of the Indian National Science Academy Part B 60: 15-32.

Hamaguchi S (1982) A light- and electron-microscopic study on the migration of primordial germ cells in the teleost, Oryzias latipes. Cell and Tissue Research 227: 139-151.

Hamaguchi S (1992) Sex differentiation of germ cells and their supporting cells in Oryzias latipes. Journal of Fish Biology 4: 11-17.

Hamre K, Harboe T (2008) Critical levels of essential fatty acids for normal pigmentation in Atlantic halibut (Hippoglossus hippoglossus L.) larvae. Aquaculture 277: 101-108.

Hamre K, Holen E, Moren M (2007) Pigmentation and eye migration in Atlantic halibut (Hippoglossus hippoglossus L.) larvae: new findings and hypotheses. Aquaculture Nutrition 13: $65-80$.

Hamre K, Mollan TA, Sæle $\varnothing$, Erstad B (2008a) Rotifers enriched with iodine and selenium increase survival in Atlantic cod (Gadus morhua) larvae. Aquaculture 284: 190-195.

Hamre K, Srivastava A, Rønnestad I, Mangor-Jensen A, Stoss J (2008b) Several micronutrients in the rotifer Brachionus sp. may not fulfill the nutritional requirements of marine fish larvae. Aquaculture Nutrition 14: 51-60.

Harboe T, Mangor-Jensen A, Naas KE, Næss T (1998) A tank design for first feeding of Atlantic halibut, Hippoglossus hippoglossus L. larvae. Aquaculture Research 29: 919-923.

Hard PR, Purser GJ (1995) Effects of salinity and temperature on eggs and yolk sac larvae of the greenback flounder (Rhombosolea tapirina Ghünter, 1862). Aquaculture 136: 221230.

Hardy RS, Livak MK (2004) Effect of temperature on the early development, growth and survival of shortnose sturgeon, Aci- 
penser oxyrhynchus, yolk-sac larvae. Environmental Biology of Fishes 70: 145-154.

Harel M, Gavasso S, Leshin J, Gubernatis A, Place AR (2001) The effect of tissue docosahexaenoic and arachidonic acids levels on hypersaline tolerance and leucocyte composition in striped bass (Morone saxatilis) larvae. Fish Physiology and Biochemistry 24: 113-123.

Hastings N, Agaba M, Tocher DR, Leaver MJ, Dick JR, Sargent JR et al. (2001) A vertebrate fatty acid desaturase with Delta 5 and Delta 6 activities. Proceedings of the National Academy of Sciences of the United States of America 98: 14304-14309.

Hatchinson S, Hawkins LE (2004) The relationship between temperature and the size and age of larvae and peri-metamorphic stages of Pleuronectes flesus. Journal of Fish Biology 65: 448-459.

Heimeier RA, Das B, Buchholz DR, Fiorentino M, Shi YB (2010) Studies on Xenopus laevis intestine reveal biological pathways underlying vertebrate gut adaptation from embryo to adult. Genome Biology 11: R55.

Hempel G, Blaxter JHS (1961) The experimental modification of meristic characters in herring (Clupea harengus L.). Journal du Conseil Permanent International Pour l'Exploration de la Mer 26: 336-346.

Hemre GI, Mommsen TP, Krogdahl A (2002) Carbohydrates in fish nutrition: effects on growth, glucose metabolism and hepatic enzymes. Aquaculture Nutrition 8: 175-194.

Henning SJ (1979) Biochemistry of intestinal development. Environmental Health Perspectives 33: 9-16.

Herzig A, Winkler H (1986) The influence of temperature on the embryonic development of three cyprinid fishes, Abramis brama, Chalcalburnus chalcoides mento and Vimba vimba. Journal of Fish Biology 28: 171-181.

Heusser S, Colin S, Figiel A, Huet C, Keller JM, Pornet P et al. (1992) Amphibian intestinal villin: isolation and expression during embryonic andlarval development. Journal of Cell Science 103: 699-708.

Hildebrand M (1995) Analysis of Vertebrate Structure J, 657 p. Wiley \& Sons Inc, New York.

Hirata Y, Kurokura H, Kasahara S (1989) Effects of thyroxine and thiourea on the development of larval red sea bream Pagrus major. Nippon Suisan Gakkaishi 55: 1189-1195.

Hiroi J, McCormick SD (2012) New insights into gill ionocyte and ion transporter function in euryhaline and diadromous fish. Respiratory Physiology and Neurobiology 184: 257-268.

Ho DH, Burggren BB (2010) Epigenetics and transgenerational transfer: a physiological perspective. Journal of Experimental Biology 213: 3-16.

Holmberg A, Schwerte T, Pelster B, Holmgren S (2004) Ontogeny of the gut motility control system in zebrafish Danio rerio embryos and larvae. Journal of Experimental Biology 207: 4085-4094.

Horn PJ, Petersen CL (2002) Chromatin higher order folding wrapping up transcription. Science 297: 1824-1827.
Hsu H-J, Lin G, Chung B-C (2003) Parallel early development of zebrafish interrenal glands and pronephros: differential control by wt1 and ff1b. Development 130 (10): 2107-2116.

Huang L, Schreiber AM, Soffientino B, Bengtson DA, Specker JL (1998) Metamorphosis of summer flounder (Paralichthys dentatus): thyroid status and the timing of gastric gland formation. Journal of Experimental Zoology 280: 413-420.

Hughes I (2011) Minireview: sex differentiation. Endocrinology 142 (8): 3281-3287.

Hughes I, Blasiole B, Huss D, Warchol ME, Rath NP, Hurle B et al. (2004) Otopetrin 1 is required for otolith formation in the zebrafish Danio rerio. Developmental Biology 276: 391402.

Hunter GA, Donaldson EM (1983) Hormonal sex control and its application to fish culture. In: Hoar WS, Randall DJ, Donalson EM (eds) Fish Physiology, Vol 9B, pp. 223-303. Academic press, New York.

van den Hurk R, Slof GA (1981) A morphological and experimental study of gonadal sex differentiation in the rainbow trout, Salmo gairdneri. Cell and Tissue Research 218: 487-497.

Hwang P-P, Wu SM, Lin JH, Wu LS (1992) Cortisol content of eggs and larvae of teleosts. General and Comparative Endocrinology 86: 189-196.

Ijiri S, Kaneko H, Kobayashi T, Wang DS, Sakai F, Paul-Prasanth B et al. (2008) Sexual dimorphic expression of genes in gonads during early differentiation of a teleost fish, the Nile tilapia Oreochromis niloticus. Biology of Reproduction 78: 333341.

Imsland A, Koedijk R, Stefansson SO, Foss A, Hjorleifsdottir S, Hreggvidsson GO et al. (2011) A retrospective approach to fractionize variation in body mass of Atlantic cod Gadus morhua. Journal of Fish Biology 78: 251-264.

Inui Y, Miwa S (1985) Thyroid hormone induces metamorphosis of flounder larvae. General Comparative Endocrinology 60: 450-454.

Inui Y, Yamano K, Miwa S (1995) The role of thyroid hormone in tissue development in metamorphosing flounder. Aquaculture 135: 87-98.

Izquierdo MS, Socorro J, Arantzamendi L, Hernández-Cruz CM (2000) Recent advances in lipid nutrition in fish larvae. Fish Physiology and Biochemistry 22: 97-107.

Izquierdo MS, Montero D, Robaina L, Caballero MJ, Rosenlund G, Ginés R (2005) Alterations in fillet fatty acid profile and flesh quality in gilthead seabream (Sparus aurata) fed vegetable oils for a long term period: recovery of fatty acid profiles by fish oil feeding. Aquaculture 250: 431-444.

Jentoft S, Held JA, Malison JA, Barry TP (2002) Ontogeny of the cortisol stress response in yellow perch (Perca flavescens). Fish Physiology and Biochemistry 26: 371-378.

de Jesus EG, Hirano T (1992) Changes in whole body concentration of cortisol, thyroid hormones, and sex steroid during early development of the chum salmon, Oncorhynchus keta. General and Comparative Endocrinology 85: 55-61.

de Jesus EG, Inui Y, Hirano T (1990) Cortisol enhances the stimulating action of thyroid hormones on dorsal fin-ray 
resorption of flounder in vitro. General Comparative Endocrinology 79: 167-173.

de Jesus EG, Hirano T, Inui Y (1991) Changes in cortisol and thyroid hormone concentrations during early development and metamorphosis in Japanese Flounder, Paralichthys olivaceus. General and Comparative Endocrinology 82: 369-376.

de Jesus EGT, Toledo JD, Sampas MS (1998) Thyroid hormones promote early metamorphosis in grouper (Epinephelus coiodes) larvae. General Comparative Endocrinology 112: 10-16.

Jobling M (1996) Temperature and growth: modulation of growth rate via temperature change. In: Wood CM, McDonald DG (eds) Global Warming: Implications for Freshwater and Marine Fish, pp. 225-253. University press, Cambridge.

Johnston IA (2006) Environment and plasticity of myogenesis in teleost fish. Journal of Experimental Biology 209: 2249-2264.

Johnston IA, Cole NJ, Abercrombie M, Vieira VLA (1998) Embryonic temperature modulates muscle growth characteristics in larval and juvenile herring. Journal of Experimental Biology 201: 623-646.

Johnston IA, Vieira VLA, Temple GK (2001) Functional consequences and population differences in the developmental plasticity of muscle to temperature in Atlantic herring $\mathrm{Clu}$ pea harengus. Marine Ecology Progress Series 213: 285-300.

Johnston IA, Bower NI, Macqueen DJ (2011) Growth and the regulation of myotomal muscle mass in teleost fish. Journal of Experimental Biology 214: 1617-1628.

Jonassen TM, Pittman K, Imsland AK (1997) Seawater acclimatation of tilapia Oreochromis spilurus spilurus Günter, fry and fingerlings. Aquaculture Research 28: 205-214.

Kardong KV (2002) Vertebrates: Comparative Anatomy, Function, Evolution. McGraw-Hill, New York.

Kassahn KS, Dang VT, Wilkins SJ, Perkins AC, Ragan MA (2009) Evolution of gene function and regulatory control after whole-genome duplication: comparative analyses in vertebrates. Genome Research 19: 1404-1418.

Kawakami Y, Saito T, Fujimoto T, Goto-Kazeto R, Takahashi E, Adachi $S$ et al. (2011) Visualization and motility of primordial germ cells using green fluorescent protein fused to $3^{\prime}$ UTR of common carp nanos related gene. Aquaculture 317: 245-250.

Kawauchi H (2006) Functions of melanin-concentrating hormone in fish. Journal of Experimental Zoology 305A: 751-760.

Keegan CE, Hammer GD (2002) Recent insights into organogenesis of the adrenal cortex. Trends in Endocrinology and Metabolism 13 (5): 200-208.

King WV, Berlinsky DL (2006) Whole-body corticosteroid and plasma cortisol concentrations in larval and juvenile Atlantic cod Gadus morhua L. following acute stress. Aquaculture Research 37: 1282-1289.

Kingsolver JG, Huey RB (1998) Evolutionary analyses of morphological and physiological plasticity in thermally variable environments. American Zoologist 38: 545-560.

Klaren PHM, Haasdijk R, Metz JR, Nitsch LMC, Darras VM, Van der Geyten S et al. (2005) Characterization of an iodothyronine 5 '-deiodinase in gilthead sea bream (Sparus aura- tus) that is inhibited by dithiothreitol. Endocrinology 146: 5621-5630.

Klaren PHM, Wunderink YS, Yúfera M, Mancera JM, Flik G (2008) The thyroid gland and thyroid hormones in Senegalese sole (Solea senegalensis) during early development and metamorphosis. General and Comparative Endocrinology 155: 686694.

Kobayashi T, Kajiura-Kobayashi H, Guan G, Nagahama Y (2008) Sexual dimorphic expression of DMRT1 and Sox9a during gonadal differentiation and hormone-induced sex reversal in the teleost fish Nile tilapia (Oreochromis niloticus). Developmental Dynamics 237 (1): 297-306.

Kolkovski S (2008) Recent advances in marine fish larvae diets. In: Cruz Suarez EL, Ricque Marie D, Tapia Salazar M, Nieto López MG, Villareal Cavazos DA, Lazo JP, Viana MT (eds) Avances in Nutrición Acuicola IX. IX Simposio Internacional de Nutrición Acuícola, 24-27 Noviembre, pp. 20-45. Universidad Autónoma de Nuevo León, Monterrey, México.

Kondrashov F (2012) Gene duplication as a mechanism of genomic adaptation to a changing environment. Proceedings of the Royal Society of London, Series B 279 (1749): 5048-5057.

Koumoundouros G, Pavlidis M, Anezaki L, Kokkari C, Sterioti K, Divanach P et al. (2002) Temperature sex determination in the European sea bass, Dicentrarchus labrax (L., 1758) (Teleostei, Perciformes, Moronidae): critical sensitive ontogenetic phase. Journal of Experimental Zoology 292: 573-579.

Koumoundouros G, Ashton C, Sfakianakis DG, Divanach P, Kentouri M, Anthwal N et al. (2009) Thermally-induced phenotypic plasticity of swimming performance in European sea bass Dicentrarchus labrax juveniles. Journal of Fish Biology 76: 1309-1322.

Koven WM, van Anholt R, Lutzky S, Ben Atia I, Nixon O, Ron B et al. (2003) The effect of dietary arachidonic acid on growth, survival, and cortisol levels in different-age gilthead sea bream larvae (Sparus aurata) exposed to handling or daily salinity change. Aquaculture 228: 307-320.

Krogdahl A, Sundby A, Olli JJ (2004) Atlantic salmon (Salmo salar) and rainbow trout (Oncorhynchus mykiss) digest and metabolize nutrients differently. Effects of water salinity and dietary starch level. Aquaculture 229: 335-360.

Kronnié GT (2000) Axial muscle development in fish. Basic and Applied Myology 10: 261-267.

Krumlauf R (1994) Hox genes in vertebrate development. Cell 78: 191-201.

Kumar S, Tembhre M (1995) Sex determination in fishes. In: Anatomy and Physiology of Fishes, pp. 254-257. Vikas Publishing House, New Delhi.

Kurokawa T, Okamoto T, Gen K, Uji S, Murashita K, Unuma T et al. (2008) Influence of water temperature on morphological deformities in cultured larvae of Japanese eel, Anguilla japonica, at completion of yolk resorption. Journal of the World Aquaculture Society 39: 726-735.

Kvåle A, Mangor-Jensen A, Moren M, Espe M, Hamre K (2007) Development and characterisation of some intestinal enzymes 
in Atlantic cod (Gadus morhua L.) and Atlantic halibut (Hippoglossus hippoglossus L.) larvae. Aquaculture 264: 457-468.

Lagardere F, Troadec H (1997) Age estimation in common Sole Solea solea larvae: validation of daily increments and evaluation of a pattern recognition technique. Marine Ecology Progress Series 155: 223-237.

Lahav E, Ra'anan Z (1997) Salinity tolerance of genetically produced tilapia (Oreochromis) hybrids. Israeli Journal of Aquaculture 49: 160-165.

Lall SP, Lewis-McCrea LM (2007) Role of nutrients in skeletal metabolism and pathology in fish - an overview. Aquaculture 267: 3-19.

Lam TJ (1980) Thyroxine enhances larval development and survival in Sarotherodon (Tilapia) mossambicus Ruppell. Aquaculture 21: 287-291.

Lam TJ (1994) Hormones and egg/larval quality in fish. Journal of World Aquaculture Society 25: 2-12.

Laurence GC (1973) Influence of temperature on energy utilization of embryonic and prolarval tautog, Tautoga onitis. Journal of the Fishery Research Board of Canada 30: 435-442.

Leatherland JF (1994) Reflections on the thyroidology of fishes: from molecules to humankind. Guelph Ichthyology Reviews 2: $1-68$.

Lebrun CR, Billard R, Jalabert B (1982) Changes in the number of germ cells in the gonads of the rainbow trout (Salmo gairdneri) during the first ten post-hatching weeks. Reproduction Nutrition Development 22: 405-412.

Leena S, Shameena B, Oommen OV (2001) In vivo and in vitro effects of prolactin and growth hormone on lipid metabolism in a teleost, Anabas testudineus (Bloch). Comparative Biochemistry and Physiology, Part B 128: 761-766.

Li M, Leatherland JF (2012) The implications for aquaculture practice of epigenomic programming of components of the endocrine system of teleostean embryos: lessons learned from mammalian studies. Fish and Fisheries. doi:10.1111/j.14672979.2012.00486.x.

Liu Y-W, Chan W-K (2002) Thyroid hormones are important for embryonic to larval transitory phase in zebrafish. Differentiation 70: 36-45.

Lombarte A, Cruz A (2007) Otolith size trends in marine fish communities from different depth strata. Journal of Fish Biology 71: 53-76.

López-Albors O, Ayala MD, Gil F, García-Alcazar A, Abellán E, Latorre R et al. (2003) Early tempterature effects on muscle growth dynamics and histochemical profile of muscle fibres of sea bass Dicentrarchus labrax L., during larval and juvenile stage. Aquaculture 220: 385-406.

Lucas A, Baker BA, Desai M, Hales CN (1996) Nutrition in pregnant or lactating rats programs lipid metabolism in the offspring. British Journal of Nutrition 76: 605-612.

Lund I, Steenfeldt SJ, Suhr KI, Hansen BW (2008) A comparison of fatty acid composition and quality of eggs and larvae from cultured and wild broodstocks of common sole (Solea solea L.). Aquaculture Nutrition 14: 544-555.
Ma HM, Cahu C, Zambonino J, Yu HR, Duan QY, Le Gall MM et al. (2005) Activities of selected digestive enzymes during larval development of large yellow croaker (Pseudosciaena crocea). Aquaculture 245: 239-248.

Ma T, Kuroki M, Miller M, Ishida R, Tsukamoto K (2008) Morphology and microchemistry of abnormal otoliths in the ayu, Plecoglossus altivelis. Environmental Biology of Fishes 83: 155167.

Maack G, Segner H (2003) Morphological development of the gonads in zebrafish. Journal of Fish Biology 62: 895-906.

Maeda K, Naganuma M (1997) Melanocyte-stimulating properties of secretory phospholipase A2. Photochemistry and Photobiology 65 (1): 145-149.

Mancera JM, Fernandez-Llebrez P (1995) Development of melanin-concentrating hormone-immunoreactive elements in the brain of gilthead seabream (Sparus auratus). Cell and Tissue Research 282: 523-526.

Manchado M, Infante C, Asensio E, Crespo A, Zuasti E, Cañavate JP (2008) Molecular characterization of gene expresión of six trypsinogens in the flatfish Senegaleses sole (Solea senegalensis Kaup) during larval development and in tissues. Comparative Biochemistry and Physiology 149B: 334-344.

Marshall WS (2013) Osmoregulation in estuarine and intertidal fishes. In McCormick SD, Farrell AP, Brauner CJ (eds) Fish Physiology, Vol. 32, Euryhaline Fishes, pp. 395-434. Elsevier, New York.

Matsuda M (2005) Sex determination in the teleost medaka, Oryzias latipes. Annual Reviews of Genetics 39: 293-307.

Matsuda K, Shimakura S-I, Maruyamaa K, Miura T, Uchiyamaa $\mathrm{M}$, Kawauchi $\mathrm{H}$ et al. (2006) Central administration of melanin-concentrating hormone $(\mathrm{MCH})$ suppresses food intake, but not locomotor activity, in the goldfish, Carassius auratus. Neuroscience Letters 399: 259-263.

Matty AJ (1985) Fish Endocrinology, 267 pp. Croom Helm Ltd, London.

May RC (1974) Larval mortality in marine fishes and the critical period concept. In: Blaxter JHS (ed.) The Early Life History of Fish, pp. 3-19. Springer-Verlag, Berlin.

Mayer-Gostan N, Kossmann H, Watrin A, Payan P, Boeuf G (1997) Distribution of ionocytes in the saccular epithelium of the inner ear of two teleosts (Oncorhynchus mykiss and Scophthalmus maximus). Cell and Tissue Research 287: 5361.

Mazurais D, Darias MJ, Gouillou-Coustans MF, Le Gall MM, Huelvan C et al. (2008) Dietary vitamin mix levels influence the ossification process in European sea bass (Dicentrarchus labrax) larvae. American Journal of Physiology. Regulatory, Integrative and Comparative Physiology 294: R520-R527.

Mazurais D, Glynatsi N, Darias MJ, Christodoulopoulou S, Cahu CL, Zambonino-Infante JL et al. (2009) Optimal levels of dietary vitamin A for reduced deformity incidence during development of European sea bass larvae (Dicentrarchus labrax) depend on malformation type. Aquaculture 294: 262270 . 
Mazurais D, Darias MJ, Zambonino-Infante JL, Cahu CL (2011) Transcriptomic for understanding marine fish larval development. Canadian Journal of Zoology 89: 500-611.

McCormick MI (1999) Delayed metamorphosis of a tropical reef fish (Acanthurus triostegus): a field experiment. Marine ecology Progress Series 176: 25-38.

McEvoy LA, Næss T, Bell JG, Lie Ø (1998) Lipid and fatty acid composition of normal and malpigmented Atlantic halibut (Hippoglossus hippoglossus) fed enriched Artemia: a comparison with fry fed wild copepods. Aquaculture 163: 237-250.

Meyer A (1987) Phenotypic plasticity and heterochrony in Cichlasoma managuense (Pisces, Cichlidae) and their implications for speciation in cichlid fishes. Evolution 41: 1357-1369.

Meyer A, van de Peer Y (2005) From 2R to 3R: evidence for a fish-specific genome duplication (FSGD). BioEssays 27: 937945.

Migaud H, Bell G, Cabrita E, McAndrew B, Davie A, Bobe J et al. (in press) Broodstock management and gamete quality in temperate fish. Reviews in Aquaculture.

Miwa S, Inui Y (1987) Effects of various doses of thyroxine and triiodothyronine on the metamorphosis of flounder (Paralichthys olivaceus). General Comparative Endocrinology 67: 356363.

Miwa S, Tagawa M, Inui Y, Hirano T (1988) Thyroxine surge in metamorphosing flounder larvae. General and Comparative Endocrinology 70: 158-163.

Miwa S, Yamano K, Inui Y (1992) Thyroid hormone stimulates gastric development in flounder larvae during metamorphosis. Journal of Experimental Zoology 261: 424-430.

Moccia RD, Leatherland JF, Sonstegard RA (1981) Quantitative interlake comparison of thyroid pathology in Great Lakes coho (Oncorhynchus kisutch) and chinook (Oncorhynchus tschawytscha) salmon. Cancer Research 41: 2200-2210.

Modin J, Fagerholm B, Gunnarsson B, Pihl L (1996) Changes in otolith microstructure at metamorphosis of plaice, Pleuronectes platessa L. ICES Journal of Marine Science 53: 745-748.

Mohamed JS, Benninghoff AD, Holt GJ, Khan IA (2007) Developmental expression of the $G$ protein-coupled receptor 54 and three GnRH mRNAs in the teleost fish cobia. Journal of Molecular Endocrinology 38: 235-244.

Moon TW (2001) Glucose intolerance in fish: fact or fiction? Comparative Biochemistry and Physiology 129B: 243-249.

Morales-Nin B (2000) Review of the growth regulation processes of otolith daily increment formation. Fisheries Research 46: 53-67.

Moren M, Opstad I, van der Meeren T, Hamre K (2006) Iodine enrichment of Artemia and enhanced levels of iodine in Atlantic halibut larvae (Hippoglossus hippoglossus L.) fed the enriched Artemia. Aquaculture Nutrition 12: 97-102.

Moren M, Sloth JJ, Hamre K (2008) Uptake of iodide from water in Atlantic halibut larvae (Hippoglossus hippoglossus L.). Aquaculture 285: 174-178.

Morohashi K-I (1997) The ontogenesis of the steroidogenic tissues. Genes to Cells 2: 95-106.
Murayama E, Herbomel P, Kawakami A, Takeda H, Nagasawa $\mathrm{H}$ (2005) Otolith matrix proteins OMP-1 and Otolin-1 are necessary for normal otolith growth and their correct anchoring onto the sensory maculae. Mechanisms of Development 122: 791-803.

Murray H, Lall SP, Rajaselvam R, Boutilier LA, Flight RM, Blanchard B et al. (2010) Effect of early introduction of microencapsulated diet to larval Atlantic halibut, Hippoglossus hippoglossus, L. assessed by microarray analysis. Marine Biotechnology 12: 214-229.

Næss T, Lie $\varnothing$ (1998) A sensitive period for the determination of pigmentation pattern in Atlantic halibut, Hippoglossus hippoglossus L. juveniles: the role of diet. Aquaculture Research 29: 925-934.

Næss T, Germain-Henry M, Naas KE (1995) First feeding of Atlantic halibut (Hippoglossus hippoglossus) using different combinations of Artemia and wild zooplankton. Aquaculture 130: $235-250$.

Nakamura M, Nagahama Y (1993) Ultrastructural study on the differentiation and development of steroid producing cells during ovarian differentiation in the amago salmon Oncorhynchus rhodurus. Aquaculture 112: 237-251.

Nakamura M, Seikai T, Aritaki M, Masuda R, Tanaka M (2010) Dual appearance of xanthophores, and ontogenetic changes in other pigment cells during early development of Japanese flounder Paralichthys olivaceus. Fisheries Science 76: 243-250.

Nathanailides C, Lopez-Albors O, Abellan E, Vázquez JM, Tyler DD, Rowlerson A et al. (1996) Muscle cellularity in relation to somatic growth in the European sea bass Dicentrarchus lab$\operatorname{rax}(\mathrm{L}$.$) . Aquaculture Research 27: 885-889.$

Navarro-Martín L, Blázquez M, Viñas J, Joly S, Piferrer F (2009) Balancing the effects of rearing at low temperature during early development on sex ratios, growth and maturation in the European sea bass (Dicentrarchus labrax). Limitations and opportunities for the production of highly female-biased stocks. Aquaculture 296: 347-358.

Navarro-Martín L, Viñas J, Ribas L, Díaz N, Gutiérrez A, Di Croce L et al. (2011) DNA methylation of the gonadal aromatase (cyp19a) promoter is involved in temperature-dependent sex ratio shifts in the European sea bass. PLoS Genetics 7 (12): e1002447.

van Nes S, Andersen $\varnothing$ (2006) Temperature effects on sex determination and ontogenetic gene expression of the aromatases cyp19a and cyp19b, and the estrogen receptors esr1 and esr2 in Atlantic halibut (Hippoglossus hippoglossus). Molecular Reproduction and Development 73 (12): 1481-1490.

Ng AN, de Jong-Curtain TA, Mawdsley DJ, White SJ, Shin J, Appel B et al. (2005) Formation of the digestive system in zebrafish: III. Intestinal epithelium morphogenesis. Developmental Biology 286: 114-135.

Norris DO (2007) Comparative aspects of vertebrate adrenals. In: Vertebrate Endocrinology, 4th edn, pp. 298-321. Elsevier Academic Press, London, UK.

Norris DA, Morelli JG, Fujita M (1998) Melanocyte interactions in the skin. In: Nordlund JJ, Boissy RE, Hearing VJ, King RA, 
Ortonne J-P (eds) The Pigmentary System: Physiology and Pathophysiology, pp. 123-133. New York, Oxford University Press.

Novales Flamarique I (2002) A novel function for the pineal organ in the control of swim depth in the Atlantic halibut larva. Naturwissenschaften 89: 163-166.

Oliveira C, Garcia EM, Lopez-Oledo JF, Sánchez-Vásquez FJ (2009) Daily and circadian melatonin release in vitro by the pineal organ of two nocturnal teleost species: Senegal sole (Solea senegalensis) and tench (Tinca tinca). Comparative Biochemistry and Physiology 153A: 297-302.

Omura Y, Oguri M (1991) Photoreceptor development in the pineal organ and the eye of Plecoglossus altivelis and Paralichthys olivaceus (Teleostei). Cell and Tissue Research 266: 315323.

Omura Y, Oguri M (1993) Early development of the pineal photoreceptors prior to the retinal differentiation in the embryonic rainbow trout, Oncorhynchus mykiss (Teleostei). Archives of Histology and Cytology 56 (3): 283-291.

Ortiz-Delgado JB, Ruane NM, Pousão-Ferreira P, Dinis MT, Sarasquete C (2006) Thyroid gland development in Senegalese sole (Solea senegalensis Kaup 1858) during early life stages: a histochemical and immunohistochemical approach. Aquaculture 260: 346-356.

Ospina-Alvarez N, Piferrer F (2008) Temperature-dependent sex determination in fish revisited: prevalence, a single sex ratio response pattern, a possible effect on climate change. PLoS One 3 (7): e2837.

Østholm T, Brännäs E, van Veen T (1987) The pineal organ is the first differentiated light receptor in the embryonic salmon, Salmo salar L. Cell and Tissue Research 249: 641-646.

Oxman DS, Barnett-Johnson R, Smith ME, Coffin A, Miller DL, Josephson $\mathrm{R}$ et al. (2007) The effect of vaterite deposition on sound reception, otolith morphology, and inner ear sensory epithelia in hatchery-reared Chinook salmon (Oncorhynchus tshawytscha). Canadian Journal of Fisheries and Aquatic Science 64: 1469-1478.

Palevitch P, Kight K, Abraham E, Wray S, Zohar Y, Gothilf Y (2007) Ontogeny of the GnRH systems in zebrafish brain: in situ hybridization and promoter-reporter expression analyses in intact animals. Cell and Tissue Research 327: 313-322.

Pandian TJ (2012) Genetic Sex Differentiation in Fish, 214 pp. CRC Press, US, ISBN 978-1-57808-799-0.

Pandolfi M, Parhar IS, Ravaglia MA, Meijide FJ, Maggese MC, Paz DA (2002) Ontogeny and distribution of gonadotropinreleasing hormone $(\mathrm{GnRH})$ neuronal systems in the brain of the cichlid fish Cichlasoma dimerus. Anatomy and Embryology 205: 271-281.

Pankhurst N, Munday P (2011) Effects of climate change on fish reproduction and early life history stages. Marine and Freshwater Research 62: 1015-1026.

Panserat S, Plagnes-Juan E, Kaushik S (2002) Gluconeogenic enzyme gene expression is decreased by dietary carbohydrates in common carp (Cyprinus carpio) and gilthead seabream (Sparus aurata). BBA-Gene Structure and Expression 1579: $35-42$.
Parichy DM, Elizondo MR, Mills MG, Gordon TN, Engeszer RE (2009) Normal table of postembryonic zebrafish development: staging by externally visible anatomy of the living fish. Developmental Dynamics 238: 2975-3015.

Paris M, Laudet V (2008) The history of a developmental stage: metamorphosis in chordates. Genesis 46: 657-672.

Parra G, Yúfera M (2000) Feeding, physiology and growth responses in first-feeding gilthead seabream (Sparus aurata L.) larvae in relation to prey density. Journal of the Experimental Marine Biology and Ecology 243: 1-15.

Pascual E, Yúfera M (1993) Energy content and chemical composition of gilthead seabream, Sparus aurata L., eggs. Aquaculture and Fisheries Management 24: 423-429.

Patzner R (1998) Gonads and reproduction in hagfishes. In: Jørgensen JM (ed.) The "Biology of hagfishes", pp. 378-394. Chapman and Hall, UK.

Pauly D, Pullin RSV (1998) Hatching time in spherical, pelagic, marine fish eggs in response to temperature and egg size. Environmental Biology of Fishes 22: 261-271.

Pavlidis M, Koumoundouros G, Sterioti A, Somarakis S, Divanach P, Kentouri M (2000) Evidence of temperaturedependent sex determination in the European sea bass (Dicentrarchus labrax L.). Journal of Experimental Zoology 287: 225-232.

Pavlidis M, Karantzali E, Fanouraki E, Barsakis C, Kollias S, Papandroulakis N (2011) Onset of the primary stress in European sea bass Dicentrarhus labrax, as indicated by whole body cortisol in relation to glucocorticoid receptor during early development. Aquaculture 315: 125-130.

Pavlov DA, Mokness E (1997) Development of the axial skeleton in wolfish Anarhichas lupus (Pisces, Anarhichadidae), at different temperatures. Environmental Biology of Fishes 49: 401416.

Payan P, Kossmann H, Watrin A, MayerGostan N, Boeuf G (1997) Ionic composition of endolymph in teleosts: origin and importance of endolymph alkalinity. Journal of Experimental Biology 200: 1905-1912.

Payan P, Borelli G, Priouzeau F, De Pontual H, Boeuf G, MayerGostan N (2002) Otolith growth in trout Oncorhynchus mykiss: supply of $\mathrm{Ca}^{2+}$ and $\mathrm{Sr}^{2+}$ to the saccular endolymph. Journal of Experimental Biology 205: 2687-2695.

Payan P, Pontual HD, Edeyer A, Borelli G, Boeuf G, MayerGostan N (2004) Effects of stress on plasma homeostasis, endolymph chemistry, and check formation during otolith growth in rainbow trout (Oncorhynchus mykiss). Canadian Journal of Fisheries and Aquatic Science 61: 1247-1255.

Peaston A, Whitelaw E (2006) Epigenetics and phenotypic variation in mammals. Mammalian Genome 17 (5): 365374.

Pelster B, Sanger AM, Siegele M, Schwerte T (2003) Influence of swim training on cardiac activity, tissue capillarization, and mitochondrial density in muscle tissue of zebrafish larvae. American Journal of Physiology. Regulatory, Integrative and Comparative Physiology 285: R339-R347. 
Pepels PPLM, Balm PHM (2004) Ontogeny of corticotropinreleasing factor and of hypothalamic-pituitary-interrenal axis responsiveness to stress in tilapia (Oreochromis mossambicus; Teleostei). General and Comparative Endocrinology 139: 251265.

Péres A, Zambonino Infante JL, Cahu C (1998) Dietary regulation of activities and mRNA levels of trypsin and amylase in sea bass (Dicentrarchus labrax) larvae. Fish Physiology and Biochemistry 19: 145-152.

Piferrer F, Donaldson EM (1989) Gonadal differentiation in coho salmon, Oncorhynchus kisutch, after a single treatment with androgen or estrogen at different stages during ontogenesis. Aquaculture 77: 2-3.

Piferrer F, Blázquez M, Navarro L, González A (2005) Genetic, endocrine, and environmental components of sex determination and differentiation in the European sea bass (Dicentrarchus labrax L.). General and Comparative Endocrinology 142: 102-110.

Pigliucci M (2010) Genotype-phenotype mapping and the end of the 'genes as blueprint' metaphor. Philosophical Transactions of the Royal Society of London, Series B 365: 557-566.

Pittman KA, Jelmert A, Næss T, Harboe T, Watanabe K (1998) Plasticity of viable postmetamorphic forms of farmed Atlantic halibut, Hippoglossus hippoglossus L. Aquaculture Research 29: 949-954.

Polo A, Yúfera M, Pascual E (1991) Effect of temperature on egg and larval development of Sparus aurata L. Aquaculture 92: 367-375.

Power DM, Liewellyn L, Faustino M, Nowell MA, Björnsson BT, Einarsdottir IE et al. (2001) Thyroid hormones in growth and development of fish. Comparative Biochemistry and Physiology, Part C: Toxicology and Pharmacology 30: 447-459.

Power DM, Einarsdóttir IE, Pittman K, Sweeney GE, Hildahl J, Campinho MA et al. (2008) The molecular and endocrine basis of flatfish metamorphosis. Reviews in Fisheries Science 16 (Suppl 1): 95-111.

Radaelli G, Patruno M, Maccatrozzo L, Funkenstein B (2003) Expression and cellular localization of insulin-like growth factor-II protein and mRNA in Sparus aurata during development. Journal of Endocrinology 178: 285-299.

Raman R (2002) Sex determination and gonadal differentiation in vertebrates: a case for unity in diversity. Proceedings of the Indian National Science Academy 6: 529-546.

Rhind SM, Rae MT, Brooks AN (2001) Effects of nutrition and environmental factors on the fetal programming of the reproductive axis. Reproduction 122: 205-214.

Ribeiro L, Zambonino-Infante JL, Cahu C, Dinis MT (1999) Development of digestive enzymes in larvae of Solea senegalensis, Kaup 1858. Aquaculture 179: 465-473.

Ribeiro ARA, Ribeiro L, Sæle $\varnothing$, Hamre K, Dinis MT, Moren M (2011) Iodine enriched rotifers and Artemia prevents goitre in Senegalese sole (Solea senegalensis) larvae reared in a recirculation system. Aquaculture Nutrition 17 (3): 248-257.

Ridha MT (2013) Preliminary observations on growth and survival of Oreochromis spilurus $\times$ GIFT Oreochromis niloticus
F1 reciprocal hybrids in fresh and seawater. Aquaculture Research (in press) doi:10.1111/j.1365-2109.2012.03256.x.

Risold PY, Croizier S, Legagneux K, Brischoux F, Fellmann D, Griffond B (2009) The development of the MCH system. Peptides 30: 1969-1972.

Roblin C, Bruslé J (1983) Gonadal ontogenesis and sex differentiation in the sea bass, Dicentrarchus labrax, under fishfarming conditions. Reproduction Nutrition Development 23: 115-127.

Rodgers BD, Weber GM, Kelley KM, Levine MA (2003) Prolonged fasting and cortisol reduce myostatin mRNA levels in tilapia larvae; short-term fasting elevates. American Journal of Physiology. Regulatory, Integrative and Comparative Physiology 284: R1277-R1286.

Roessig JM, Woodley CM, Cech JJ Jr, Hansen LJ (2004) Effects of global climate change on marine and estuarine fishes and fisheries. Reviews in Fish Biology and Fisheries 14: 251-275.

Romanov AA, Altufev Y (1992) Extraregional histogenesis of sexual cells in the Caspian Sea sturgeons. Journal of Ichthyology 32: 145-154.

Romanov AA, Altufyev Y (1993) Ectopic histogenesis of sexual cells of Caspian Sea sturgeons. Journal of Ichthyology 33: 140150.

Rønnestad I, Yúfera M, Ueberschär B, Ribeiro L, Sæle Ø, Boglione C (2013) Feeding behaviour and digestion physiology in larval fish - current knowledge, and gaps and bottlenecks in research. Reviews in Aquaculture (in press).

Rougeot C, Prignon C, Ngouana Kengne CV, Mélard C (2008) Effect of high temperature during embryogenesis on the sex differentiation process in the Nile tilapia, Oreochromis niloticus. Aquaculture 276: 205-208.

Sæle Ø, Pittman K (2010) Looking closer at the determining of a phenotype? Compare by stages or size, not age. Journal of Applied Ichthyology 26: 294-297.

Saga T, Yamaki K, Doi Y, Yoshizuka M (1999) Chronological study of the appearance of adenohypophysial cells in the ayu (Plecoglossus altivelis). Anatomy and Embryology 200: 469475.

Sampath-Kumar R, Byers RE, Munro AD, Lam TJ (1995) Profile of cortisol during the ontogeny of the Asian seabass, Lates calcarifer. Aquaculture 132: 349-359.

Sargent J, Bell G, McEvoy L, Tocher D, Estevez A (1999) Recent developments in the essential fatty acid nutrition of fish. Aquaculture 177: 191-199.

Sasagawa T, Mugiya Y (1996) Biochemical properties of watersoluble otolith proteins and the immunobiochemical detection of the proteins in serum and various tissues in the tilapia Oreochromis niloticus. Fisheries Science 62: 970-976.

Schneider E, Pliushch G, El Hajj N, Galetzka D, Puhl A, Schorsch M et al. (2010) Spatial, temporal and interindividual epigenetic variation of functionally important DNA methylation patterns. Nucleic Acids Research 38 (12): 3880-3890.

Schreiber AM, Specker JL (1998) Metamorphosis in the summer flounder (Paralichthys dentatus): stage-specific developmental 
response to altered thyroid status. General and Comparative Endocrinology 111: 156-166.

Schreiber AM, Mukhi S, Brown DD (2009) Cell-cell interactions during remodeling of the intestine at metamorphosis in Xenopus laevis. Developmental Biology 331: 89-98.

Schwehr KA, Santschi PH (2003) Sensitive determination of iodine species, including organo- iodine, for freshwater and seawater samples using high performance liquid chromatography and spectrophotometric detection. Analytica Chimica Acta 482: 59-71.

Schwerte T, Voigt S, Pelster B (2005) Epigenetic variations in early cardiovascular performance and hematopoiesis can be explained by maternal and clutch effects in developing zebrafish (Danio rerio). Comparative Biochemistry and Physiology 141A: 200-209.

Scott G, Jacobs S, Leopardi S, Anthony FA, Learn D, Malaviya R et al. (2005) Effects of PGF2a on human melanocytes and regulation of the FP receptor by ultraviolet radiation. Experimental Cell Research 304: 407-416.

Seikai T (1985) Reduction in occurrence frequency of albinism in juvenile flounder, Paralichthys olivaceus, hatchery-reared on wild zooplankton. Nippon Suisan Gakkaishi 51: 12611268.

Seikai T, Shimozaki M, Watanabe T (1987) Estimation of larval stage determining the appearance of albinism in hatcheryreared juvenile flounder, Paralichthys olivaceus. Nippon Suisan Gakkaishi 53: 195-200.

Seiliez I, Bruant JS, Zambonino Infante JL, Kaushik S, Bergot P (2006) Effect of dietary phospholipid level on the development of gilthead seabream (Sparus aurata) larvae fed a compound diet. Aquaculture Nutrition 12: 372-378.

Servili A, Bufalino MR, Nishikawa R, Sanchez de Melo I, Muñoz-Cueto JA, Lee EJ (2009) Establishment of long term cultures of neural stem cells from adult sea bass, Dicentrarchus labrax. Comparative Biochemistry and Physiology 152A: 245-254.

Sfakianakis DG, Koumoundouros G, Divanach P, Kentouri M (2004) Osteological development of the vertebral column and of the fins in Pagellus erythrinus (L. 1758). Temperature effects on the developmental plasticity and morpho-anatomical abnormalities. Aquaculture 232: 407-424.

Sgaramella V (2010) Variability of our somatic (epi)genomes. Science 329: 32-33.

Shapiro DY (1990) Sex-changing fish as a manipulable system for the study of the determination, differentiation, and stability of sex in vertebrates. Journal of Experimental Zoology 4 (Suppl.): 132-136.

Sherrill J, Whitaker BR, Wong GTF (2004) Effects of ozonation on the speciation of dissolved iodine in artificial seawater. Journal of Zoology and Wildlife Medicine 35: 347-355.

Shi Y-B, Browns DD (1993) The earliest change in gene expression in tadpole intestine induced by thyroid hormone. Journal of Biological Chemistry 268 (27): 20312-20317.

Shi Y-B, Ishizuya-Oka A (2001) Thyroid hormone regulation of apoptotic tissue remodeling: implications from molecular analysis of amphibian metamorphosis. Progress in Nucleic Acid Research and Molecular Biology 65: 53-100.

Shi Y-B, Fu L, Hsia SCV, Tomita A, Buchholz D (2001) Thyroid hormone regulation of apoptotic tissue remodeling during anuran metamorphosis. Cell Research 11 (4): 245-252.

Shiao JC, Hwang PP (2004) Thyroid hormones are necessary for teleostean otolith growth. Marine Ecology-Progress Series 278: 271-278.

Shiao JC, Wu SM, Hwang YP, Wu DP, Hwang PP (2008) Evaluation of thyroid-mediated otolith growth of larval and juvenile tilapia. Journal of Experimental Biology 211: 19191926.

Shields RJ, Bell JG, Luizi FS, Gara B, Bromage NR, Sargent JR (1999) Natural copepods are superior to enriched Artemia nauplii as feed for halibut larvae (Hippoglossus hippoglossus) in terms of survival, pigmentation and retinal morphology: relation to dietary essential fatty acids. Journal of Nutrition 129: 1186-1194.

Simontacchi C, Negrato E, Pazzaglia M, Bertotto D, Poltronieri C, Radaelli G (2009) Whole-body concentrations of cortisol and sex steroids in white sturgeon (Acipenser transmontanus, Richardson 1836) during early development and stress response. Aquaculture International 17 (1): 7-14.

Skinner SK, Manikkan M, Guerrero-Bosagna C (2010) Epigenetic transgenerational actions of environmental factors in disease etiology. Trends in Endocrinology and Metabolism 21: 214-222.

Solbakken J, Pittman K (2004) Photoperiodic modulation of metamorphosis in Atlantic halibut (Hippoglossus hippoglossus L.). Aquaculture 232: 613-625.

Solbakken JS, Norberg B, Watanabe K, Pittman K (1999) Thyroxine as a mediator of metamorphosis of Atlantic halibut, Hippoglossus hippoglossus. Environmental Biology of Fishes $\mathbf{5 6}$ 53-65.

Solbakken JS, Berntssen MHG, Norberg B, Pittman K, Hamre K (2002) Different iodine and thyroid hormone levels between Atlantic halibut larvae fed wild zooplankton or Artemia from first exogenous feeding until post metamorphosis. Journal of Fish Biology 61: 1345-1362.

Sollner C, Burghammer M, Busch-Nentwich E, Berger J, Schwarz H, Riekel C et al. (2003) Control of crystal size and lattice formation by starmaker in otolith biomineralization. Science 302: 282-286.

Sonstegard RA, Leatherland JF (1978) Growth retardation in rats fed Coho salmon collected from the Great Lakes of North America. Chemosphere 11: 902-910.

Stouthart AJHX, Lucassen ECHET, van Strien FJC, Balm BHM, Lock RAC, Wendelaar Bonga SE (1998) Stress responsiveness of the pituitary-interrenal axis during early life stages of common carp (Cyprinus carpio). Journal of Endocrinology 157: $127-137$.

Stratholt ML, Donaldson EM, Liley NR (1997) Stress induced elevation of plasma cortisol in adult female Coho salmon (Oncorhynchus kisutch), is reflected in egg cortisol content, 
but does not appear to affect early development. Aquaculture 158: $141-153$.

Stuckenholz C, Lu L, Thakur P, Kaminski N, Bahary N (2009) FACS-assisted microarray profiling implicates novel genes and pathways in zebrafish gastrointestinal tract development. Gastroenterology 137 (4): 1321-1332.

Swapna I, Sudhakumari CC, Sakai F, Sreenivasulu G, Kobayashi T, Kagawa H et al. (2008) Seabream GnRH immunoreactivity in brain and pituitary of XX and XY Nile tilapia, Oreochromis niloticus during early development. Journal of Experimental Zoology 309A: 419-426.

Sweeting RM, Beamish RJ, Neville CM (2004) Crystalline otoliths in teleosts: comparisons between hatchery and wild coho salmon (Oncorhynchus kisutch) in the Strait of Georgia. Reviews in Fish Biology and Fisheries 14: 361-369.

Szisch V, Papandroulakis N, Fanouraki E, Pavlidis M (2005) Ontogeny of the thyroid hormones and cortisol in the gilthead sea bream, Sparus aurata. General and Comparative Endocrinology 142: 186-192.

Tagawa M, Tanaka M, Matsumoto S, Hirano T (1990) Thyroid hormones in eggs of various freshwater, marine and diadromous teleosts and their changes during egg development. Fish Physiology and Biochemistry 8: 515-520.

Takahashi A, Kobayashi Y, Amano M, Yamanome T (2009) Structural and functional diversity of proopiomelanocortin in fish with special reference to barfin flounder. Peptides 30: 1374-1382.

Takashima F, Patino R, Nomura M (1980) Histological studies on the sex differentiation in rainbow trout. Nippon Suisan Gakkaishi 46: 1317-1322.

Takeuchi Y, Yoshizaki G, Kobayashi T, Takeuchi T (2002) Mass isolation of primordial germ cells from transgenic rainbow trout carrying the green fluorescent protein gene driven by the vasa gene promoter. Biology of Reproduction 67: 1087-1092.

Tanaka M, Tanangonan JB, Tagawa M, de Jesus EG, Nishida H, Isaka M et al. (1995) Development of the pituitary, thyroid and interregnal glands and applications of endocrinology to the improved rearing of marine fish larvae. Aquaculture 135: 111-126.

Tandler A, Anav FA, Choshniak I (1995) The effect of salinity on growth rate, survival and swimbladder inflation in gilthead seabream, Sparus aurata, larvae. Aquaculture 135: 343-353.

Thomas M, Langley B, Berry C, Sharma M, Kirk S, Bass J et al. (2000) Myostatin, a negative regulator of muscle growth, functions by inhibiting myoblast proliferation. Journal of Biological Chemistry 275: 40235-40243.

To TT, Hahner S, Nica G, Rohr KB, Hammerschmidt M, Winkler C et al. (2007) Pituitary-interrenal interaction in zebrafish interrenal organ development. Molecular Endocrinology 21 (2): 472-485.

Tohse H, Takagi Y, Nagasawa H (2008) Identification of a novel matrix protein contained in a protein aggregate associated with collagen in fish otoliths. FEBS Journal 275: 2512-2523.
Tomas J, Geffen AJ (2003) Morphometry and composition of aragonite and vaterite otoliths of deformed laboratory reared juvenile herring from two populations. Journal of Fish Biology 63: 1383-1401.

Tomas J, Geffen AJ, Allen IS, Berges J (2004) Analysis of the soluble matrix of vaterite otoliths of juvenile herring ( $\mathrm{Clu}$ pea harengus): do crystalline otoliths have less protein? Comparative Biochemistry and Physiology 139A: 301-308.

Tomita Y, Takeda A, Matsunaga J, Okinaga S, Shibahara S, Tagami H (1992) Molecular bases of tyrosinase-negative oculocutaneous albinism: a single base insertion or a missense point mutation in the tyrosinase gene. Pigment Cell Research Suppl 2: 96-100.

Torres GJ, Lombarte A, Morales-Nin B (2000) Sagittal otolith size and shape variability to identify geographical intraspecific differences in three species of the genus Merluccius. Journal of the Marine Biological Association of the United Kingdom 80: 333-342.

Trippel EA (1998) Egg size and viability and seasonal offspring production of young Atlantic Cod. Transactions of the American Fisheries Society 127: 339-359.

Tytler P, Fox CJ, Folkvord A (2002) Glycoconjugates in the otolithic membrane of herring larvae: a possible framework for encoding the life history recorder in fishes. Journal of Fish Biology 61: 39-49.

Uchida D, Yamashita M, Kitano T, Iguchi T (2002) Oocyte apoptosis during the transition from ovary-like tissue to testes during sex differentiation of juvenile zebrafish. Journal of Experimental Biology 205: 711-718.

Unsicker K, Huber K, Schütz G, Kalcheim C (2005) The chromaffin cell and its development. Neurochemical Research 30 (6-7): 921-925.

Vagner M, Robin JH, Zambonino-Infante JL, Tocher DR, Person-Le Ruyet J (2009) Ontogenic effects of early feeding of sea bass (Dicentrarchus labrax) larvae with a range of dietary n-3 highly unsaturated fatty acid levels on the functioning of polyunsaturated fatty acid desaturation pathways. British Journal of Nutrition 101: 1452-1462.

Valente LMP, Moutou KA, Conceição LEC, Engrola S, Fernandes JMO, Johnston IA (2013) What determines growth potential and juvenile quality of farmed fish species? Reviews in Aquaculture (in press).

Vallone D, Lahiri K, Dickmeis T, Foulkes NS (2007) Start the clock! Circadian rhythms and development. Developmental Dynamics 236: 142-155.

Varsamos S, Nebel C, Charmantier G (2005) Ontogeny of osmoregulation in postembryonic fish: a review. Comparative Biochemistry and Physiology, Part A 141: 401-429.

Venter JC, Adams MD, Myers EW, Li PW, Mural RJ, Sutton GG et al. (2001) The sequence of the human genome. Science 291 (5507): 1304-1351.

Vieira VLA, Johnston IA (1992) Influence of temperature on muscle-fibre development in larvae of herring Clupea harengus. Marine Biology 112: 333-341. 
Vijayan MM, Pereira C, Grau EG, Iwama GK (1997) Metabolic responses associated with confinement stress in tilapia: the role of cortisol. Comparative Biochemistry and Physiology 116C: 89-95.

Villalta M, Estévez A, Matthew P, Bransden MP (2005) Arachidonic acid enriched live prey induces albinism in Senegal sole (Solea senegalensis) larvae. Aquaculture 245: 193-209.

Villalta M, Estévez A, Bransden MP, Bell JG (2008) Arachidonic acid, arachidonic/eicosapentaenoic acid ratio, stearidonic acid and eicosanoids are involved in dietary-induced albinism in Senegal sole (Solea senegalensis). Aquaculture Nutrition 14: 120-128.

Villamizar N, García-Alcazar A, Sánchez-Vázquez FJ (2009) Effect of light spectrum and photoperiod on the growth, development and survival of European sea bass (Dicentrarchus labrax) larvae. Aquaculture 292: 80-86.

Villeneuve L, Gisbert E, Moriceau J, Cahu C, Zambonino Infante JL (2006) Intake of different levels of vitamin A and polyunsaturated fatty acids during different developmental periods modifies the expression of morphogenesis genes in European sea bass (Dicentrarchus labrax). British Journal of Nutrition 95: 677-687.

Wallace KN, Pack M (2003) Unique and conserved aspects of gut development in zebrafish. Developmental biology 255: 12 29.

Wallace KN, Akhter S, Smith EM, Lorent K, Pack M (2005) Intestinal growth and differentiation in zebrafish. Mechanisms of Development 122: 157-173.

Wendelaar Bonga SE (1997) The stress response in fish. Physiological Reviews 77: 591-625.

West-Eberhard MJ (2003) Phenotypic plasticity and the origins of diversity. Annual Review of Ecology and Systematics 20: 249-278.

Wieser W (1994) Cost of growth in cells and organisms: general rules and comparative aspects. Biological Reviews 69: 1-33.

Willey S, Bengtson DA, Harel M (2003) Arachidonic acid requirements in larval summer flounder, Paralichthys dentatus. Aquaculture International 11: 131-149.

Wimberger PH (1991) Plasticity of jaw and skull morphology in the neotropical Geophagus brasiliensis and Geophagus steindachneri. Evolution 45: 1545-1563.

Witt EM, Laidley CW, Liu KKM, Hirano T, Grau EG (2009) Correlation between environmental iodide concentrations and larval growth, survival, and whole body concentrations of thyroid hormones and cortisol in Pacific threadfin (Polydactylus sexfilis). Aquaculture 289: 357-364.

Wong GTF (1991) The marine geochemistry of iodine. Reviews in Aquatic Sciences 4: 45-73.
Wong TT, Gothilf Y, Zmora N, Kight KE, Meiri I, Elizur A et al. (2004) Developmental expression of three forms of gonadotropin-releasing hormone and ontogeny of the hypothalamicpituitary-gonadal axis in gilthead seabream (Sparus aurata). Biology of Reproduction 71: 1026-1035.

Wright PJ (1991) Calcium-binding by soluble matrix of the otoliths of Atlantic salmon, Salmo salar L. Journal of Fish Biology 38: 625-627.

Wright PJ (1993) Otolith microstructure of the lesser sandeel, Ammodytes marinus. Journal of the Marine Biological Association of the United Kingdom 73: 245-248.

Yamamoto T (1969) Sex differentiation. In: Hoar W, Randall D (eds) Fish Physiology, pp. 117-175. Academic Press, New York.

Yamano K, Tagawa M, de Jesus EG, Hirano T, Miwa S, Inui Y (1991) Changes in whole body concentrations of thyroid hormones and cortisol in metamorphosing conger eel. Journal of Comparative Physiology 161B: 371-375.

Yoshizaki G, Okutsu T, Ichikawa M, Hayashi M, Takeuchi Y (2010) Sexual plasticity of rainbow trout germ cells. Animal Reproduction 7 (3): 187-196.

Yúfera M, Darias MJ (2007) The onset of feeding in marine fish larvae. Aquaculture 268: 53-63.

Yúfera M, Fernández-Diaz C, Pascual E (2005) Food microparticles for larval fish prepared by internal gelation. Aquaculture 248: 253-262.

Yúfera M, Astola A, Douglas SE, Martínez-Rodríguez G (2008) Microarray analysis of Solea senegalensis larvae fed on live and inert diets from first feeding. Poster, XIII International Simposium on Fish Nutrition and Feeding. June 1-5, Florianópolis, Brazil.

Yúfera $\mathrm{M}$, Conceição LEC, Battaglene S, Fushimi $\mathrm{H}$, Kotani T (2011) Early development and metabolism. In: Pavlidis M, Mylonas CC (eds) Sparidae. Biology and Aquaculture of Gilthead Seabream and Other Species, pp. 133-168. WileyBlackwell, Oxford, UK.

Yúfera M, Halm S, Beltran S, Fusté B, Planas JV, MartínezRodríguez G (2012) Transcriptomic characterization of the larval stage in gilthead seabream (Sparus aurata) by 454 pyrosequencing. Marine Biotechnology 14: 423-435.

Zabielski R, Godlewski MM, Guilloteau P (2008) Control of development of gastrointestinal system in neonates. Journal of Physiology and Pharmacology 59: 35-54.

Zambonino-Infante JL, Gisbert E, Sarasquete S, Navarro I, Gutiérrez J, Cahu CL (2008) Ontogeny and physiology of the digestive system of marine fish larvae. In: Cyrino JEP, Bureau D, Kapoor BG (eds) Feeding and Digestive Functions in Fishes, pp. 281-348. Science Publishers, Enfield, NH. 